NIST Special Publication 1224

\title{
Research Needs to Support Immediate Occupancy Building Performance Objective Following Natural Hazard Events
}

\author{
Siamak Sattar \\ Therese McAllister \\ Katherine Johnson \\ Christopher Clavin \\ Christopher Segura \\ Steven McCabe \\ Juan Fung \\ Leslie Abrahams \\ Emily Sylak-Glassman \\ Marc Levitan \\ Kenneth Harrison \\ John Harris
}

This publication is available free of charge from:

https://doi.org/10.6028/NIST.SP.1224

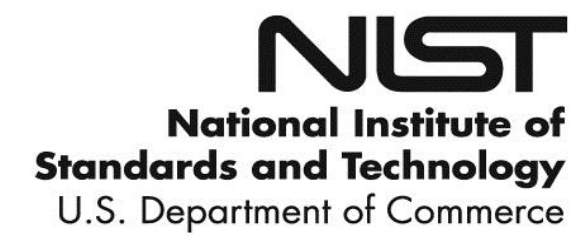


[This page intentionally left blank] 
NIST Special Publication 1224

\title{
Research Needs to Support Immediate Occupancy Building Performance Objective Following Natural Hazard Events
}

\author{
Siamak Sattar \\ Therese McAllister \\ Katherine Johnson \\ Christopher Segura \\ Steven McCabe \\ Juan Fung \\ Marc Levitan \\ Kenneth Harrison \\ John Harris \\ Materials and Structural System Division \\ National Institute of Standards and Technology
}

This publication is available free of charge from:

https://doi.org/10.6028/NIST.SP.1224

August 2018

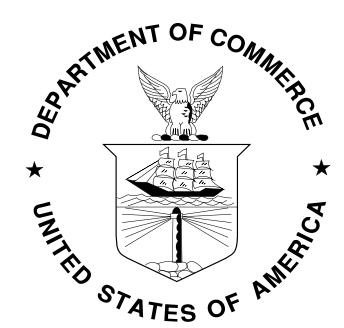

U.S. Department of Commerce

Wilbur L. Ross, Jr., Secretary

National Institute of Standards and Technology

Walter Copan, NIST Director and Under Secretary of Commerce for Standards and Technology 
Certain commercial entities, equipment, or materials may be identified in this document in order to describe an experimental procedure or concept adequately. Such identification is not intended to imply recommendation or endorsement by the National Institute of Standards and Technology, nor is it intended to imply that the entities, materials, or equipment are necessarily the best available for the purpose.

National Institute of Standards and Technology Special Publication 1224

Natl. Inst. Stand. Technol. Spec. Publ. 1224, 95 pages (August 2018)

CODEN: NSPUE2

This publication is available free of charge from: https://doi.org/10.6028/NIST.SP.1224 


\section{Acknowledgement}

NIST acknowledges the extensive input and support of the expert steering committee members, Mary Comerio, Gregory Deierlein, Susan Dowty, John Gillengerton, James Harris, William Hirano, Laurie Johnson, Timothy Reinhold, and James Rossberg, who assisted in developing this report. Their subject-matter expertise, diversity of perspectives, and critical input were essential to the comprehensive nature of the topics addressed. Their time and effort are greatly appreciated. Authors also gratefully acknowledge Matthew Heyman, Jason Averill, and Howard Harary for their advice and suggestions.

\section{Technical and Analytical Contributions}

NIST acknowledges the contribution of the Science and Technology Policy Institute (STPI) in collaboration and development of this plan. STPI supported the development of the report and organization of the workshop under contract with NIST. STPI is a federally funded research and development center of the Institute for Defense Analyses (IDA) chartered by Congress to provide rigorous and objective analysis of science and technology (S\&T) policy issues for the Office of Science and Technology Policy (OSTP) and other offices and councils within the executive branch of the U.S. government and federal agencies. 


\begin{abstract}
The performance of a building and its functionality after a natural hazard event depend on multiple factors, including the original design and the current condition and capacity of the building to resist the risks posed by hazards. Building functionality also depends on the condition of the supporting infrastructure and the availability of utilities supplied to the building.
\end{abstract}

Rapid recovery or uninterrupted operation of buildings can minimize disruptions to the community, decrease costs associated with repair and rebuilding, and lessen the overall economic burdens on communities and individuals impacted by natural hazards. However, given the range of age and condition of buildings across a community, there are often situations where the built environment does not perform well during natural hazard events. To address this gap between current and desired performance of buildings, Congress tasked the National Institute of Standards and Technology (NIST) to identify research needs and implementation activities that would help improve building performance in case of a natural hazard. This mandate would expand the application of immediate occupancy performance beyond critical buildings, such as hospitals, to other buildings that are important to residents, businesses, and the broader community.

With a longstanding focus on preserving lives, building codes help reduce the likelihood of significant damage or structural collapse and provide some degree of property protection. But current codes generally do not address continued functionality after a hazard event. With the damage and losses the nation and communities have been experiencing following natural hazard events, there is interest in understanding what would be required to move beyond the current design paradigm to include functionality. For example, an apartment building may be uninhabitable after an earthquake due to expected structural damage or after a wind hazard event due to damage to the building envelope. The resulting economic and social disruption caused by the displacement of residents is significant and is compounded when residential and commercial buildings across the community are similarly damaged. To address this problem and move toward development of a new immediate occupancy performance objective, this report identifies a large portfolio of research and implementation activities that target enhanced performance objectives for residential and commercial buildings. This exploratory report provides information about steps that could be taken; NIST is not charged with making recommendations about the desirability, practicality, or government or private sector resources that would be needed to carry out these actions if a decision is made to give immediate occupancy greater attention.

These potential activities developed by NIST were aided by a steering committee of individual experts and informed by additional stakeholder input, including a national workshop hosted by NIST in January 2018. Four primary topic areas were identified: 1) building design, 2) community considerations, 3) economic and social considerations, and 4) acceptance and adoption considerations. If a decision is made to advance immediate occupancy performance goals, these topics need to be addressed concurrently through cooperative efforts among researchers, engineers, standards and code officials, and community stakeholders to reach the next level of building design and performance. 


\section{Key words}

Building functionality, Community impacts, Economic impacts, Immediate occupancy, Life safety, Natural hazard, Performance objective, Resilience, Structural performance. 


\section{Table of Contents}

Executive Summary ......................................................................................................................... vii

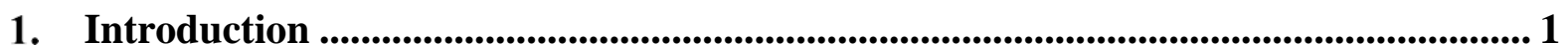

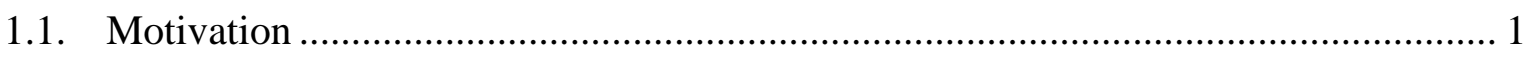

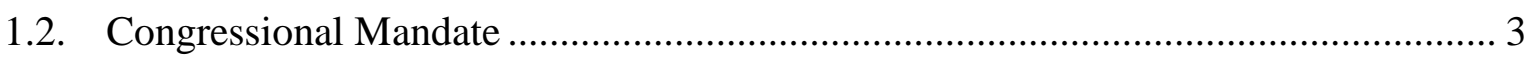

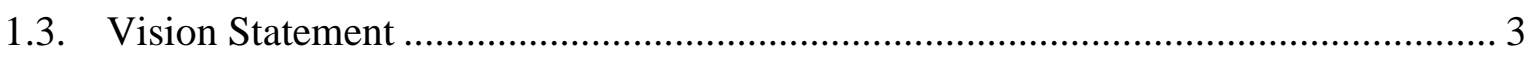

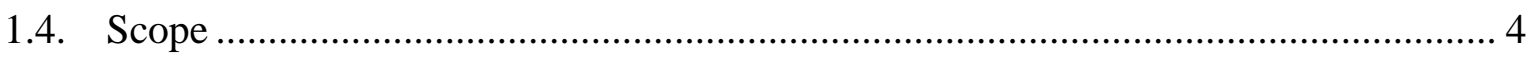

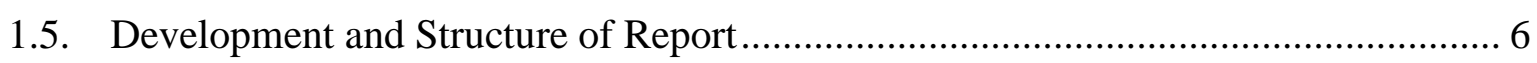

2. Current State of Practice for Designing Buildings ............................................................... 9

2.1. Building Codes and Standards ......................................................................... 9

2.2. Hazard Types and Levels ................................................................................ 10

2.3. Performance Requirements for Code-Compliant Buildings .................................... 13

2.4. Prescriptive Design vs. Performance-Based Design ............................................... 14

3. Building Design Considerations ............................................................................................ 16

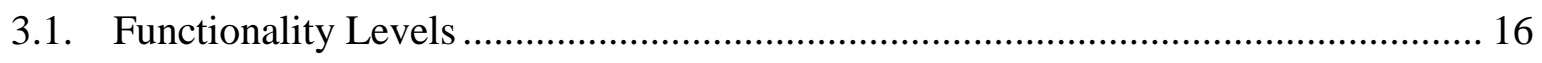

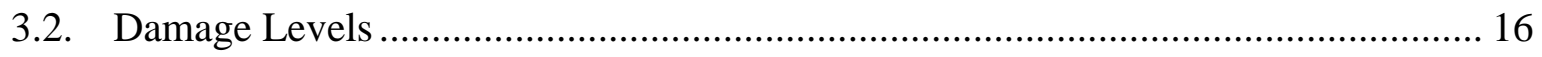

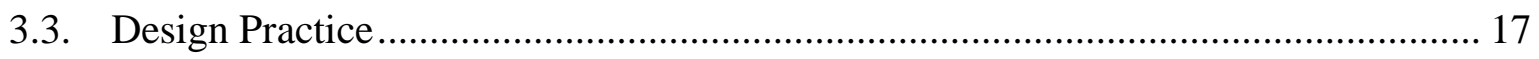

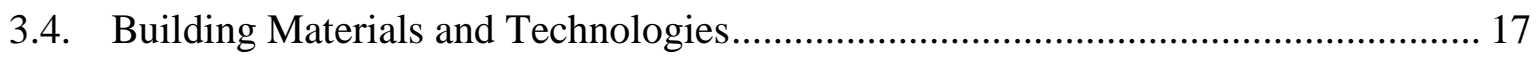

3.5. Maintenance, Repair, and Retrofit Methods ……………................................. 18

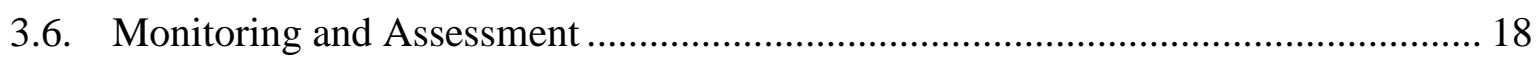

4. Community Considerations for IO Buildings .................................................................... 20

4.1. Infrastructure and Building Cluster Interactions ....................................................... 21

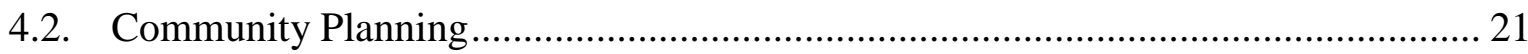

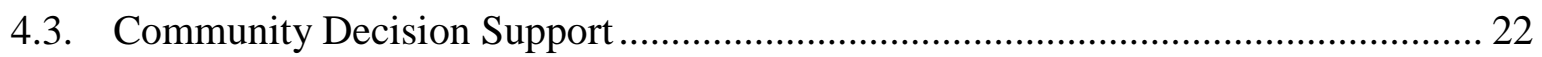

4.4. Community Stakeholder Communications .......................................................... 22

5. Economic and Social Considerations............................................................................. 23

5.1. Economic Feasibility ...................................................................................... 23

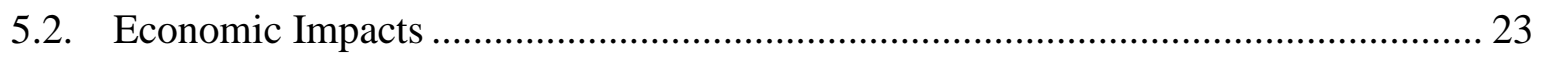

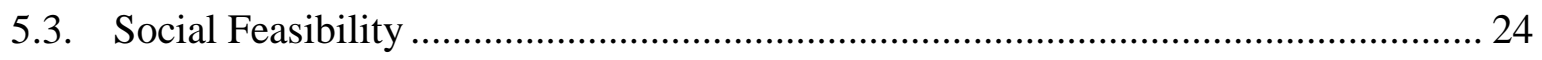

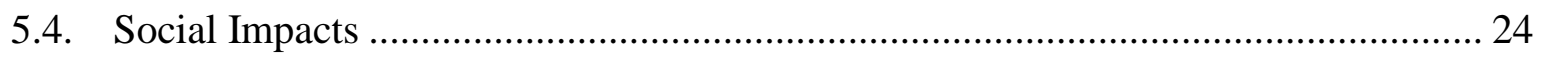

6. Adoption and Acceptance Considerations ........................................................................ 25

6.1. Adoption Mechanisms................................................................................. 25

6.2. Education, Training, and Outreach..................................................................... 26 
6.3. Monitoring and Assessing IO Performance Objectives Adoption, Practice and Performance 26

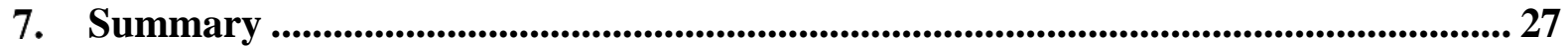

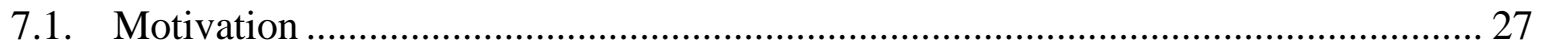

7.2. Summary of Research Topics and Subtopics ................................................ 27

7.3. Crosscutting Research Needs and Implementation Activities ............................. 29

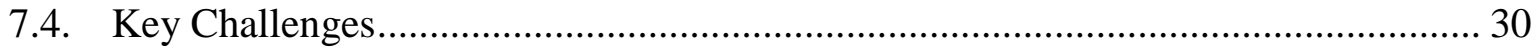

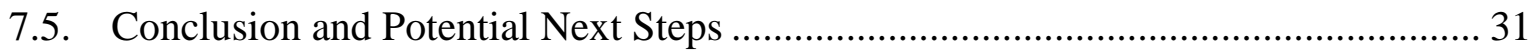

References............................................................................................................................................. 33

Appendix A: Building Design Considerations........................................................................... 35

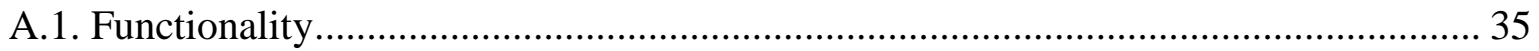

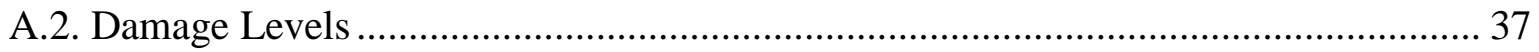

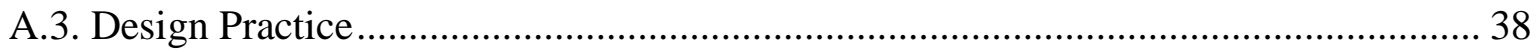

A.4. Building Materials and Technologies.............................................................. 42

A.5. Maintenance, Repair, and Retrofit Methods ....................................................... 44

A.6. Monitoring and Assessment ................................................................................... 46

Appendix B: Community Considerations for IO Buildings................................................. 49

B.1. Infrastructure and Building Cluster Interactions .............................................. 49

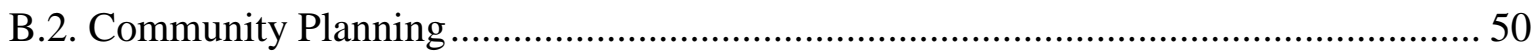

B.3. Community Decision Support ........................................................................ 53

B.4. Community Stakeholder Communication .......................................................... 54

Appendix C: Economic and Social Considerations ........................................................... 56

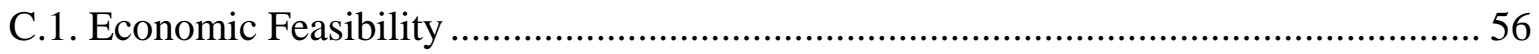

C.2. Economic Impacts ....................................................................................... 58

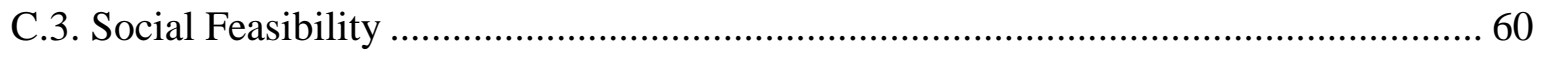

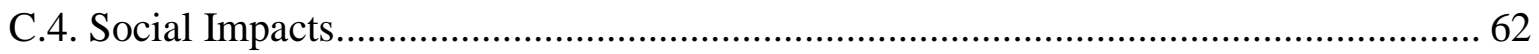

Appendix D: Adoption and Acceptance Considerations........................................................ 64

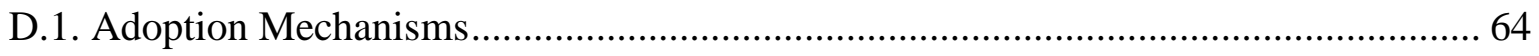

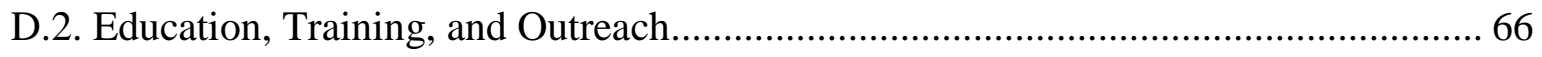

D.3. Monitoring and Assessing IO Performance Objectives Adoption, Practice, and

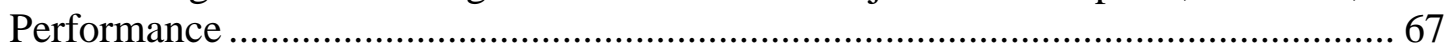

Appendix E: Research Needs Summary Tables.................................................................... 70

Appendix F: Steering Committee Member Affiliations ......................................................... 77

Appendix G: January 2018 Workshop Agenda .......................................................................... 78

Appendix H: Abbreviations ................................................................................................................. 80 


\section{List of Tables}

Table 1. Material-specific standards for conventional construction materials with large market shares

Table 2. Summary of three hazard levels defined as a function of hazard types and intensity (adapted and modified from [13]) 12

Table 3. Research Needs from Chapter 3, Building Design Considerations ..................... 70

Table 4. Research Needs from Chapter 4, Community Considerations............................ 72

Table 5: Research Needs from Chapter 5, Economic and Social Considerations............... 74

Table 6: Research Needs from Chapter 6, Adoption and Acceptance Considerations ....... 75

\section{List of Figures}

Fig. 1. Frequency of Impact to States from Billion-Dollar Weather and Climate Disasters from 1980 to 2017 by Hazard Type [1] .................................................................. viii

Fig. 2. Top 15 Most Costly U.S. Natural Hazard Events from 1980-2017 (2017 Dollars, Adjusted for Inflation but Not Population or Wealth) [developed from data in [1]].... 2 


\section{Executive Summary}

\section{i. Purpose}

This report was developed in response to a mandate from the U.S. Congress to the National Institute of Standards and Technology (NIST) to identify the basic and applied research and implementation activities, as well as supporting engineering principles, needed to improve the performance of residential and commercial buildings subjected to natural hazards. This document presents an exploratory, interdisciplinary assessment of activities needed to target a higher level of building performance referred to as immediate occupancy (IO). Needs are organized around four areas: building design, community considerations, economic and social considerations, and acceptance and adoption considerations. Engineering design principles are integral to the proposed research and implementation activities. Design principles include defining the desired function and damage levels, characterizing building site condition and hazard risk, the selection of building systems and materials, and computer simulation and physical testing.

The path from research and development to codes and standards, and to subsequent use, typically involves the following steps: obtaining data and developing and validating models; developing design guidelines, best practice documents, and tools; and developing industry consensus standards and national model building codes. Communities may then choose to adopt and enforce standards and codes to support local goals. Advancing IO research and implementation needs would require integrated research and development among federal agencies, academic institutions, building designers and construction professionals, product manufacturers, building owners and developers, and community planners. Accordingly, the research and implementation topics in this report address technical and social issues and identify key challenges to promoting and achieving IO performance in buildings. This report provides information about steps that could be taken; NIST is not charged with making recommendations about the government or private sector resources that would be needed to carry out these actions if a decision is made to give immediate occupancy greater attention.

\section{ii. Motivation}

Natural hazard events affect communities through loss of life, injury, property damage, displacement of residents and businesses, and long-lasting economic and social impacts. Each geographic region in the United States faces a unique combination of natural hazards. Figure 1 reflects the frequency with which each state has been impacted by natural hazard events exceeding one billion dollars in damage between 1980 and 2017 [1]. Note that seismic hazards are not reported in this data, but significant additional losses would occur given a major urban earthquake. Additionally, 2017 is reported to be the costliest year for natural hazard events in the U.S., with an estimated $\$ 306$ billion in damages [2]. Figure 1 shows that every part of the country is affected by a range of hazards, and that they cause extensive damage and disruption to buildings, infrastructure, and communities, and affect individuals, families, and communities, and even the economy and spirit of the nation. 

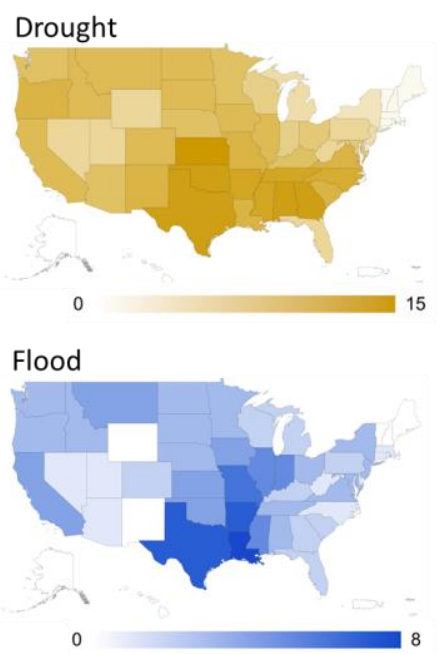
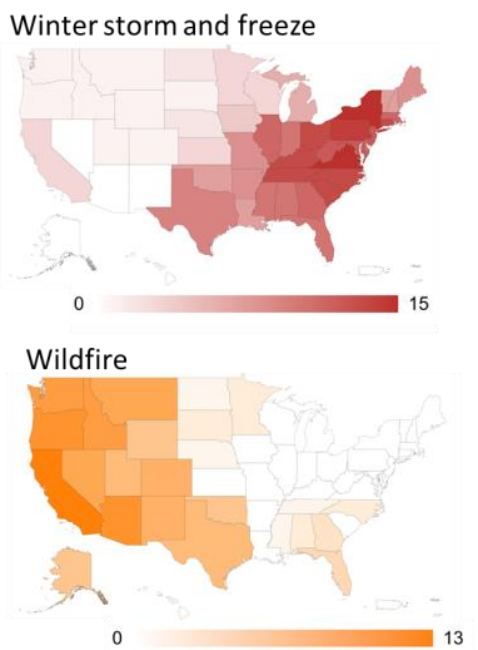
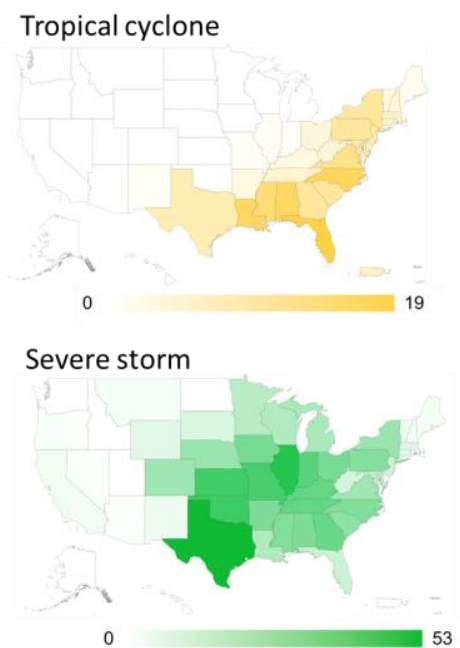

Fig. 1. Frequency of Impact to States from Billion-Dollar Weather and Climate Disasters from 1980 to 2017 by Hazard Type [1]

Hazard events each year lead to failures in buildings and infrastructure, as well as deaths and injuries, short-and-long term displacement of the affected population, adverse health effects, and disruption to social order related to the impaired functioning of schools, government, and businesses. By improving the ability of residential and commercial buildings to provide shelter and continue functioning post-event, IO building performance would also protect individuals and reduce economic impacts. By ensuring access to housing and resumption of local businesses following a hazard event, communities can use IO buildings to mitigate and recover from natural hazards and to reduce vulnerability and long-term negative consequences. Greater emphasis on IO buildings has the potential to reduce not only the cost of natural hazard events but also to lessen the social, psychological, and health consequences across the nation.

\section{iii. Statement of Problem}

Communities would benefit if owners and residents could expect and rely on buildings to maintain their structural integrity and continue to function after a natural hazard event. Buildings that are able to do so would make it possible to avoid lengthy and costly repairs or rebuilding and related disruptions. However, the primary, longstanding goal of building codes is to protect lives by reducing the likelihood of immediate substantial damage or structural collapse for a design-level event, and to provide some level of property protection. For commercial and residential buildings that meet modern code requirements, loss of life and structural collapse are infrequent for hazards addressed in the codes. However, some hazards, such as tornadoes, are currently not considered by building codes for the design of most buildings. Additionally, exterior cladding (e.g., walls, windows, doors, roofs, etc.) and interior non-structural systems (e.g., sprinklers, communication systems, etc.) or components (e.g., HVAC equipment) often have different design requirements and may sustain damage that leads to partial or total loss of building function. The lack of integration between performance goals for structural, exterior, and interior systems means that even if the structural system performs well, the building may not be available for its intended use (such as if broken pipes render building sprinkler systems inactive and the building is deemed not fit for occupancy). While 
some buildings, such as hospitals, are currently designed with increased loads and performance requirements in recognition of their role in the community the actual performance anticipated for the entire building (structural and nonstructural systems) for a given hazard event is difficult to predict. Ensuring building integrity and functionality after a natural hazard event occurs requires comprehensive design criteria, retrofit technologies, and supporting tools and procedures along with community support.

\section{iv. Goal for IO Performance Objectives}

After a design-level hazard event, which is the hazard level basis for designing buildings in codes and standards, IO buildings would ideally sustain minimal loss of function, and any necessary repairs would be minor and not interfere with occupancy or function. If adopted as a goal and implemented, such performance levels could improve community resilience and quality of life by reducing damage and allowing continued access to jobs, housing, and community services such as education and healthcare. So, the goal for IO performance objectives is to develop and put in place building design and retrofit criteria that preserve the integrity of the building cladding, structural frame, and interior systems, and support continued functionality.

Developing IO performance objectives can enhance current practice and could improve the resilience of communities and the nation. Improved engineering design approaches and construction techniques, combined with considerations of community, social, economic, and acceptance and adoption issues would all be necessary to improve the performance of commercial and residential buildings. This would be a major undertaking for both government and private sectors in terms of research and supporting implementation activities required.

\section{v. Organization and Scope}

The efforts needed to develop IO performance objectives for residential and commercial buildings were informed by a national workshop of subject matter experts and stakeholder representatives. Three significant findings from the workshop were: (1) focus on buildings alone would not meet the intended goal of IO performance, (2) social, economic, and community considerations inform the desired building performance and (3) specific performance criteria for the range of commercial and residential buildings need more input from stakeholders.

This report is organized around four topic areas:

1) Building design issues include all considerations related to designing or retrofitting an individual building to meet IO performance objectives;

2) Community considerations discuss the resilience context for the role of buildings in community physical, social, and economic systems before and after hazard events;

3) Economic and social considerations address the potential impacts that improved building performance may have on social and economic systems; and

4) Acceptance and adoption considerations address activities required to implement IO performance objectives for different stakeholder communities, including state 
and local government officials, engineers, architects, urban planners, developers, building owners, and building occupants.

A chapter and appendix supplement are provided that outline basic and applied research as well as implementation activities for each of the four topics. Basic research focuses on the collection and development of data and model development. Applied research seeks to validate data and models for building performance and community interactions with case studies and real-life scenarios. Implementation activities relate to developing guidance, tools, standards, and codes which will enable their use by multiple stakeholders including building professional, owners and occupants, and communities.

This report focuses primarily on performance of individual buildings. There are other factors beyond buildings, such as the infrastructure supporting their functionality, that need to be considered in striving to achieve an IO performance level. Building functionality depends on the availability of water, power, transportation, communication, fuel, and other services. Research on the performance of infrastructure services as well as their impacts on building function would also be needed if reaching the goal of IO is desired. This is a major topic that should be given considerable attention before potentially undertaking any large-scale IO research effort.

\section{vi. Key Findings}

Development of specific IO performance objectives should address both technical and social barriers to implementation. Innovation and advances in current engineering and design of commercial and residential buildings are necessary, but not sufficient, if progress toward IO goals is to be achieved. Community, social, economic, and acceptance and adoption issues would also need to be addressed through a multidisciplinary approach to achieve IO building performance. Without this perspective, the current paradigms of design and practice are unlikely to change soon.

Several cross-cutting research needs are identified across the four topics:

1) identifying relationships and dependencies between building functional levels, damage and recovery levels, and effects on populations, social and economic systems, and communities;

2) standardizing data collection across fields for better communication and reporting on the performance of physical, social, and economic systems in the postevent/recovery time period; and

3) developing predictive models that address multiple spatial scales (building system, building cluster, community) and temporal scales (days to decades) to improve understanding of the direct and indirect effects of improved performance levels and system interactions.

In addition, cross-cutting needs for implementation include:

1) guidance documents for professionals and non-professionals related to IO practices;

2) metrics and tools to support prediction and evaluation of anticipated performance and decision-making by stakeholders; and 
3) education, outreach, and training for acceptance and adoption of IO criteria and methods.

Key challenges identified for success in promoting IO building performance objectives include: motivating action by communities to adopt IO buildings; incentivizing private owners to participate in improving the performance of their buildings; identifying adoption mechanism for the public sector (federal or state agencies, etc.); and garnering public trust and participation in IO building initiatives.

In addition, the following challenges related to equity, fairness, and liability need to be considered: managing the distribution of both costs and benefits between stakeholders (owners vs. occupants); ensuring impacts on vulnerable populations are considered; and addressing legal and liability issues that may pose barriers to application of IO performance objectives. A final challenge in setting achievable IO goals is finding ways to support and coordinate multidisciplinary collaborations for research and implementation of IO performance objectives; this collaboration can be difficult due to traditional roles and responsibilities relating to building design, construction, and use.

\section{vii. Potential Next Steps}

The potential research and implementation activities outlined in this exploratory report represent initial thinking and planning for the development of IO performance objectives for commercial and residential buildings. Further development and prioritization of these topics and activities would be needed in order to develop a robust roadmap with additional input from the federal government, state and local governments, the private sector, standard developing organizations, and others. International progress and experience should also be considered.

Development and implementation of IO building performance objectives that effectively mitigate natural hazard risks would require a substantial shift in practice and philosophy in development, construction, and maintenance or retrofit of buildings. It would necessitate a national effort to develop integrated research and implementation activities among stakeholders at all levels, including but not limited to: building owners and developers, building designers, community planners, academic institutions, building code and enforcement professionals, regional and state governments, and federal agencies. Substantial changes would be required for related education, training and practice within the engineering, architectural, and building professions. The involvement and enthusiasm of professional societies and other key stakeholders would be necessary to produce change within standards developing organizations and in building codes. Beyond the initial assessment included in this report, a prioritized research plan with coordinated, detailed, interdisciplinary research goals and implementation activities would be needed. 


\section{Introduction}

\subsection{Motivation}

The public may expect a building in compliance with current codes to be capable of functioning at its pre-hazard level after a hazard event. However, the primary objective of current commercial and residential building codes is to preserve the lives of occupants during significant, non-routine natural hazard events. In reality, both the structural and nonstructural systems of a code-compliant building may sustain damage during a hazard, potentially leading to lengthy repair, or even complete demolition. Moreover, damage to key infrastructure systems including water, power, transportation, communication, fuel, and other services may not allow the structure to be occupied immediately after an event. As a result, residents of communities impacted by hazards may be left without access to housing, jobs, education, and other important community services. In some cases, residents may choose to leave the community in search of housing and employment, compromising the community's long-term recovery.

An immediate occupancy (IO) performance objective would require design criteria that preserve building integrity and meet a higher level of functionality, in addition to protecting lives. Following a significant natural hazard event, buildings designed to an IO performance objective are intended to maintain occupancy and functionality with minimal repairs. This facilitates community recovery and resilience by allowing continued access to jobs, housing, and community services. Moving towards an IO performance objective requires technical innovation and advances in current design practices for commercial and residential buildings. Community, social, economic, and acceptance and adoption issues that can guide or constrain design also play a major role.

This issue is of interest because natural hazard events can affect communities through loss of life, displacement of residents and businesses, injuries, property damage, and economic impacts. The National Centers for Environmental Information (NCEI) within the National Oceanic and Atmospheric Administration (NOAA) estimate that there have been 219 hazardous climate and weather events in the U.S., each resulting in at least $\$ 1$ billion in damage and economic losses, between 1980 and October of 2017 [1]. The 15 most costly natural hazard events in the United States (2017 adjusted dollars) are presented in Figure 2. This figure demonstrates the magnitude of threat to communities from natural hazards, with losses from individual events reported between $\$ 21$ billion and $\$ 161$ billion. Designing buildings to meet higher IO performance objectives could help communities reduce these significant potential economic costs. 


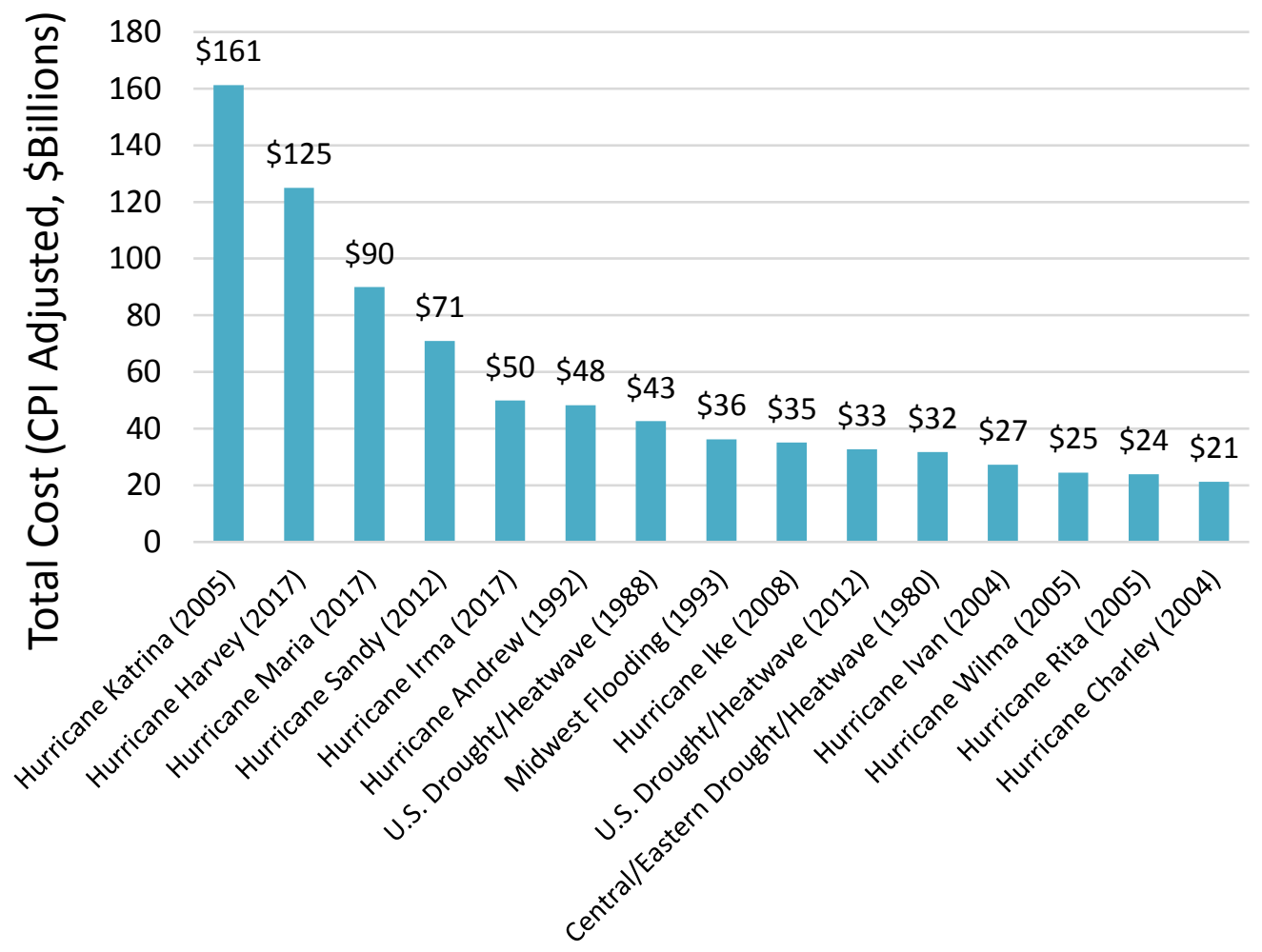

Fig. 2. Top 15 Most Costly U.S. Natural Hazard Events from 1980-2017 (2017 Dollars, Adjusted for Inflation but Not Population or Wealth) [developed from data in [1]]

While the risk of inadequate building performance for particular hazards varies across the nation, all communities should consider how to prepare for and mitigate against natural hazards. By ensuring community members have access to functional housing and local businesses can resume operations following a hazard event, communities can reduce short- and long-term consequences, such as direct and indirect economic losses, migration, and increased vulnerability levels.

Developing IO performance objectives would advance current practices and is important for improving community and national resilience. While some buildings that support critical functions are currently designed with increased loads and performance requirements in recognition of their role in the community, the actual performance for the entire building (structural and non-structural systems) for a given hazard event is not clearly understood. New engineering design approaches, innovative materials and building systems, and new construction techniques offer the opportunity to improve the likelihood of achieving IO objectives and, in turn, improving the resilience of commercial and residential buildings by reducing property loss and enabling more rapid economic recovery in addition to saving lives. Beyond the engineering and technical solutions, considerable resources and effort would be needed for assessing community needs as well as social and economic considerations of IO buildings in order to ensure efficient application of IO performance objectives. 
This document responds to a Fiscal Year (FY) 2017 assignment from the U.S. Congress to develop the science, technology, and tools needed to develop a new IO performance objective for residential and commercial buildings. Specifically, this report serves as an interdisciplinary assessment of the basic and applied research and implementation activities that would be needed to achieve a more advanced state of building design that would enable communities to construct new, or retrofit existing, buildings to a higher level of performance.

\subsection{Congressional Mandate}

The U.S. Senate Committee on Appropriations in Senate Report 114-239 for FY 2017 mandated that NIST develop a report on the development and implementation of an IO performance objective:

The Committee recognizes the importance of industry and municipal standards to better mitigate the impact of natural disasters and extreme weather events, which can save lives, reduce destruction to property, and enable faster economic recovery. Current building codes often do not provide the necessary protection against natural hazards, particularly with regard to enabling immediate occupancy after a significant earthquake, hurricane, tornado, flood, or other natural disaster. The Committee supports efforts to promote the use of resilient engineering design and construction techniques to improve the resiliency of buildings, homes, and infrastructure, and encourages NIST to partner with academic research institutions and industry stakeholders that have expertise in mitigating the effects of natural disasters to study and recommend best practices for resilient planning and construction.

Additionally, not later than 1 year after the enactment of this act, NIST, in coordination with other relevant agencies and standards development organizations, shall provide to the Committee a plan detailing the basic research, applied research, and implementation activities necessary to develop a new "immediate occupancy" safety building performance objective for commercial and residential properties, as well as the engineering design principles needed to fulfill this objective.

This report fulfills the Congressional direction by identifying technical challenges and other considerations associated with developing an IO performance objective and identifying the basic research, applied research, and potential implementation activities.

\subsection{Vision Statement}

This report identifies essential research needs to address the challenges associated with developing IO performance objectives. The following long-term vision for IO performance of commercial and residential buildings is used to identify basic, applied, and implementation research priorities:

An immediate occupancy performance objective has the potential to provide a future in which communities across the nation are resilient to natural hazards, with minimal disruption to lives and property. Residential and commercial buildings will have access to essential services that support their occupancy and functions. An immediate occupancy performance objective will enable buildings to remain functional or experience interim loss of function for a 
limited time with repairs that can take place during occupancy. By designing buildings to meet this immediate occupancy performance objective, occupants will have continued access to housing, jobs, and educational facilities, and local governments will be able to continue supporting their communities, ensuring reduced disruption to the local economy.

It is important to note that this report is not advocating for acceptance of the IO goal; rather, this vision statement is critical as a basis for understanding the range of research and implementation activities described in this report.

\subsection{Scope}

The term "immediate occupancy", or IO, implies that a building is immediately safe to occupy after a hazard event. Although a building may be safe for occupancy it may not be fully functional. The term IO does not convey information on the specific timeframe required for the building to regain its functionality. There may be several performance levels that can serve the needs of residential and commercial buildings and their occupants, depending on the buildings' role in meeting the community's needs and recovery. Therefore, in developing criteria for a new IO performance objective, multiple functional levels that may differ in terms of the acceptable recovery time should be considered, depending on the building's role in the community, the services it provides, and the hazard level.

In this report, IO performance is considered as the building's condition after a hazard event where damage to the building's structural system is controlled, limited, and repairable while the building remains safe to occupy. The building's ability to function at full or minimally reduced capacity is also affected by the damage state of the non-structural systems of the building (e.g., building envelope, equipment, interior utilities), as well as the infrastructure that connects the building to its surrounding community. Functional levels may vary from continuous function to partial loss of function for a specified recovery time. The term IO is used for general reference to a potential range of functional levels for consistency with the congressional language.

In this report, basic research focuses on the collection and development of data and model development. Applied research seeks to validate data and models for building performance and community interactions with case studies and real-life scenarios. The majority of the research areas discussed necessitate both basic and applied research activities; therefore, a distinction between the two research types is not made. Implementation activities relate to developing guidance, tools, standards, and codes which will enable their use by multiple stakeholders including building professionals, owners and occupants, and communities. Engineering design principles refers to processes used to design and construct buildings including: defining the desired building function, damage, and recovery levels, characterizing building site condition, hazards, and risks, selecting building systems and materials, and conducting computer simulation and physical testing. Engineering design principles are included in the research needs discussed here.

The congressional mandate refers both to "commercial and residential buildings" as well as to "resiliency of buildings, homes, and infrastructure". This report interprets this language to include buildings for which loss of function will impact individuals as well as communities. Therefore, this report includes the majority of buildings that comprise a community, including 
one- and two-family dwellings, apartment buildings, hotels, office buildings, healthcare facilities, educational institutions, etc. This broad description of commercial and residential buildings supports an understanding that needs for IO performance will vary by community and should be determined at the local level.

This report discusses the research and implementation activities necessary to develop and fulfill IO performance objectives. Such performance objectives may inform future voluntary or mandatory applications. This report is an initial step toward identifying the multidisciplinary research needs for developing IO performance objectives. The described research and implementation activities provide a broad, multi hazard basis necessary to develop IO performance objectives. Research and implementation activities, therefore, are not differentiated according to hazard type. Further development and prioritization of these research and implementation activities would be necessary to formulate hazard-specific performance criteria.

\subsubsection{Limitations}

Designing buildings to minimize damage and preserve function is not a new concept; it has been implemented for military and civilian applications (e.g., hospitals and other critical facilities). However, applying these design principles to all commercial and residential buildings is not typically recognized as economically feasible or necessary. This report is intended to describe efforts that would be needed to:

1) articulate how IO performance can be defined for buildings or building clusters (collection of buildings that support community social and economic functions, such as healthcare, education, business, or governance) by characterizing acceptable levels of damage and functionality for specified hazard intensities;

2) develop new design criteria, construction methods, and innovative materials and building systems that can meet desired building performance;

3) quantify and communicate the community benefits in terms of social and economic impacts to motivate and justify future investments in IO; and

4) support development of enhanced building codes for adoption and implementation by state and local jurisdictions.

In describing these core research areas, this report addresses the structural and non-structural elements of the building, processes by which buildings are designed and sited, and policies and processes by which owners, tenants, and other stakeholders interact with building systems. While this report describes a possible research path forward for IO performance for residential and commercial buildings, it is not intended to promote IO buildings above other community resilience investments nor to suggest that it would be effective for all residential and commercial buildings across the U.S. to be built or retrofitted to meet IO performance objectives. Further, the role of IO performance objectives in supporting broader economic, social and community resilience goals is an area that would be appropriate for more detailed study but outside the scope of this exploratory report.

While this report is focused on the performance of individual buildings, it is essential to recognize that individual building performance is affected by factors related to the broader 
community. Although many of these considerations are acknowledged in the report, such as the importance of continuity of infrastructure services for building functionality (e.g., a building needs to have electricity to maintain certain core functions), research into improving resilience of those external factors (e.g., establishing performance requirements for the electricity grid) is not specifically discussed in this report. Other research topics not addressed in this report include: improving fundamental knowledge regarding hazard occurrence and impacts; establishing performance requirements for infrastructure systems; and understanding the broader influence of community- and regional-scale social and economic systems on the ability of buildings to function after a hazard event.

Because of the variation in hazard risks, existing infrastructure, financial resources, and community support and motivation for investing in resilience measures across the United States, this report does not attempt to define a single approach to achieving IO building performance. Instead, it describes important research areas that would need to be investigated. For example, this report describes how building functionality may be characterized and further outlines the importance of relating desired functionality to broader community resilience efforts. However, it does not seek to define specific functionality levels to given building types, nor does it establish a specific post-disaster time frame by which functionality should be recovered. These needs will vary by community size, hazard risk, and resource availability, but common factors for many communities are expected to emerge. Furthermore, while this report describes research into tools that would help communities to conduct economic costbenefit analyses of IO investments, it assumes that prioritization of implementation by building type would be left to individual communities. NIST recognizes that local and state governments, structural engineering professionals, building code and enforcement officials, and other non-governmental organizations have leading roles in determining the future implementation paths for IO building performance objectives. The possible research efforts outlined in this report would require coordination and collaboration across these stakeholder communities in order to identify effective design guidelines and potential adoption pathways.

Further development and prioritization of the topics and activities outlined in this report would be needed in order to develop a robust roadmap with additional input from the federal government, state and local governments, the private sector, standard developing organizations (SDOs), and others.

\subsection{Development and Structure of Report}

This report details research that would be needed to develop and implement IO performance objectives for commercial and residential buildings. The research areas and implementation actions identify steps needed to improve understanding of the technical, economic, and social considerations in developing, implementing, and achieving an IO performance objective for new and existing buildings. The report was developed with participation from a steering committee and a broad range of stakeholders across multiple sectors through remote discussions and a workshop hosted by NIST. Therefore, NIST has relied heavily upon stakeholder data to develop not only the content, but also the scope and framework of this report. This effort represents a substantial first step towards development of IO performance objectives. 


\subsubsection{Steering Committee}

A steering committee was convened to elicit individual subject matter expertise to support the development of this report. Steering committee members included structural engineers, facility managers, and academic researchers who specialize in disaster recovery, urban planning, seismic evaluations, feasibility analysis, loading and structural response, and building codes. Committee members are listed in Appendix F. Steering committee members were called upon to provide initial scoping of relevant topics, provide leadership and expertise at a stakeholder workshop (described below), and were asked to review and provide comment on final drafts of this report.

\subsubsection{Development and Organization of Research Needs}

The four research topics addressed in this report are (1) building design, (2) community considerations, (3) social and economic considerations, and (4) adoption and acceptance considerations. These topics were developed through an iterative process that included a literature review and subject-matter expert input from the steering committee members and workshop participants as described below.

- Building design (Chapter 3) - Building design includes all considerations related to designing or retrofitting an individual building to meet IO performance objectives. Research under this topic includes efforts to establish the technical resources to design a building to meet the limited damage and functionality requirements for IO performance; to develop and improve building materials and technologies that address the challenges associated with meeting IO performance objectives; and to develop technologies and standards for the maintenance, repair, and monitoring and assessment of a building to ensure acceptable performance is achieved throughout the building's lifecycle.

- Community considerations (Chapter 4) - Community considerations address two perspectives: (1) the requirements of individual buildings that support a social function, such as education or healthcare, as well as support needed from external systems; and (2) the community perspective on IO building impacts on its resilience. Research topics include the performance of community facilities and building clusters as well as external systems such as utilities, transportation networks, or other infrastructure on the occupancy and functionality of an individual residential or commercial building. Other research activities include community planning and decision support, such as the performance of IO buildings and how land use and zoning codes can potentially help or hinder IO performance objectives.

- Economic and social considerations (Chapter 5) - Economic and social considerations address the potential intended and unintended impacts that IO building performance may have on social and economic systems. Positive or negative effects on economic and social systems may result from the consequences of performance objectives that improve building performance. Both costs and benefits are considered related to economic and social well-being including feasibility of IO building design and the importance of clearly defining stakeholder objectives for improved building performance.

- Adoption and acceptance considerations (Chapter 6) - Acceptance and adoption considerations address activities related to stakeholder communities that would be affected by, involved with, or could benefit from IO buildings. Research areas include: 
understanding of current IO practices and drivers; hazards not adequately addressed in current building codes; and market-based and public policy mechanisms supporting voluntary and mandatory adoption of IO. Education and training considerations vital to implementation of IO are also discussed. Lastly, monitoring and assessment of future IO performance objective adoption, practices, and performance of IO buildings during hazard events is covered.

\subsubsection{Stakeholder Workshop}

A stakeholder workshop was conducted on January 16-17, 2018, at the Institute for Defense Analyses in Alexandria, VA. The workshop provided input from a broad range of stakeholders through facilitated discussions of the four major research areas identified to assist with identification of research needs and potential implementation activities for developing IO performance objectives. Participants came from federal agencies, local governments, academia, standard developing organizations, non-governmental organizations, professional organizations, architects, engineers, and building developers as follows.

- At the federal level, participating agencies included NIST, the Federal Emergency Management Agency (FEMA), U.S, Geological Survey (USGS), the Department of Veterans Affairs (VA), and the General Services Administration (GSA). At the regional, state, and local government level, stakeholders from California, New York, and Washington were present at the workshop.

- Subject-matter experts from academia included, but were not limited to, those specializing in structural, exterior, and interior systems; community, regional, and urban planning; hazard assessment of buildings; disaster research and management; and community resilience.

- Representatives from SDOs included the International Code Council (ICC) and the American Society of Civil Engineers (ASCE).

- Delegates from non-governmental or professional and trade organizations included the National Association of Home Builders (NAHB), the Applied Technology Council (ATC), and the National Institute of Building Sciences (NIBS).

Workshop participants were asked to identify basic research, applied research, and implementation activities necessary to develop and implement an IO performance objective.

\subsubsection{Organization of Report}

Chapter 1 describes the congressional mandate initiating this report, the scope of research, a vision statement, and information related to the development and structure of the report. Chapter 2 provides an overview of building codes and standards currently used to design a building and discusses the building performance objectives targeted by these codes and standards. This information is used to introduce some of the challenges associated with constructing new buildings and retrofitting existing buildings to meet enhanced safety and functionality objectives for IO performance. Chapters 3 through 6 describe the four major research topics: building design, community considerations, economic and social considerations, and adoption and acceptance considerations. Chapter 7 provides a summary of the report discussion, identifies key challenges, and outlines the next steps required to develop IO performance objectives. In addition, a table summarizing the research needs and implementation activities identified in the report is provided in Appendix E. 


\section{Current State of Practice for Designing Buildings}

This chapter presents information about the building codes and standards currently used to design commercial and residential buildings, providing context for the challenges in developing a new immediate occupancy performance objective. Typical hazard types and hazard levels used to design a building are discussed.

\subsection{Building Codes and Standards}

Building codes establish minimum requirements for the design, construction, alteration, and maintenance of buildings so that they provide a minimum level of safety, public health, and general welfare, including protection from natural hazards that is deemed acceptable by practitioners through the consensus process. Model building codes are published by standards developing organizations (SDOs); federal, state, and local governments can choose to adopt or customize the provisions to standardize design and construction practices within their jurisdiction and so that they are enforceable by law. This variation in building code adoption means that the minimum design requirements across the United States vary.

SDOs producing model codes regularly review proposed changes submitted by industry representatives, design professionals, code officials, and other interested parties. The model codes currently used in the United States are developed and maintained by the International Code Council (ICC) and the National Fire Protection Association (NFPA). The ICC publishes a family of coordinated model codes, referred to as the I-Codes that are updated every three years. The two principal ICC model codes that address the design and construction of residential and commercial structures are the International Building Code (IBC) [3] and the International Residential Code for One- and Two-Family Dwellings (IRC) [4]. These principal codes reference other ICC codes that cover the design and construction of mechanical, electrical, plumbing, fire protection, and other systems. The ICC also publishes the International Existing Building Code (IEBC) [5], which applies to the repair, retrofit, alteration, change of occupancy, and relocation of existing buildings, and the Performance Code for Buildings and Facilities (ICCPC) [6], which provides guidelines for defining performance objectives for buildings designed by performance-based design. NFPA similarly publishes a family of coordinated codes and standards. The principal NFPA model codes are the NFPA 5000: Building Construction and Safety Code [7], NFPA 101 Life Safety Code [8], and the NFPA 70: National Electric Code [9], each updated every 3 years.

Model codes and standards frequently reference other national standards developed by industry organizations to address specific design and construction issues. One such standard is ASCE/SEI 7-16: Minimum Design Loads and Associated Criteria for Buildings and Other Structures [10], hereafter referred to as ASCE 7, which provides the minimum design loads for natural hazards to determine the effects of various loading conditions on a building. Model building codes also reference material-specific standards that include requirements for designing building systems using common construction materials and practices. Table 1 provides the current material-specific standards used in the United States for conventional construction materials with large market shares. In some cases, material-specific criteria are developed for particular hazard types. For example, ACI 318, published by the American Concrete Institute (ACI), contains special seismic design criteria; American Institute of Steel Construction (AISC) publishes seismic design criteria in a separate standard; and the American Wood Council (AWC) publishes special criteria for wind hazards and seismic hazards. Given 
the interconnectedness of the many codes and standards used to design buildings, one of the challenges associated with implementing a new IO performance objective is the need to provide consistency in performance requirements across multiple resources used to design and construct a building.

Federal agencies participate in the consensus model building codes and standards development process. For example, NIST, along with FEMA and USGS, have contributed to the development of seismic codes and standards as members of the Natural Earthquake Hazards Reduction Program (NEHRP), mandated by Congress in 1977 [11]. The National Science Foundation (NSF), also a NEHRP agency, provides funding for the engineering and seismology community to conduct basic research that further contributes to building codes and standards development. FEMA publishes the NEHRP Recommended Seismic Provisions for New Buildings and Other Structures [12], commonly referred to as the NEHRP Provisions, which is the resource document for new seismic provisions to be adopted in ASCE 7 [10].

Table 1. Material-specific standards for conventional construction materials with large market shares

\begin{tabular}{cccc}
\hline Material & Organization & Standard & Edition \\
\hline Structural Concrete & American Concrete Institute & ACI 318: Building Code Requirements for & 2014 \\
(ACI) & Structural Concrete and Commentary \\
Structural Steel & American Institute of Steel & AISC 360: Specification for Structural & 2016 \\
Cold-formed Steel & American Iron and Steel & Steel Buildings & AISI S100: North American Specification \\
& Institute (AISI) & for the Design of Cold-formed Steel \\
Wood & American Wood Council & National Design Specification for Wood & 2016 \\
& (AWC) & Construction & 2018 \\
Masonry & The Masonry Society (TMS) & TMS 402/602: Building Code & 2016 \\
& & Requirements and Specification for \\
& & Masonry Structures &
\end{tabular}

\subsection{Hazard Types and Levels}

Three hazard levels commonly referred to in practice are routine, design, and extreme. Each of these hazard levels are described below.

- A routine hazard, sometimes referred to as a serviceability load, is expected to occur more frequently than the design level hazard, but at a lesser intensity. Routine hazard levels have a high probability of occurring during the service life of a building and can be specified for a range of values (e.g., wind speeds that occur about every 10 years, 25 years, or 50 years) depending on the hazard type and the desired building performance.

- A design hazard level is the basis for designing typical buildings in codes and standards. The design hazard level may be adjusted, depending on the risk to human life, health, and welfare associated with unacceptable building performance.

- An extreme hazard is expected to occur less frequently than the design level hazard, but at a greater intensity. Extreme events have a small probability of occurrence. The extreme hazard level includes rare hazards that may plausibly affect a community. 
Where hazard levels are not defined by code, the community may establish a scenario or hazard level based on professional guidance or expected frequency of occurrence. Table 2 summarizes typical occurrence frequencies for each of the three hazard levels for different hazard types that are commonly considered for the design of a building. It is important to point out that building codes typically only target the design level hazard event. Alternative performancebased standards, which are discussed in Section 2.3, may include additional performance objectives for routine level and extreme level hazards. The likelihood of occurrence for each hazard level is reported in Table 2 in two ways: 1) as an average interval of occurrence over time, called the mean recurrence interval (MRI), and 2) the equivalent probability of the event level occurring at least once within a 50-year time period. 
Table 2. Summary of three hazard levels defined as a function of hazard types and intensity (adapted and modified from [13])

\begin{tabular}{|c|c|c|c|}
\hline Hazard & Routine & Design & Extreme \\
\hline Ground Snow & $\begin{array}{l}50 \text { yr MRI or } \\
64 \% \text { in } 50 \text { years }\end{array}$ & $\begin{array}{l}300 \text { to } 500 \mathrm{yr} \mathrm{MRI}^{1} \text { or } \\
15 \text { to } 10 \% \text { in } 50 \mathrm{yr}\end{array}$ & Locally determined \\
\hline Rain & Locally determined ${ }^{2}$ & Locally determined & Locally determined \\
\hline Wind - Non-Hurricane & $\begin{array}{l}10 \text { to } 100 \text { yr MRI or } \\
99 \% \text { to } 39 \% \text { in } 50 \text { years }\end{array}$ & $\begin{array}{c}700 \text { to } 3,000 \mathrm{yr} \text { MRI or } \\
7 \% \text { to } 1.6 \% \text { in } 50 \mathrm{yr}\end{array}$ & Not typically considered \\
\hline Wind - Hurricane & $\begin{array}{l}10 \text { to } 100 \mathrm{yr} \text { MRI or } \\
99 \% \text { to } 39 \% \text { in } 50 \mathrm{yr}\end{array}$ & $\begin{array}{c}700 \text { to } 3,000 \mathrm{yr} \text { MRI or } \\
7 \% \text { to } 1.6 \% \text { in } 50 \mathrm{yr}\end{array}$ & $\begin{array}{l}10,000 \mathrm{yr} \text { MRI or } 0.5 \% \\
\text { in } 50 \mathrm{yr}^{3}\end{array}$ \\
\hline Wind - Tornado & Not typically considered & Not typically considered & Variable $^{4}$ \\
\hline Earthquake & $\begin{array}{l}50 \text { yr MRI or } \\
64 \% \text { in } 50 \text { years }\end{array}$ & $\begin{array}{l}500 \mathrm{yr} \text { MRI or } \\
10 \% \text { in } 50 \mathrm{yr}^{5}\end{array}$ & $\begin{array}{l}2,500 \mathrm{yr} \text { MRI or } \\
2 \% \text { in } 50 \mathrm{yr}^{6}\end{array}$ \\
\hline Tsunami & Locally determined $^{3}$ & $\begin{array}{l}2,475 \mathrm{yr} \text { MRI or } \\
2 \% \text { in } 50 \mathrm{yr}\end{array}$ & Locally determined $^{3}$ \\
\hline Flood & Locally determined & $\begin{array}{l}100 \mathrm{yr} \text { MRI or } \\
39 \% \text { in } 50 \mathrm{yr}\end{array}$ & $\begin{array}{c}500 \mathrm{yr} \text { MRI or greater or } \\
10 \% \text { or less in } 50 \mathrm{yr}^{7}\end{array}$ \\
\hline $\begin{array}{c}\text { Fire - Wildland Urban } \\
\text { Interface }\end{array}$ & Locally determined $^{7}$ & Locally determined $^{7}$ & Locally determined $^{7}$ \\
\hline Fire - Urban & Locally determined $^{7}$ & Locally determined $^{7}$ & Locally determined $^{7}$ \\
\hline
\end{tabular}

Note - Mean Recurrence Interval (MRI) values from ASCE 7-16 unless otherwise noted.

${ }^{1}$ Varies regionally. For the Northeast U.S., the product of the 50-year ground snow load and load factor (1.6) is equivalent to the 300 to $500 \mathrm{yr}$ snow load.

${ }^{2}$ Rain is designated by rainfall intensity of inches per hour or $\mathrm{mm} / \mathrm{h}$, as specified in the local code.

${ }^{3}$ For hurricane shelters, from the ICC/NSSA Standard for Design and Construction of Storm Shelters, ICC 500-2014 [14]

${ }^{4}$ Tornado shelters are designed per the ICC/NSSA Standard for Design and Construction of Storm Shelters, ICC 500-2014 [14], for a deterministic tornado wind speed. This represents a maximum considered tornado. The MRI varies with geographic location and is not defined.

${ }^{5}$ This is an approximation. The current design is based on $2 / 3$ of the extreme event (see footnote 6). The return period for design level shaking is therefore different at every site.

${ }^{6}$ This is an approximation. The current design extreme event is based on a risk-target of $1 \%$ probability of building collapse in 50 years. The return period for MCE shaking is therefore different at every site and in general is less than $2 \%$ in 50 years.

${ }^{7}$ Hazards to be determined in conjunction with design professionals based on deterministic scenarios. 


\subsection{Performance Requirements for Code-Compliant Buildings}

ASCE 7 specifies a set of general requirements around which the prescriptive design instructions of the design standard have been developed [10]. The general requirements include:

- "Strength and Stiffness. Buildings and other structures, and all parts thereof, shall be designed and constructed with adequate strength and stiffness to provide structural stability, protect nonstructural components and systems, and meet the serviceability requirements."

- "Serviceability. Structural systems, and members thereof, shall be designed under service loads to have adequate stiffness to limit deflections, lateral drift, vibration or any other deformations that adversely affect the intended use and performance of buildings based on requirements set forth in the applicable codes and standards, or as specified in project design criteria."

- "Functionality. Structural systems and members and connections thereof assigned to Risk Category IV shall be designed with reasonable probability to have adequate structural strength and stiffness to limit deflections, lateral drift, or other deformations such that their behavior would not prevent function of the facility immediately following any of the design level environmental hazard events specified in this standard. Designated nonstructural systems and their attachment to the structure shall be designed with sufficient strength and stiffness such that their behavior would not prevent function immediately following any of the design level environmental hazard events specified in this standard. Components of designated nonstructural systems shall be designed, qualified, or otherwise protected such that they shall be demonstrated capable of performing their critical function after the facility is subjected to any of the design level environmental hazard events specified in this standard."

To address these requirements, ASCE 7 provides minimum design loads for a building and its nonstructural systems [10]. Design loads are based on a building's assigned Risk Category, which describes the risk to human life, health, and welfare associated with unacceptable performance of the building. There are four Risk Categories, from I to IV. They reflect the consequences of failure from the lowest risk to human life, Risk Category I, to the highest, Risk Category IV.

- Risk Category I buildings are those that pose low risk to human life in the event of failure, examples of which include storage facilities and barns.

- Risk Category II includes all buildings except those classified as Risk Categories I, III, and IV. Most commercial and residential buildings fall into this Risk Category.

- Risk Category III buildings are those designed to accommodate a high number of occupants (e.g., schools and theatres), potentially posing substantial risk to human life in the event of failure.

- Risk Category IV buildings include those classified as essential facilities, the failure of which could pose substantial hazard to the community.

The loads used to design a building reflect the building's Risk Category. Design loads generally increase as Risk Category increases. Accordingly, Risk Category IV buildings are targeted for better performance than Risk Category III buildings, and similarly Risk Category III is targeted for better performance than Risk Category II. 
Understanding the actual performance expected of code-compliant buildings, both new and existing, will inform the development of IO performance objectives. Given the additional performance requirements for Risk Category III and IV buildings, elements of the IO performance objectives may already be addressed to some degree. However, benchmarking the performance of a building in terms of code requirements is challenging for several reasons. For one, hazard events of the magnitudes typically used to design a building are infrequent, making it difficult to assess whether prescriptive design requirements satisfy the desired performance objectives based on observed damage from hazard events. Also, the prescriptive design requirements in ASCE 7 do not involve a direct comparison of performance outcomes with performance objectives. In addition, the design philosophy used to satisfy prescriptive design requirements differs by hazard type.

For example, for a design level seismic hazard, certain building components are intentionally designed to reach their strength limits and undergo local damage that does not affect building stability. As a result, a code-compliant building may require extensive repair, or even demolition, following an earthquake, even though the building fulfilled its primary objective of saving lives during the event. In contrast, a building may suffer substantially less structural damage during a design level wind or snow hazard because building components are not designed to reach their strength limits. Accordingly, the extent to which code-complaint buildings satisfy or exceed building code performance objectives may be challenging to quantify and may vary considerably between buildings and hazard types.

\subsection{Prescriptive Design vs. Performance-Based Design}

The two approaches used to satisfy building code requirements are prescriptive design and performance-based design. Most existing buildings were designed and constructed using a prescriptive design approach. Prescriptive standards, such as ASCE 7, have been vetted over decades of research and practice, making them a reliable approach to satisfy building code performance objectives. A drawback of prescriptive design is that building performance outcomes are not explicitly evaluated against performance criteria. Instead, the prescriptive requirements provide a detailed design approach that is deemed to satisfy building code performance objectives without explicitly assessing building performance. Risk Category III and IV buildings are implicitly designed to satisfy aspects of IO performance objectives. However, it is difficult to evaluate the effectiveness of these buildings in meeting IO objectives because the prescriptive design approach does not provide an indication of building damage from a hazard event. As a result, the post-hazard functionality of a building designed using a prescriptive approach may not be well understood.

As an alternative to prescriptive design, performance-based design (PBD) can be used to directly compare performance outcomes (e.g., building deflection) to performance objectives. To date, PBD standards have been developed primarily for seismic assessment of buildings. In current PBD documents, performance objectives are typically defined in terms of the maximum level of damage that a building can tolerate while satisfying the intended performance objective. To assess building performance against performance criteria, the damage state of the building is evaluated at each hazard level for which performance criteria are defined. While this approach may be more suitable for evaluating damage that may occur to the building and the repair needs required after a hazard event, research is still needed to develop an understanding of building functionality in terms of recovery time for the building to return to full function. 
To assist with the development of IO performance objectives, which emphasize building functionality, comprehensive studies are needed to quantify the extent to which Risk Category III and IV buildings designed by a prescriptive approach satisfy IO objectives. As an important component of these studies, there is a need to validate existing and develop new building performance assessment tools that can be used to evaluate damage, repair needs, and recovery times for a large number for buildings representing common commercial and residential structures. Specific research to address this need is discussed in more detail in Chapter 3. 


\section{Building Design Considerations}

There are significant challenges associated with designing new and retrofitting existing commercial or residential buildings to meet IO performance objectives. Research under this topic could lead to the development of new design guidelines and analytical tools to assist developers, architects, engineers, and researchers in designing and assessing buildings for achieving IO performance objectives. Development and adoption of guidelines and tools to implement IO objectives would advance current standards of practice and lead to buildings that are more resilient to natural hazards, providing a greater level of safety and minimizing disruptions for building occupants.

General challenges and research needs associated with designing a building for IO are presented within six subtopic areas. A more detailed discussion of the research and implementation activities that would be needed to address these challenges is provided in Appendix A.

Note: This report does not advocate for acceptance of the IO goal; rather, it identifies the range of research and implementation activities that would be appropriate if the IO goal is adopted.

\subsection{Functionality Levels}

One of the primary differences between IO performance objectives and current building code design objectives is the consideration of the functionality level of a building throughout its lifecycle, including the timeframe following a hazard event. Design criteria for incorporating building functionality goals into the design process are lacking. Major challenges in developing such tools include a general lack of understanding of the diverse factors that can impede building functionality, and the inability to characterize the recovery timeframe for a building impacted by a hazard event.

To overcome the challenges in developing performance objectives that prioritize building functionality, analytical tools that can predict the functionality level of a building for a variety of hazard scenarios are needed. Development of such tools should build upon existing tools such as FEMA P-58 [15], which was developed for seismic assessment of buildings. To develop these tools, research is needed to quantify the impacts of building damage, repair methods, and building age and condition on building functionality. Research is also needed to characterize acceptable building functionality levels to be considered for IO performance. These building functionality levels should describe the ability of the building to meet its intended purpose prior to a hazard, and to retain essential functions and return to pre-hazard functionality within a predetermined, acceptable timeframe following a hazard.

\subsection{Damage Levels}

The functionality of a building, without considering infrastructure services, mainly depends on the amount of damage experienced by the building as a result of hazard events and environmental impacts. In an engineering framework, building functionality needs to be measured as a function of damage to the building's structural components, nonstructural components, and any other components or equipment that can hinder functionality. As a result, the quantification of damage, both at the component and system levels, is essential to develop the design criteria to meet IO functionality goals. 
Developing material- and component-level damage prediction models is essential to design of new buildings and the repair and retrofitting of existing buildings to meet IO performance objective. To develop damage prediction models, research is needed to improve the understanding of the building response under different hazard types and levels as well as different environmental factors and aging. Detailed post-event field reconnaissance and experimental data are needed to develop and validate the damage prediction models, and to evaluate the extent of damage experienced by code-compliant buildings. Numerical models that can incorporate the damage prediction models are needed to simulate the response of building components and link component damage to overall building performance. Research is also needed to predict the impact of potential secondary sources of damage, such as mold growth due to water intrusion, on the building functionality.

\subsection{Design Practice}

Designing a building involves evaluating the building's conformance with building code and standards requirements. To do so, anticipated performance metrics, such as beam deflection or lateral building drift, need to be determined for the hazard scenarios that may affect the building. The anticipated performance is usually evaluated through computer analyses, using analytical tools that simulate the key characteristics of the building. It is common to only include the structural system in the evaluation; thus, most analytical tools may not be suitable for assessing IO performance objectives because they cannot account for the overall damage state of a building (structural and nonstructural), and, consequently, are not capable of fully assessing building functionality. Because buildings designed for IO performance will be required to meet damage and functionality criteria that are more restrictive than current prescriptive code requirements, the development of new guidelines and standards is necessary.

To address the shortcomings of current analytical tools, research is needed to develop improved capabilities to predict structural and nonstructural building damage and functionality over time, while accounting for the effects of various hazard scenarios, aging, maintenance, and repair. To address shortcomings with current design criteria, research to develop new hazard-specific technical design requirements is needed to achieve the enhanced performance objectives for IO - that is, limited damage and minimal functionality disruption.

\subsection{Building Materials and Technologies}

Advances in building materials and technologies have the potential to provide architects and engineers improved options to prevent, detect, and mitigate damage from hazards. Techniques like integrating sensors into buildings can be used to detect accelerations during an earthquake, temperature extremes, and potentially building damage. New materials and technologies may offer improved building performance or faster recovery times, but incentivizing adoption remains a significant challenge.

Research is needed to develop materials, technologies, and strategies that lower the likelihood of damage and are cheaper, easier, and/or faster to repair or replace. This work will require understanding the relationship between material properties and technologies and building performance. In addition, research is needed to understand how to incentivize the adoption of these new materials, technologies, and practices to ensure uptake. 


\subsection{Maintenance, Repair, and Retrofit Methods}

Damage and degradation to a building can reduce the building's structural capacity and ultimately its ability to meet its intended safety and functionality performance objectives. Periodic building maintenance can help minimize the effects of building aging, however the environmental factors that may hinder a building's ability to meet its performance objectives are not well understood. When moderate or severe damage occurs, either due to aging or during a hazard event, repair is often required to restore building safety and retain building function. For buildings designed for IO performance, repairs will need to be conducted in a timely manner to satisfy functionality objectives. Depending on the type and extent of damage sustained, repair can be costly, and even uneconomical. In addition, the timeframe required to complete repairs can be extensive due to high demands for materials and skilled labor after hazard events that causes wide spread damage. There are unique challenges for existing buildings, many of which may not currently be capable of meeting IO performance objectives. Where IO performance is desired for an existing building, retrofit may be required to improve building performance. New retrofit strategies will likely need to be developed to target IO performance objectives.

To improve and optimize building maintenance, research is needed to quantify the impacts of environmental factors on the degradation of building materials and how such degradation affects capacity of building components. Doing so will make it possible to develop maintenance schedules to address typical environmental aging effects for buildings designed for IO performance objectives, thus enabling such buildings to meet IO performance throughout the building's service life. Research is also needed to develop low cost, rapid repair technologies for damaged building components. This research should identify and prioritize the building components and systems that have the greatest potential to slow the repair process for a building. The challenges associated with availability of parts and skilled labor required to repair a building after a hazard also need to be studied. Research is also needed to develop effective retrofit technologies that make it possible to achieve IO performance objectives for existing buildings. Additionally, research is needed to understand the decision-making processes that influence whether a building owner will choose to invest in maintenance, repair, and retrofit.

\subsection{Monitoring and Assessment}

The state of an IO building should be monitored periodically to determine how aging, environmental factors, and hazards affect the building's ability to meet IO performance objectives. Moreover, assessing the building's performance after a natural hazard event is essential to evaluate whether the building is safe to occupy and to determine the post-hazard functionality level of the building. The main challenge in monitoring building performance is developing new cost-effective monitoring techniques. Timely assessment of buildings after a hazard is also a key challenge, as it needs to be completed prior to reoccupying the building and returning to function. In addition to technical issues, another challenge may be associated with privacy and ownership of the collected data. Moreover, there could be commercial and liability concerns if a building is found not to meet the IO performance objectives for which it was designed.

Research is needed to develop cost-effective monitoring methods that focus on collecting a broad dataset that reflects the performance of various structural and nonstructural components of the building. The use of new data collection methods, such as crowdsourcing, citizen 
science, and social media, to collect information on the building condition following a hazard event needs to be explored. Research is also needed to develop methods to assess building performance, in a timely manner, using the data from each of these collection methods. 


\section{Community Considerations for IO Buildings}

In establishing IO building performance objectives, community planning and decision-making should also be considered. Tools are needed to determine how IO buildings can best fit within the broader community and contribute to supporting social functions, such as healthcare, education, business, and governance. The risk for substantial damage and losses across the nation is greater now than ever before due to urban development and population growth. The U.S. population increased from 1970 to 2010 by about 50\%, from 203 million [16] to 309 million [17]. In areas that are susceptible to natural hazards (e.g., along coastlines, in the wildland-urban interface, and in earthquake-prone regions), similar population growth and development has occurred. The population of coastal shoreline counties increased by 39 percent, and coastal watershed counties increased by 45 percent [18]. Compounding the situation, the nation's physical infrastructure is aging, diminishing its capacity to resist hazards [19].

Community resilience, the ability to prepare for and adapt to changing conditions and withstand and recover rapidly from disruptions [20], may involve preparing for anticipated natural hazard events, withstand the impacts of those hazards, and recover rapidly from disruption to community functions. This is a local and a national issue. Just as the effects of a disruptive hazard event cascade locally through impacted infrastructure and society, they can also cascade across entire regions, or even nationally. Preventing hazard events, such as earthquakes, hurricanes, and community-scale fires, from becoming disasters depends on the resilience of buildings and infrastructure systems.

While many tools exist to assess risks and vulnerabilities of individual assets, science-based tools are lacking for assessing the integrated performance of a community's physical, social, and economic systems, including the dependencies among these systems. There are ongoing research activities addressing these needs, including the Community Resilience Program at NIST, [21] the NIST-funded Center for Risk-Based Community Planning, [22] and the Department of Homeland Security (DHS) Coastal Resilience Center of Excellence and the Critical Infrastructure Resilience Institute [23]. Other federal agencies as well as many private sector, not-for-profit, and public organizations also are devoting research efforts to this area.

The challenges and research for IO buildings at the community scale are addressed from two perspectives. One is the IO building perspective: what is needed from community infrastructure and services to achieve IO performance? The other is the community's perspective: how can IO buildings improve community performance and recovery of functions?

There are several challenges associated with community planning and decision-making that need to be considered for IO implementation. Economic development, business continuity, urban design, social equity and affordability, and livability, among other objectives, need to be addressed through integrated multidisciplinary approaches [13]. Community resilience and related decisions are also affected by local culture and preferences, available resources, and plans for economic growth and resilience, which adds to the complexity of IO planning. Moreover, effective communication with community stakeholders likely will have a substantial effect on whether IO performance benefits, costs, and trade-offs are understood and accepted. Advancing knowledge and developing tools for community stakeholders and 
building owners to understand how IO performance objectives can support both the community and their own performance goals and how to effectively plan and design IO buildings in a community is a major challenge.

General challenges and research needs associated with community considerations for IO buildings are presented within four subtopic areas. A more detailed discussion of the recommended research and implementation activities to address these challenges is provided in Appendix B.

\subsection{Infrastructure and Building Cluster Interactions}

The relationships, dependencies, and factors that characterize IO building performance and its effect on community functions need to be defined. For example, the anticipated performance of existing buildings, which is often difficult to assess, may affect the performance of an IO building within a building cluster (of existing buildings). Buildings also require infrastructure services to meet their intended functions for their owners and the community. Some IO buildings may maintain their functions by use of temporary sources of infrastructure services, such as generators or water tanks, for commercial buildings or high density residential buildings. Rural areas with low density may be supported with temporary water supplies and portable toilets.

Including IO buildings as part of the community building portfolio may require altering local policies and criteria for decision-making, especially concerning community development and resilience goals. Integrated community planning includes consideration of goals and plans of stakeholders for physical, social, and economic systems in a community, which presents multiobjective coordination and optimized decision-making challenges.

These challenges can be advanced by conducting research to: characterize the recovery process for buildings and infrastructure; characterize dependencies and redundancies for IO buildings, building clusters, and infrastructure systems; identify temporary solutions for providing infrastructure services to support IO buildings; and develop tools that analyze and visually present community data for design and assessment purposes.

\subsection{Community Planning}

Analyses that support community planning for IO buildings are needed. Community planners and stakeholders require tools that quantitatively link IO performance objectives to community functions, which includes community metrics, system dependencies, stakeholder performance needs and goals, and the role of IO buildings in mitigating risks and improving community recovery.

Research activities to address these challenges include: developing metrics and analysis methods to assess community functions in relation to IO building performance, the ability of existing buildings to support IO building performance, and the effect of hazards on IO building performance and community functions. Additionally, land use and zoning policy influence on IO building performance and community development need to be evaluated. Methods would need to be developed for prioritizing which buildings should be designated as IO in a community or which land areas are inappropriate for development, given the known hazards. The results of this research can be used to develop multidisciplinary guidance and tools for IO building planning and design. 


\subsection{Community Decision Support}

Decision support tools should help assess where and how IO buildings should be implemented by considering the role of IO buildings in mitigating risks for hazard events and improving recovery of social and economic functions. Technical and administrative decision parameters for community resilience planning for a range of community types, and the design and construction requirements of IO buildings, need to be identified. For example, a large city may control or manage many of its buildings and infrastructure systems, while small communities may rely on their county and state to manage much of their buildings and infrastructure systems.

Research activities to address these challenges include: developing metrics for assessing the effect of IO buildings on community functions, developing technical and administrative requirements for managing IO buildings, and assessing the decision-making process for residential and commercial buildings. This knowledge can be used to develop decision support tools that integrate community data for IO buildings.

\subsection{Community Stakeholder Communications}

Effective communication approaches will help communities engage and inform all stakeholders, including business owners, residents, and design professionals. Costs and benefits need to be presented in ways that support both the community and stakeholder performance goals and how to effectively plan and design IO buildings in a community. Communication challenges include identifying the information and communication methods to educate all community stakeholders about IO performance objectives, developing methods and approaches that effectively communicate trade-offs and elicit feedback, and developing improved methods to communicate risks and uncertainty.

These challenges can be advanced by conducting research to identify the type of information needed by community stakeholders, develop methods of effective risk communication, and develop technical communication capacity through education and training curricula. This knowledge will support the development of stakeholder communication tools for IO buildings. 


\section{Economic and Social Considerations}

Economic and social considerations are integral to the development of IO performance objectives. Research and implementation activities discussed in this chapter emphasize areas where further efforts are needed to clarify potential consequences of IO performance objectives at the local, regional, and national scale. Research and implementation efforts related to economic and social effects will require collaboration and communication across social science disciplines, as well as between social scientists, engineers, and practitioners. Insights on areas for further research will be useful for decision makers at the building or community level who are interested in improving social and economic well-being while also providing benefits during hazard event recovery.

The most direct benefit of IO buildings is continued functionality after a hazard event. For example, a residential building designed to be immediately occupiable should provide continuous shelter and support the health and welfare of its occupants. In a commercial building, a business can continue operations following an event, allowing the building owner to collect rent, the business owner to avoid losses due to disruptions in business activity, and workers to earn wages. There are also benefits of IO buildings in the absence of a hazard event for individuals, social institutions, and economic systems. Research is needed to characterize both positive and negative effects to society and the economy relative to the cost of building or retrofitting for IO performance to improve economic and social well-being. This chapter addresses key concerns related to economic and social impacts and feasibility of IO.

General challenges and research needs associated with economic and social considerations are presented within four subtopic areas. A more detailed discussion of the recommended research and implementation activities to address these challenges is provided in Appendix C.

\subsection{Economic Feasibility}

Cost and affordability are key questions related to IO building design and construction. There are concerns that the direct, indirect, and long-term expense of IO buildings could limit the adoption of IO buildings by building owners and communities. Economic feasibility covers a range of issues related to initial and long-term costs and direct and indirect benefits for IO performance objectives for new and existing buildings, as well as the role of financing mechanisms for construction or retrofit. The scope for this research topic is limited to costs, benefits, and financing for stakeholders of a single building. The remaining research topics consider broader social and economic effects.

\subsection{Economic Impacts}

This research topic covers effects on the local, regional, and national economy from a building, or group of buildings, that are being designed or retrofitted for an IO performance objective. At a high level, these effects may be thought of as positive or negative externalities (secondary or unintended consequences) imposed on society by a building-level decision, since building owners will not bear the full impact of meeting IO performance objectives. IO buildings may benefit residents, occupants, or communities, but may also confer some burden: for example, increased rents as a result of IO improvements could drive small business owners out of an area. On the other hand, assurances of continued functionality may draw businesses into an area or encourage existing businesses to stay. Consideration of economic impacts across a 
broad range of stakeholders and at the building level and beyond should be linked closely with issues related to social feasibility and impacts discussed in the following sections.

\subsection{Social Feasibility}

The ability of decision makers (whether building owners or a city council) to promote IO buildings and implement IO performance objectives will vary widely due not only to economic concerns, but also reflecting many other factors that support or constrain willingness to invest in buildings that meet IO performance objectives. Chief among these are perception of risk (lack of knowledge; or overestimating or underestimating risk) as well as the desires and preferences that various stakeholders have for the performance of IO buildings. These need to be better evaluated and considered alongside other factors that can constrain decision-making to support social feasibility of IO building performance objectives.

\subsection{Social Impacts}

Social impacts cover a range of effects created for individuals, populations, and communities from the development of IO buildings. Work to identify potential positive and negative effects from application of IO performance objectives can help various stakeholders to maintain or even enhance social well-being. It is important to note that consideration of social effects should extend beyond the people involved in an IO building itself to include those that may be affected through secondary or unintended consequences (externalities). For example, commercial and residential tenants may bear costs of increased rent and vulnerable populations may find fewer housing choices. Research in this section includes influences on social functions, organizations, and institutions, as well as to vulnerable populations. Such research may help to reshape how we think about planning, design, and recovery for natural hazard events utilizing IO performance objectives. 


\section{Adoption and Acceptance Considerations}

Decision makers at all levels will need new information if they are expected to consider adopting and implementing IO performance objectives. Decisions would be made on: whether to use mandates or incentives; how to conduct education, training, and outreach; how to garner support for these initiatives; and how to ensure that buildings continue to meet desired performance objectives. There will be many stakeholders participating in the decision-making process, so research on the best ways to educate, communicate, and collaborate with them will also be necessary. Examples of these participants include: state and local government officials; engineers; architects; urban planners; building owners, and building occupants.

The key challenges regarding adoption and acceptance of an IO performance objective can be organized into three main areas:

- adoption mechanisms, which include the identification of building performance during and after hazard events, and development of options for how IO performance objectives are implemented;

- education, training, and outreach, which includes new curricula and materials for professional education, workforce development, and public engagement; and

- monitoring and assessment, which involves the development of technologies and methods to analyze IO building performance over time and after hazard events, as well as methods to track IO building implementation progress.

The following sections describe these challenges and identify areas in which basic and applied research and implementation activities could help address them. Additional details are provided in Appendix D.

\subsection{Adoption Mechanisms}

It is necessary to establish a benchmark of the performance of existing building stock, to characterize the performance of code-compliant buildings and those identified for IO capability under geographically relevant natural hazard risks. There is currently no consensus-based approach to evaluate buildings in terms of their potential to continue operating after a hazard event, so a standardized approach needs to be developed. With the ability to evaluate an existing building, the capacity for a building or class of buildings to support IO performance objectives can be identified.

It is also necessary to identify market forces that will influence the adoption of IO performance objectives within different sectors, and to determine funding sources for retrofits. Given the historical difficulties in mandatory retrofit adoption, an emphasis should be placed on evaluating voluntary incentives, although mandatory requirements such as building codes and zoning ordinances will have a role. Research into the application of voluntary IO or IO-like performance objectives, which are beginning to find their way into practice, can be a starting point. An example is a hospital in Joplin, Missouri, which was destroyed by a tornado in 2011. It was rebuilt with many features beyond current code requirements to enable continued functionality of at least part of the facility if the hospital should be struck by another tornado [24]. Other voluntary programs that have been successful in related fields include: public private partnerships; incentive systems implemented through public policies; government grant programs; conservation easements; tax-increment financing, and incentive zoning. Identification of legal barriers and possible solutions is also important. Once the sources of and 
possible solutions to legal barriers are identified, guidance and tools are needed to support decision makers. The outcomes of research in all these areas combined will help decision makers decide whether to adopt IO performance objectives for certain buildings, what performance is desired, and the best policy approaches.

\subsection{Education, Training, and Outreach}

Recruiting and maintaining a workforce knowledgeable about IO performance objectives and implementation methods will be crucial to ensure a common understanding across professions. For the engineering and architectural fields, designing buildings to IO performance objectives would be a notable shift from current practice. It may require an IO-specific set of competencies, and a licensure or accreditation program for designers, contractors, and code officials. This could have widespread implications on undergraduate and graduate curriculum content as well as future workforce recruitment and retention. In addition to the technical workforce necessary to design and construct IO buildings, code officials will need to be trained to enforce the design standards and ensure buildings are constructed to code and can meet IO performance objectives. In particular, if performance-based design is to become more prevalent, code officials likely would need additional training in advanced modeling tools.

Building owners and community leaders need education on hazard risks, costs and benefits, and best practices. Additionally, opportunities for diverse sets of stakeholders to interact and communicate in a group setting, such as community workshops, should also be explored. Examples of these stakeholders include financial institutions, insurance companies, foundations, federal and state governments, business, utilities, commercial building owners, and homeowners.

\subsection{Monitoring and Assessing IO Performance Objectives Adoption, Practice and Performance}

An important component of IO adoption and implementation will involve identification of buildings designed for IO performance in a community and assessment of the effectiveness of newly developed IO objectives in ensuring those buildings meet the desired functionality level. Research to support this IO adoption need will entail collecting basic information about the buildings in a community that were designed and constructed or retrofitted for IO performance, as well as identifying buildings that were designed according to current life safety standards. Collection of this data will enable periodic evaluation of the anticipated performance of IO buildings throughout their lifecycle. After a natural hazard event, this data will also enable a comparison of the observed performance of IO buildings to the anticipated performance. Additionally, the availability of data for a large number of buildings designed for different performance objectives will enable a direct comparison between the performance of IO buildings and those designed for life safety.

Research is also needed to develop new inspection techniques and standardized IO evaluation systems that can be adopted by local jurisdictions to periodically evaluate the ability of buildings within a community to meet IO performance objectives. Following a natural hazard event, rapid evaluation of a building's performance can assist decision makers to determine whether any restrictions are needed prior to re-occupancy. These inspection protocols may need to be modified to produce rapid assessments specifically developed to ensure that buildings designed for IO can remain safely occupied and functional. 


\section{Summary}

\subsection{Motivation}

Natural hazard events affect communities through loss of life, displacement of residents and businesses, injuries, property damage, and potentially long-lasting economic impacts. For commercial and residential buildings that are constructed to modern building code requirements, the likelihood of loss of life and collapse is low; however, the buildings still may sustain extensive, and possibly irreparable, damage to the structural system, interior nonstructural systems or components, or exterior components, including those forming the building envelope so that building functions are degraded or lost.

When this level of devastating damage affects a community or a state, the possible economic and social effects may have regional and potentially national implications. Improved performance of residential and commercial buildings could help mitigate or reduce these impacts. Such improvement would require performance objectives and associated design criteria that preserve building integrity and provide higher levels of post-event functionality, in addition to meeting the basic requirement of life safety. Ideally, after a design-level hazard event, buildings designed to an IO performance objective would have minimal or acceptable loss of function; any needed repairs would not interfere with building occupancy and intended use. Such performance levels would reduce actual building damage and resulting economic losses, accelerating community recovery by allowing continued access to jobs, housing, and community services.

Achieving enhanced commercial and residential building performance requires a substantial shift in traditional approaches to building design and building code enforcement. Changes in land use planning, zoning, legal and other important factors influencing building development and ownership would also be required. Moreover, even if individual buildings performed better, the infrastructure systems that occupants rely upon would need to perform well enough to deliver critical services. In addition, potential positive impacts to the broader community from retrofitting existing buildings to the IO performance objectives could take several decades due to a large building stock and long service life of buildings.

This report examines the many aspects involved in developing an IO performance objective. Consistent with the direction to NIST by the U.S. Senate Committee on Appropriations in Senate Report 114-239 for FY 2017, the research identified in this exploratory report describes the first steps toward providing the knowledge, information, and technical foundation that would be needed to advance IO performance objectives as a feasible engineering and building design practice that can reduce the immediate and longer term impact of natural hazard events on the Nation's buildings and communities.

It is important to note that this report does not advocate for acceptance of the IO goal; rather, it identifies the range of research and implementation activities that would be appropriate if the IO goal is adopted.

\section{2. $\quad$ Summary of Research Topics and Subtopics}

New engineering design approaches and construction techniques, combined with considerations of community, social, economic, and acceptance and adoption issues, are needed to improve the performance of commercial and residential buildings and community resilience. This section summarizes key topics of investigation within these four broad areas. 
1. Building Design: This topic includes considerations related to designing or retrofitting an individual building to meet IO performance objectives.

a. Functional Levels - Functional level classifications for integrated building performance that consider recovery times, to establish desired performance levels for $\mathrm{IO}$ residential and commercial buildings

b. Damage Levels - Damage levels associated with functional level classifications for integrated building performance that consider degradation effects

c. Design Practice - Design and evaluation methods for predicting and evaluating the anticipated performance of new and existing building

d. Building Materials and Technology - New building materials and technologies that improve construction and performance and facilitate repair and recovery of function

e. Maintenance, Repair, and Retrofit - Improved maintenance, repair, and retrofit methods for existing buildings, and determination of the effectiveness of proposed actions

f. Monitoring and Assessment - Improved monitoring methods for existing buildings and new buildings going in to service, as well as improved technology to collect data and assess building condition and capability following a natural hazard event

2. Community Consideration: This topic considers the role of buildings in community physical, social, and economic systems before and after hazard events.

a. Infrastructure and Building Cluster Interactions - Characterization of dependencies between physical, social, and economic functions; redundancies in infrastructure services to buildings; and temporary solutions to rapidly recover building functions across clusters

b. Community Planning - Community metrics, methods, and tools to assess required community infrastructure support and the role of IO buildings in building cluster performance and community resilience

c. Community Decision Support-Community metrics, methods, and tools to support decision-making about the effect of IO buildings on communities and their social and economic functions

d. Community Stakeholder Communication - Methods and tools to communicate benefits and risks of improved performance to a range of stakeholders

3. Economic and Social Considerations: This topic considers the potential impacts that improved building performance may have on social and economic systems.

a. Economic Feasibility - Cost and affordability data and tools that consider initial and long-term costs, direct and indirect benefits, and financial mechanisms for individual buildings

b. Economic Impacts - Economic effects for building owners, occupants, businesses, and communities for IO buildings, including property values, recovery of households and businesses, and other direct and indirect impacts

c. Social Feasibility - Considerations underlying IO building feasibility, including perception of risk, local preferences for building performance, and constraints on decision-making 
d. Social Impacts - Impacts to social functions, organizations, and institutions, as well as to vulnerable populations that inform decision-making by individuals, organizations, and governments

4. Adoption and Acceptance Considerations: This topic includes activities that would be required to implement IO performance objectives for different stakeholder communities, including state and local government officials, engineers, architects, urban planners, building owners, and building occupants.

a. Adoption Mechanisms - Identify current methods and information that support voluntary and mandatory adoption of building practices and standards. Identify innovative policy initiatives to empower communities and states to move forward with IO.

b. Education, Training, and Outreach - Develop educational and professional curricula and training, including accreditation programs

c. Monitoring and Assessment of Future IO Adoption, Practice, and PerformanceIdentify methods to evaluate the hazard performance of buildings designed for IO and life safety objectives. Develop new inspection and IO evaluation criteria to ensure IO buildings continue to meet IO objectives and to ensure rapid assessment of the safety and functionality of buildings after a hazard event.

Appendix E summarizes the specific basic and applied research needs and implementation activities associated with each sub-topic as well as the potential outcomes.

\subsection{Crosscutting Research Needs and Implementation Activities}

In addition to the specific research areas discussed within each chapter, there are several key themes addressing basic and applied research needs and implementation activities that are pertinent to all four topic areas. These cross-cutting components are described below.

- Basic and applied research needs:

Relationships and dependencies - Models of relationships and dependencies between functional levels, damage and recovery levels, and effects on populations, social and economic systems, and communities

Data-Databases, collection of comprehensive data sets, and protocols for standardized data collection on the performance of physical, social, and economic systems in the pre-event, post-event, and recovery time periods

Predictive models - Predictive models that address multiple spatial scales (building system, building cluster, community) and temporal scales (days to decades) to improve understanding of the direct and indirect effects of interventions on complex systems and system interactions

- Implementation activities:

IO Design Practices - Guidance documents and standards for design practices that support achieving functional levels for IO buildings, with associated considerations for their role in a community and their effects on social and economic systems

Metrics and Tools - Metrics and tools to support prediction and evaluation of anticipated performance and decision-making by stakeholders

Education, Outreach, and Training - Stakeholder education, outreach, and training for acceptance and adoption of IO criteria and methods 


\subsection{Key Challenges}

In exploring the research and implementation needs for IO building design and adoption, it has become clear that enhanced building performance is more than a technical problem of how to design and construct buildings that are more resilient to natural hazards. There are multiple complex social, economic, and policy challenges that should also be addressed to ensure that adoption of IO performance objectives is not only viable, but would also be successful in meeting goals for increased community resilience to natural hazard events. The key challenges described below are outside the scope of singular research topics or implementation activities. They would require coordinated and cooperative work over time and across sectors. Careful assessment of policy, economic, and social considerations could hasten effective post-hazard event recovery and provide long-term benefits for resilience across the nation. The challenge of achieving IO performance is just as much a social and economic matter as it is a technical one.

Motivating action: While communities often reflect on desired building performance in the wake of a natural hazard event, a key barrier to adoption and acceptance of an IO performance objectives is motivating the community to invest in improved building performance in advance of hazard events. There is a general expectation that current building codes and regulations protect against damage or loss of functionality from hazard events. In reality, they are primarily designed to safeguard lives and only provide some degree of property protection. Shifting public expectations to IO performance and functionality and ensuring those objectives are reflected in revised engineering and code design will require coordinated actions over time. This report addresses technical limitations and education and outreach needs to ensure stakeholders, including community officials, engineers and architects, building owners and the public at large, have the necessary tools to make effective decisions about the value of enhanced performance by designing to IO performance objectives.

Managing the distribution of costs and benefits: One of the core challenges in constructing for enhanced building performance for both new and existing buildings is that owners and developers who invest in IO performance measures may not be the primary beneficiaries of the investment. Research is needed to help clarify costs and benefits and to support development of innovative and feasible adoption mechanisms, such as financial incentives to offset investment costs, that can help balance costs and benefits for stakeholders including occupants, building owners and communities.

Influencing private owners: While the performance of individual buildings during a hazard event cumulatively affects the ability of a community to respond to and recover from the event, the majority of buildings are privately owned. Research is needed to identify the considerations associated with how private owners may be influenced or incentivized to participate in improving the performance of their buildings.

Influencing public sector: Buildings that are owned by local, state, or federal agencies (hospitals, nursing homes, housing, etc.) may affect community recovery, especially in economically disadvantaged regions. As public buildings may not be subject to local codes, research is needed to identify appropriate implementation and adoption mechanisms for the public sector. 
Protecting vulnerable populations: Vulnerable populations are more likely to live in older structures and often in areas that are more prone to certain natural hazards such as flood plains. It is important that adoption measures ensure all populations, such as those who are socioeconomically disadvantaged, the elderly, and those requiring medical or caregiving attention, have opportunities to benefit from enhanced building performance and hazard resilience.

Addressing liability for building performance: Buildings may not perform as anticipated during a hazard event. While in some circumstances this may be due to error in design, construction, or maintenance of the structure, building performance can be affected by factors beyond the control of the designer. For example, performance might be impacted by an extreme hazard level that is not considered in the design, the availability of infrastructure services, or other factors outside of the building envelope and beyond building code requirements. Additional research and stakeholder outreach is needed to address legal issues surrounding liability for actual building performance post-event and the influence these considerations will have on IO performance objective adoption.

Coordinating interdisciplinary collaboration: Due to the interdisciplinary nature of designing, implementing, and enforcing measures for IO building performance, collaboration is needed across the array of stakeholders that have an interest in enhanced building performance. This includes collaboration across disciplines, professions, and across sectors within a community. This collaborative approach is often challenging due to the traditional roles and responsibilities of individuals involved in building design. Harnessing the diverse set of relevant expertise is essential to ensure IO performance objectives are adopted in an effective, successful manner.

Garnering public support: Stakeholder support is critical to the success achieving IO performance. Eliciting stakeholder buy-in and support across individuals, public and private sectors, and communities, is essential to garnering community trust, participation, and influence in developing IO building performance initiatives. By collaborating with existing community networks and leveraging the role of community leaders, local knowledge, skills, resources, and priorities can more effectively be integrated to achieve IO goals.

\subsection{Conclusion and Potential Next Steps}

This report fulfills the congressional mandate to develop a report that details the basic and applied research and the implementation activities necessary to develop IO performance objectives for commercial and residential buildings. The research actions described in this report provide a basis for potential advances in science, engineering, technology, and decisionmaking to support the development of new building design guidelines that consider the needs of communities to have access to housing and resume the operations of local businesses, educational facilities, and other community services following natural hazard events. The results of the proposed research would provide knowledge to support the development and implementation of an IO performance objective in future building codes and standards.

The identified research and implementation activities emphasize factors that impact performance of buildings while also addressing community concerns, social and economic impacts, and issues related to the adoption of IO performance objectives. While these activities are necessary for achieving IO performance objectives, additional research and implementation 
activities would be needed. For example, research is needed to investigate enhanced performance of infrastructure, and to study the interaction of infrastructure with the functionality of IO buildings. In addition to addressing building design and engineering aspects, social and economic issues for developing an IO performance objective will require thoughtful engagement of stakeholders, development of public policy initiatives, and public support.

Moving towards IO building performance objectives would represent a substantial change from the current design philosophy for commercial and residential buildings, which prioritizes occupant safety and not post-hazard functionality, to a design philosophy that also emphasizes preservation of building function and supports community economic and social objectives. Increasing the performance goals for buildings would not be easily achieved, but the advantages may be substantial. The development of an IO performance objective would require engagement from all levels of society and entail reallocation of existing effort, time, resources and financial investment.

Development and implementation of IO building performance objectives would entail a significant shift in practice for development, construction, and maintenance or retrofit of buildings. Changes in building design and practice would require a multidisciplinary perspective and a commitment to advances in science, engineering, social science, and economics. International advances in the development and implementation of performance objectives that emphasize building functionality and the post-hazard social and economic needs of communities should also be considered in development and implementation of IO performance objectives. Moreover, substantial changes would be required for education, training and practice within the engineering, architectural, and building professions. The involvement and enthusiasm of professional societies and other key stakeholders would be necessary to produce change within standards developing organizations and in building codes.

The potential research and implementation activities outlined in this exploratory report represent initial thinking and planning for the development of IO performance objectives for commercial and residential buildings. This report neither advocates for acceptance of the IO goal nor suggests that it would be effective or feasible for all commercial and residential buildings across the U.S. to be built or retrofitted to meet IO performance objectives. More detailed study is appropriate to determine whether and how IO performance objectives can support broader economic and social community goals.

If a decision is made to pursue IO performance objectives, further development of report topics and activities would require additional input from the federal government, state and local governments, academic institutions, building designers and construction professionals, product manufacturers, building owners and developers, and community planners. The initial assessment included in this report could be used to develop a prioritized plan with coordinated and detailed research goals and implementation activities to effectively mitigate natural hazard risk. 


\section{References}

[1] National Oceanic and Atmospheric Administration, National Centers for Environmental Information (NCEI) (2018) Billion-Dollar Weather and Climate Disasters: Overview. Available at http://www.ncdc.noaa.gov/billions/. Accessed February, 2018.

[2] Mooney C, Dennis B (2018) Extreme hurricanes and wildfires made 2017 the most costly U.S. disaster year on record. The Washington Post. (Published January 8, 2018).

[3] International Code Council (2017) 2018 International Building Code. Washington, D.C.

[4] International Code Council (2017) 2018 International Residential Code for One- and Two-Family Dwellings. Washington, D.C.

[5] International Code Council (2015) 2015 International Existing Building Code. Washington, D.C.

[6] International Code Council (2014) 2015 International Code Council Performance Code for Buildings and Facilities. Washignton, D.C.

[7] National Fire Protection Association (2018) NFPA 5000: Building Construction and Safety Code. Quincy, MA.

[8] National Fire Protection Association (2018) NFPA 101: Life Safety Code. Quincy, MA.

[9] National Fire Protection Association (2017) NFPA 70: National Electrical Code. Quincy, MA.

[10] American Society of Civil Engineers, Structural Engineering Institute (2017) Minimum Design Loads and Associated Criteria for Buildings and Other Structures. Reston, VA.

[11] Earthquake Hazards Reduction Act of 1977 (2004) Public Law 95-124 Amended through Public Law 108-360, and enacted October 24, 2004.

[12] Federal Emergency Management Agency (2015) NEHRP Recommended Seismic Provisions for New Buildings and Other Structures, Volume 1. FEMA P-1050-1/2015 Edition, prepared for the Federal Emergency Management Agency by the Building. Seismic Safety Council of the National Institute of Building Sciences, Washington, D.C.

[13] National Institute of Standards and Technology (2016) Community Resilience Planning Guide for Buildings and Infrastructure Systems, Volume 1. NIST SP-1190. http://dx.doi.org/10.6028/NIST.SP.1190v1.

[14] International Code Council (2014) ICC 500-2014: ICC/NSSA Standard for the Design and Construction of Storm Shelters. Washington, D.C.

[15] Federal Emergency Management Agency (2012) Seismic Performance Assessment of Buildings (FEMA P-58), prepared by the Applied Technology Council for the Federal Emergency Management Agency. Washington, D.C.

[16] U.S. Census Bureau (1970) 1970 Decennial Census. Suitland, MD.

[17] U.S. Census Bureau (2010) 2010 Decennial Census. Suitland, MD.

[18] National Oceanic and Atmospheric Administration (2013) The National Coastal Population Report: Population Trends from 1970 to 2020. Charleston, SC.

[19] American Society of Civil Engineers (2017) 2017 Infrastructure Report Card. Available at http://www.infrastructurereportcard.org/. Accessed February, 2018.

[20] The White House Office of the Press Secretary (2013) Presidential Policy Directive 21: Critical Infrastructure Security and Resilience. Available at 
http://obamawhitehouse.archives.gov/the-press-office/2013/02/12/presidential-policydirective-critical-infrastructure-security-and-resil Accessed February, 2018.

[21] National Institute of Standards and Technology (2018) Community Resilience Program. Available at http://www.nist.gov/programs-projects/community-resilienceprogram. Accessed Feburary, 2018.

[22] Colorado State University (2018) Center for Risk-Based Community Resilience Planning. Available at http://resilience.colostate.edu/. Accessed February, 2018.

[23] Department of Homeland Security (2018) DHS Science and Technology Centers of Excellence. Available at http://www.dhs.gov/science-and-technology/centersexcellence. Accessed February, 2018.

[24] National Institute of Standards and Technology (2014) Technical Investigation of the May 22, 2011, Tornado in Joplin, Missouri. NIST NCSTAR 3. http://dx.doi.org/10.6028/NIST.NCSTAR.3.

[25] General Services Administration (2017) Smart Buildings. Available at http://www.gsa.gov/real-estate/workplace-innovation/applied-research/highperformance-buildings/operations-and-facilities-management/smart-buildings. Accessed February, 2018.

[26] General Services Administration (2018) Life Cycle Costing. Available at http://www.gsa.gov/node/81412. Accessed February, 2018.

[27] National Institute of Standards and Technology (2018) New NIST "EDGe\$” Tool Can Help Communities Select Cost-Effective Resilience Projects. Available at http://www.nist.gov/news-events/news/2018/01/new-nist-edge-tool-can-helpcommunities-select-cost-effective-resilience. Accessed Februrary, 2018.

[28] NEHRP Consultants Joint Venture (2014) Recommendations for Seismic Design of Reinforced Concrete Wall Buildings Based on Studies of the 2010 Maule, Chile Earthquake. NIST GCR 14-917-25. Gaithersburg, MD.

[29] Ertl M (2016) Christchurch earthquake: The battle to rebuild, five years on. Available at http://www.bbc.com/news/world-asia-35612298. Accessed February, 2018.

[30] San Francisco Bay Area Planning and Urban Research Association (2018) The Resilient City: Creating a new framework for disaster planning. Available at http://www.spur.org/featured-project/resilient-city. Accessed February, 2018.

[31] Allen G (2017) After Deaths During Hurricane Irma, Florida Requiring Changes For Nursing Homes. Available at http://www.npr.org/2017/12/24/573275516/after-deathsduring-hurricane-irma-florida-requiring-changes-for-nursing-homes. Accessed February, 2018.

[32] International Code Council, National Institute of Building Sciences (2014) The Future of Code Officials: Results and Recommendations from a Demographic Survey. Washington, D.C.

[33] California Office of Statewide Health Planning and Development (2013) Guide for Working on Projects Under OSHPD Jurisdiction - Tips from the Experts. Sacramento, CA. 


\title{
Appendix A: Building Design Considerations
}

In Chapter 3, general challenges and research needs associated with designing a building for IO performance objectives were presented. This section provides a more detailed discussion of the challenges related to each of the subtopics introduced in Chapter 3, as well as specific research needs and implementation activities to address these challenges.

\begin{abstract}
A.1. Functionality
Research within this subtopic focuses on developing resources to design a building to meet the functionality desires of building stakeholders. Because the post-hazard functionality of a building is typically not considered in the design process, building designers currently lack the tools and expertise necessary to assess a building's potential functionality for different loading scenarios, as well as the tools needed to determine the timeframe required for a building to return to its pre-hazard functionality level following a hazard event. Developing the tools to do so is challenging because the factors that influence functionality are not well understood, and because adequate data to relate functionality and recovery time to building damage, material degradation, and maintenance and repair is not currently available.
\end{abstract}

Research to address challenges in designing a building to meet functionality desires consists of identifying appropriate functionality levels to target for immediate occupancy and developing new analytical tools for building designers to evaluate building functionality and recovery for a variety of hazard scenarios. Recommended research and implementation activities to achieve these goals are summarized in the following section.

\section{A.1.1. Basic and applied research activities \\ A.1.1.1. Functionality classification:}

Research is needed to identify acceptable functionality levels to be considered for immediate occupancy. These functionality levels express the technical design criteria used by building designers to evaluate the performance of a building designed for immediate occupancy performance objectives. Functionality levels reflect the performance desires of building stakeholders, which may vary depending on the building's role in a community, the individual preferences of building owners and occupants, and other factors. The following topics should be considered in defining each of the functionality levels:

- The type and severity of hazards that pose risks to the building

- The maximum allowable recovery timeframe

- The acceptable level of functionality for essential and non-essential building functions

- The acceptable level of occupancy during recovery - that is, whether the number of building occupants should be smaller than allowed during normal circumstances

- The type and quantity of backup utility services (e.g., water, generator) provided

- Potential benefits of allowing reduced functionality for non-essential functions of the building.

- In defining functionality levels, the social and economic benefits and tradeoffs for individual building stakeholders and communities, which are discussed in Chapters 4 and 5 , should also be considered. 


\section{A.1.1.2. Recovery data:}

Detailed field reconnaissance data are needed to study the recovery process for buildings following hazard events. Recovery data needs to be collected over time to document the stages of recovery for individual buildings and at the community level. The data can be used to inform the development of functionality levels and to develop and validate numerical models for predicting building functionality level. In order to develop a comprehensive understanding of the hazard recovery process, data are needed for a large number of buildings impacted by hazards, as well as the supporting infrastructure and social and economic impacts. Data should be collected at two levels: at the building level for different building types, of various ages and various geometries, and constructed with different building materials and at the community level for building clusters. When possible, the building code under which buildings were designed should be identified. It is important that data be collected for buildings with various levels of observed damage, including buildings that appear to have outperformed others. Furthermore, data are needed for retrofitted buildings and buildings that were repaired following previous hazards.

A review of reconnaissance data from previous field studies should be conducted to determine the scope of previous studies (building, infrastructure support, economic and social impacts, etc.) and the type and extent of available information, to identify data collection needs for future reconnaissance efforts, and to evaluate the effectiveness of different design standards in achieving IO performance objectives. Based on the findings of the review, a standardized recovery data collection process should be developed to benefit ongoing efforts to develop and improve immediate occupancy performance objectives for new and existing buildings. Research will be needed to develop sound sampling protocols that will ensure that the resulting data supports the research needs and is carried out in a cost-effective manner.

\section{A.1.1.3. Factors that influence functionality and recovery time:}

The factors that contribute most to reductions in the functionality of a building and the timeframe to repair a building to pre-hazard functionality are not well understood. Research is needed to characterize the building systems that most influence functionality, to understand the influence of maintenance and repair, and to identify issues that may affect functionality but are not commonly considered when planning and designing a building. Impacts on functionality due to damaged connections to utilities (e.g., water and electricity) should be considered, and the influence of providing different levels of backup utilities should be investigated.

\section{A.1.2. Implementation activities}

\section{A.1.2.1. Analytical tools to predict building functionality:}

To enable the adoption of a new immediate occupancy performance objective that directly considers post-hazard functionality, building designers would need to be equipped with analytical tools to assess functionality for a variety of hazard scenarios. Building upon findings of the basic and applied research recommended within the Functionality Levels subtopic, analytical tools should be developed to quantify the functionality of a building over time, considering the impacts of hazard damage, degradation of building components, and maintenance, repair, and retrofit. The analytical tools should be developed in a reliability-based format using quantifiable data, from which a level of uncertainty can be expressed for achieving desired functionality levels. 


\section{A.2. Damage Levels}

Damage level is a physically meaningful engineering parameter that identifies the reduction in the capacity of the building to serve its intended function at each point in time. Damage to a building can be quantified and used to assess immediate occupancy damage limits and functionality requirements, and to inform the repair actions needed to return the building to its pre-hazard functionality level within an acceptable timeframe.

One of the key challenges in the damage quantification is improving the understanding of the structural response under different hazard types. Research has been conducted in the past few decades to understand the response of building components and systems under different hazards. However, more experimental and field data are needed, particularly related to the nonstructural components of a building. In addition, some natural hazards may cause secondary sources of damages to the building for which no established damage measurement and prediction method is currently available. On the other hand, certain damage is hard to identify and measure, for example, cracks in welds of steel structures.

Simulating and predicting damage remains a key challenge in the response prediction of buildings. More accurate and simple modeling techniques are needed to simulate the damage response of structural and nonstructural components within the building, including building contents, as well as their interaction. Another challenge related to damage quantification is identification of acceptable level of damage and linking it to the desired functionality level of the building. The acceptable level of damage varies depending on the building types, hazard type, and hazard intensity. The following categories summarize the research needs and implementation activities identified concerning damage.

\section{A.2.1. Basic and applied research activities}

\section{A.2.1.1. Acceptable damage levels:}

Research is needed to quantify the acceptable levels of damage for each of the immediate occupancy functionality levels. The acceptable level of damage associated with a particular functionality level should be quantified at the component level as well as at the system level, considering the extent and expected timeframe of repair needs to address the damage.

\section{A.2.1.2. Field reconnaissance and laboratory data:}

Detailed field reconnaissance and laboratory data are needed to characterize the damage types and quantify damage levels for individual components of a building. This data should also include the global response of the buildings after a hazard. The data can be used to support the development of appropriate functionality levels for immediate occupancy and to develop and validate damage prediction tools. Reconnaissance data should reflect the performance of a large number of buildings of various age and construction type, with various levels of damage, including buildings that sustained little or no damage. As part of this work, reconnaissance teams should evaluate the effectiveness of the different standards used to design individual buildings in achieving the intended performance objectives as well as IO performance objectives.

\section{A.2.1.3. Understanding damage levels for different hazards:}

Understanding the response of the building is the first step toward developing a framework for targeting a specific performance level. Research is needed to improve the understanding of the building response both at the component and systems levels. This effort includes field or 
experimental studies on the performance of various building components under different hazard types and levels. In addition to studying individual building components, the interactions among and between structural and nonstructural components need to be studied to identify how the response of one can affect the performance of another one.

\section{A.2.1.4. Understanding degradation due to aging and environmental effects:}

There is a substantial need to understand how buildings and their structural and non-structural components age and respond to their environment. Environmental factors, such as exposure to ultraviolet radiation, humidity, and temperature, impact the degradation of building components. This effort includes experimental as well as field studies to characterize the aging and environmental effects for existing and new materials used in new and existing buildings. Research is needed to develop numerical models capable of simulating the impacts of environmental factors on the response and functionality of a building.

\section{A.2.1.5. Damage prediction models:}

A key step toward designing a new building or evaluating an existing building is developing a model that can capture the key characteristics of the building such as residual capacity of the building after a natural hazard. Research is needed to improve the accuracy of damage prediction models, and to develop numerical models for different materials and components that accurately simulate damage formation and propagation. This effort includes developing physics-based models as well as simplified models that can predict the damage response under different hazard types. The impact of cumulative damage due to the impact of multiple hazard events, from the same or different hazard types, needs to be investigated. The damage prediction models include evaluating the impact of secondary sources of damage. Improved damage prediction models will inform the repair and retrofit process as well as the functionality level and recovery time.

\section{A.2.2 Implementation activities}

\section{A.2.2.1. Standardize data collection:}

One of the challenges in analyzing data from different reconnaissance studies is the lack of standardization and interoperability among the datasets. Different teams may collect different types of data and use different collection protocols. Research is needed to identify the crucial data that need to be collected in reconnaissance studies. Research is also needed to minimize the human bias in the collected data from field studies. Protocols and guidelines on sampling and data collection in reconnaissance studies need to be developed to improve the consistency in the data collected by different teams and ensure that data are recorded in a consistent and interoperable manner.

\section{A.3. Design Practice}

Research within this subtopic focuses on developing the technical design criteria used by building developers, architects, and engineers to design and evaluate buildings and their systems for immediate occupancy. In comparison to current prescriptive code criteria, immediate occupancy requires satisfaction of enhanced performance objectives that limit damage and enable post-hazard functionality. Developing the technical criteria to address these enhanced performance objectives is challenging because, as discussed in the Functionality Levels and Damage Levels subtopics, fundamental research is needed to identify the acceptable levels of damage and building functionality that should be considered for immediate occupancy. In addition, the impact of some of the hazards that may affect a building are not 
yet well understood. Current prescriptive code criteria require higher design loads for high occupancy and essential buildings (Risk Category III and IV buildings, respectively), as compared to typical (Risk Category II) building. Some of the design criteria for these buildings may be suitable for new immediate occupancy performance objectives. However, because the hazard levels typically used for design rarely occur, limited data are available to assess the reliability of prescriptive requirements in meeting immediate occupancy performance objectives.

To address these challenges, research is needed to better characterize the hazards to be considered for design, to develop new analytical tools to predict the building performance, and to evaluate the performance of buildings designed according to current prescriptive and performance-based design codes and standards. Informed by the findings of this research, recommended implementation activities include the development of hazard-specific design requirements by which building performance predictions are evaluated.

\section{A.3.1. Basic and applied research activities \\ A.3.1.1 Hazard levels and considering multiple hazards in design:}

In order to develop immediate occupancy performance objectives, the hazard types and distinct hazard levels considered in the design process would need to be clearly articulated in the design criteria used by building designers. Inadequate information is currently available to reliably predict the hazard risks for a particular building; thus, research to better characterize these hazards is needed. Important outcomes of the research should include improved hazard models, for all of the natural hazards to be considered for immediate occupancy, and the development of hazard risk maps to be included in technical design criteria. For example, the development of improved flood maps and wind-driven rain maps have been identified as priorities within the engineering community. As hazard risk resources are developed, research should be conducted to express the appropriate hazard levels to evaluate the performance of buildings designed for immediate occupancy performance objectives. Research on approaches that allow comparison across hazard types (e.g., risk-consistent approaches) is needed. The hazard levels should consider the social and economic benefits and tradeoffs for individual building stakeholders and communities, which are discussed in Chapters 4 and 5.

Individual buildings are often vulnerable to different hazard types and multiple occurrences of certain hazards over the building's lifecycle. Considering multiple hazards in the design process is challenging for several reasons. For one, the various loading scenarios that should be considered for design need to be determined. For example, it may be overly conservative to design simultaneously for design level or extreme level effects of two separate hazard types (e.g., design wind event and design flood event), while considering the two hazards separately may not be conservative. Additionally, typical building performance assessments are conducted on models representing undamaged buildings, although certain hazard scenarios may necessitate modeling cumulative building damage over time. As discussed under the Damage Levels, research is needed to develop the numerical models to predict damage levels over time. Research, therefore, is necessary to determine the loading scenarios that are appropriate for buildings with multiple hazard risks, with consideration of their joint probability of occurrence, and to develop analytical tools and design guidelines for assessing the performance of damaged buildings. 


\section{A.3.1.2. New design philosophies for immediate occupancy:}

Implementing immediate occupancy performance objectives will require fundamental changes in the approaches used to design a building due to the enhanced safety standards and functionality requirements. A major challenge associated with immediate occupancy is the need to minimize building damage and the impacts of that damage. Research is needed to study the potential performance benefits of implementing new and existing low damage and rapidly reparable alternatives to common building designs. For this research, numerical and experimental simulations should compare the reparability, functionality, and recovery timeframe for traditional building designs to those of low damage alternative for various hazard scenarios. It is important that researchers consider alternatives to damageable systems within a building and alternatives to damageable building envelopes. It is just as important to consider alternative land use options and alternative designs for potentially damaging items surrounding a building (e.g., vegetation). The selection of low damage and reparable building systems should be informed by the technologies developed and discussed under the Building Materials and Technologies subtopic. It is recommended that detailed guidelines communicating the process of evaluating damage-minimizing design alternatives be published to provide building designers key resources to expedite uptake of this potential new design philosophy.

For certain hazard events and certain buildings, damage may be unavoidable. Research is needed to identify methods to streamline the repair and recovery processes for buildings damaged in hazard events. Research investigating the ways in which repair and recovery strategies can be incorporated into the building design process is necessary. For this study, simulations should be conducted to characterize building damage levels for various scenarios that pose risks to a building, and to plan the repair and retrofit activities to return the building to its desired (pre-hazard) safety and functionality in an acceptable timeframe. This research should investigate ways to optimize recovery by minimizing the quantity of damaged building components and designing rapid repair methods to be implemented if damage occurs. As an outcome to this research, it is recommended that detailed guidelines be published to educate building designers on this potential new design philosophy.

\section{A.3.1.3. Benchmarking the performance of code-compliant buildings:}

Building codes and standards are developed to ensure life safety of the occupants and to provide some degree of property protection, but measuring the reliability of those codes and standards to meet certain performance objectives is difficult. Some of the challenges include: limited field data is available for code-compliant buildings impacted by design level or extreme level hazards; very few research laboratories have the capacity and resources to conduct tests on large-scale building models; and relatively large uncertainty measurements have been reported for performance predictions made using analytical simulation tools. Nonetheless, understanding the performance of code-compliant buildings is an important research topic for developing immediate occupancy performance objectives because some Risk Category III \& IV buildings may be capable of meeting IO objectives. Research is needed to benchmark the performance of code-compliant buildings. It is recommended that the benchmarking efforts be conducted using newly developed analytical simulation capabilities, new laboratory test data on large-scale building models, and applicable reconnaissance field data.

The investigation should explore the expected damage, repair activities, and recovery timeframe for code-compliant buildings designed according to typical construction practices and subjected to various hazard scenarios. As a component of the research, the level of 
uncertainty related to important performance metrics should be quantified to communicate the reliability of the numerical research. For the laboratory testing component of the research, large-scale tests should be conducted on building models with functioning mechanical systems and enclosed by a building envelope. The model should be subjected to appropriate hazard scenarios, some with hazard demands consistent with design level and extreme level hazard events.

\section{A.3.1.4. Data on the performance of existing buildings:}

Hazard response data from sensors in buildings and similar data from laboratory tests is needed to develop, calibrate, and validate numerical models that assess building performance. In addition to collecting hazard response data, detailed information should be collected for each of the buildings and lab specimens for which response data is available. As much as possible, building information should summarize building component design parameters (e.g., geometry, materials) such that the hazard resistance of each component can be predicted using newly developed damage prediction and functionality prediction models.

\section{A.3.1.5. Analytical models to conduct building performance evaluations:}

Research is needed to incorporate newly developed damage predictions models and functionality prediction models into analytical simulation tools to be used to evaluate the performance of buildings designed for immediate occupancy. The newly developed tools should be capable of capturing the cumulative impacts of damage and aging on all structural and nonstructural building components, making it possible to evaluate the hazard performance and functionality of a building over its lifecycle. The research should prioritize developing tools that enable integrated modeling of all of a building's systems, such that the interdependencies between systems can be studied. The newly developed analytical tools should be calibrated and validated by conducting numerical simulations for buildings from which hazard response data has been collected.

\section{A.3.2. Implementation activities \\ A.3.2.1. Design requirements and performance evaluation criteria for immediate occupancy:}

Building upon the findings of the recommended basic and applied research activities, immediate occupancy design guidelines and standards should be developed for all hazard types that are appropriate for designing a building to meet immediate occupancy performance objectives. The guidelines should include hazard-specific performance criteria by which new and existing buildings are evaluated for their effectiveness in meeting immediate occupancy safety and functionality requirements.

The performance evaluation criteria should communicate specific damage levels that are acceptable for certain functionality levels that apply to immediate occupancy, and which are discussed within the Functionality Levels subtopic. These criteria should be informed by laboratory data, field data, and numerical studies, considering the appropriate level of risk that should be assumed for different damage levels, hazard types, and hazard levels. Because mechanical systems and envelope of a building play a crucial role in the ability of the building to conduct its intended functions, guidelines and standards for nonstructural building systems should be developed in a manner that is consistent with those developed for the structural system. 


\section{A.4. Building Materials and Technologies}

New building materials and technologies, as well as new adaptive uses for existing materials and technologies, are crucial to improve the capabilities of residential and commercial buildings to meet immediate occupancy performance objectives. Currently, the quality of structures' materials is one of the factors that limits building performance and strength following a hazard event. Lower quality or poorly suited materials increase the likelihood of long-term damage to the structure, often including latent issues that appear after the event and render the building not occupiable.

One challenge is a lack of knowledge about how materials themselves perform and how new materials improve building performance during a hazard event. A related challenge is the lack of damage measurement technologies and data collection tools. For the building community to improve their understanding of materials and system-level impacts, new data technologies should be developed and implemented that can track and evaluate performance of materials both in the laboratory and in-situ, both longitudinally and post-disaster in a timely manner. These new technologies and sensors could be integrated into "smart buildings," which are able to monitor both material- and system-level performance, indicate repair needs, and even selfheal. Developing new materials that can be used for construction of new buildings and for retrofit of existing buildings is a research need.

Another challenge is that many commercial and residential buildings rely on custom parts, are site-built and are not designed in a modular fashion. Replacement parts may be custom made and would have to be ordered months in advance. This long lead time is further extended following a hazard event when there is a high order volume and potential disruptions to the supply chain. Due to the non-modular design, engineers may have to often disrupt functional parts of the building in order to access and repair the damaged parts of the structure. Advances in materials and technologies would encourage the integration of mitigation and recovery techniques into the design process and minimize potential adverse outcomes in the building use phase. Specifically, new plug-and-play materials should be developed and implemented to facilitate easier, faster, and cheaper repairs after a disaster.

Research into low-damage building materials and technologies should also include investigations to mitigate potential sources of damage that occur to the building during a hazard event. Research needs include damage-resistant materials (e.g., mold-resistant), hazardresilient building components (e.g., building envelopes) and low-damage structural systems (e.g., floating structures for flood-prone regions).

While some materials and technologies that support Immediate Occupancy are currently available, and research is keeping up with the market, a key challenge is integration of these innovative materials into building design practice. Research is needed to improve and adapt existing materials and technologies, as well as to develop any new technologies to increase the economic feasibility of building materials meeting immediate occupancy performance objectives and other applications where building owner or community desires may warrant the use of advanced technology or materials to increase building performance. Builders, developers, manufacturers and other building professionals may be reluctant to assume the higher costs of these materials without consistent requirements standardizing practice across the industry. To further encourage acceptance of existing hazard-resilient and damage-resistant materials, continued efforts are needed to lower their costs and make them competitive with 
materials currently in use. Furthermore, engineers are slow to adopt new technologies into their design processes due to a lack of design guides and standards for the new technologies.

Advances in building materials and technologies have the potential to address the challenges outlined previously, and to provide architects and design engineers increasing capabilities to meet building owner and community needs for higher performance objectives.

\section{A.4.1. Basic and applied research activities}

\section{A.4.1.1. Lower-cost materials:}

High costs of extant hazard-resilient and damage-resistant materials and technologies are a barrier to their adoption by the engineering and building communities. This calls for the development of lower cost materials, both for constructing new buildings and for retrofitting existing buildings. Research should also investigate integrating the economics of building materials into design practice through lifecycle analysis.

\section{A.4.1.2. Performance of new materials:}

While many new materials have been developed in recent years, additional research is needed to evaluate the performance of these new materials and how they improve building performance. This research will likely require new damage measurement technologies to evaluate performance and involve collecting data characterizing the performance of new materials.

\section{A.4.1.3. Materials for modular, standardized construction and repair:}

Currently, many commercial and residential buildings rely on custom parts, are site-built and are not designed in a modular fashion. Replacement parts may be custom made and ordered months in advance. Research is needed to develop new plug-and-play, easier-to-repair materials and modular building design techniques, particularly for non-structural systems, to facilitate rapid repairs and replacements. Both laboratory and in-situ testing of these new materials and structures should be conducted.

\section{A.4.1.4. Smart buildings:}

Material- and system-level research is needed to develop smart buildings that "integrate major building systems onto a common network and share information and functionality between systems in order to improve building operations" [25]. Smart buildings would assist with decisions for evacuation and reoccupation, and expedite the post-hazard repair process. Research on new smart materials should include: expiration indicators (e.g., glass that changes color when it should be replaced), communicating damages and repair needs, self-repair or self-healing, adaptive materials (e.g., better impact-resistant glazing to resist hurricane or tornado debris, but which firefighters could break in case of fire). Systems-level research should include developing new sensors and technical systems that can determine building function and identify which systems are hindering safety and functionality.

A.4.1.5. Damage-tolerant, rapidly-repairable building systems:

Developing low-damage structural systems that experience reduced amounts of damage with no permanent system-level damage, such as permanent drift, after a hazard as well as buildings that are designed to experience damage in non-key components of the building such that the rest of the building is left with no damage (i.e., damage-tolerant buildings), need to be studied further for designing immediately occupiable buildings. One of the key challenges in designing 
damage-tolerant buildings is expediting the repair process such that the building is back to its intended function in a minimum amount of time.

Research across materials, components, and systems is needed to design and build more damage-tolerant buildings, such that these structures experience less significant damage levels following a hazard event. Materials research should both develop new damage-resistant materials (e.g., mold-resistant materials) and increase accessibility-by lowering costs - to existing hazard- and environment-appropriate building materials, (e.g., masonry rather than drywall for flood-prone areas). Component level research needs include designing damageresistant building envelopes, for example, improved impact resistant glazing for hurricane- and tornado-prone regions. System-level research needs include developing new low-damage and damage-tolerant structural systems, such as floating or amphibious homes to rise with water in flood-prone regions, and isolated floor slips for multi-hazard seismic and wind events. Moreover, system-level study should focus on developing phases that are easy to replace after a hazard with minimum downtime.

\section{A.4.2. Implementation activities}

\section{A.4.2.1. Adoption of new materials and technologies:}

Engineers, architects, and building owners have been slow to accept and adopt new materials and technologies. This hesitation stems from cost factors, liability issues, and patent restrictions. Furthermore, design codes and standards are generally slow to address these new technologies, and sometimes prevent their use. Research is needed to better understand how the building industry responds to advances in materials and technologies and what steps are needed to encourage their adoption. Design guidelines and standards should be adapted to providence guidance on new materials and technologies. Additionally, the U.S. should study international communities that have successfully adopted these new methods, such as Japan, which encouraged the use of new materials using visual, interactive examples of the performance of different building designs under various earthquake strengths.

\section{A.5. Maintenance, Repair, and Retrofit Methods}

Buildings require regular maintenance to minimize major damage and to ensure that the building continues to function as intended. If damage occurs, due to either a hazard event or building aging, repairs may be necessary to return the building to its intended functionality. In the context of developing an immediate occupancy performance objective, maintenance and repair are crucial to ensure that a building designed for immediate occupancy continues to meet the intended performance objectives throughout its lifecycle. For existing buildings, retrofit may be necessary to upgrade a building to meet immediate occupancy performance objectives, or even to meet current building code requirements. For existing buildings, reaching IO performance levels may be cost ineffective or not feasible for other reasons. However, rather than focusing on interim levels of performance based on current limitations, research should focus on the steps needed to achieve the vision for IO buildings.

One of the key challenges that limits the ability to provide informed guidelines and protocols for how a building should be maintained is a lack of data about how structural and nonstructural components age. This information would be useful to identify what building components should be replaced or retrofitted and at what times. This sort of data would also be useful to inform where repairs might be most necessary within a structure following a hazard event. 
An additional challenge is that, even if it is known which parts need to be maintained, repaired, or retrofitted, the costs to do so may be prohibitively high, reducing the likelihood that building owners undertake these activities. Part of the cost is from the fact that many buildings require custom components. Research and development is needed to reduce the costs of building components as well as the labor necessary to repair and replace these components. In the case of post-hazard recovery, repairs may be delayed due to lack of availability of resources, including both supplies and labor. Additionally, custom components may require a long lead time to produce, increasing the amount of time that building occupants are displaced posthazard. Stockpiling parts may also not be feasible, depending on whether the components degrade over time. Research efforts are also needed to explore strategies to ensure that a community and its building owners have the resources they need to repair their buildings as quickly as possible after a hazard event.

Another issue for both post-hazard repairs and retrofits is the lack of data about building stock (e.g., architectural drawings, information about non-structural components in a building). This data is needed to identify where damage may have occurred and where repairs and retrofits may be most impactful.

\section{A.5.1. Basic and applied research activities}

\section{A.5.1.1. Inventory of existing building stock:}

Data collection efforts are needed to inform a number of different studies. First, information is needed about the building stock in a community, including architectural drawings, land use, and information about maintenance, repairs, retrofits, and other modifications that have occurred. This information is needed in order to prioritize buildings that might require retrofits or repairs prior and after a hazard event. Currently, this information is lacking in many communities. In addition, there is the need to collect data about the costs (both in dollars and in time) and methods used for repairs and retrofits so that communities and building-owners can make informed decisions about undertaking these efforts.

\section{A.5.1.2 Decreasing cost and improving methods to repair and retrofit buildings:}

Following a hazard event, individual components of a building may need to be repaired or replaced. Decreasing the cost to replace or repair these components may come from less expensive materials, as well as from parts that are easier to repair or replace. Making damaged components easier to access could help decrease the cost for repairs and replacements. In addition, increasing the modularity and standardization of building components would reduce the amount of custom repair work needed. Research is therefore needed to explore different options to decrease the cost of repairs and replacements, including developing low-cost materials, modular buildings and standardized building components, and strategies that reduce the amount of labor and time needed for the retrofits or repairs. In addition, smart materials that communicate repair needs or are able to self-repair could aid maintenance and repair processes.

Retrofitting buildings to mitigate against future damage can be expensive, and these costs should be weighed alongside other considerations, such as the desire to preserve a historic site. Developing less expensive retrofitting materials and methods may help influence a building owner to improve the hazard resilience of their residence or business. 


\section{A.5.1.3. Behavioral research:}

Behavioral research is needed to understand current decision-making processes concerning how building owners choose to invest in maintenance and repair. This research should include understanding when a building owner chooses to upgrade a building, and for what purposes. In addition, research is needed to understand whether building owners view retrofits and repairs to improve hazard resilience as valuable.

\section{A.5.1.4. Understanding and enhancing repair effectiveness:}

Research is needed to assess and enhance repair methods. In particular, research is needed to understand how to repair or retrofit a building envelope and the nonstructural systems of a building. In addition, methods that restore the strength and stiffness of buildings are needed. Moreover, research needs to be done on the potential impact of retrofitting existing historic buildings to meet IO performance objective.

\section{A.5.1.5. Understanding resources needed for repairs and retrofits:}

Analytical studies are needed to investigate the amount of time and money required to repair damage for a variety of building types following a variety of different hazards types and levels, as well as the costs associated with retrofitting to mitigate against future hazards. Integrative models that can predict the extent of damage and associated repair resources, or alternatively the resources required for retrofits, could help inform decisions about building design, repairs, and retrofits.

\section{A.5.2. Implementation activities}

A.5.2.1. Improving availability of tools, parts, and labor:

After a hazard event that causes wide spread damage, there is often a high demand for repairs, which requires skilled labors, specialty tools, and often custom parts. This demand is often unable to be met immediately following a hazard event, leading to long repair times. Understanding and improving the availability of tools, parts, and skilled labor for recovery could help reduce the amount of time required for building repairs, decreasing the disruption on the community, building owners, and occupants.

\section{A.5.2.2. Methods to strategically implement retrofits:}

Because of the high costs associated with building repairs and retrofits, it is likely that a prioritization scheme will have to be implemented to determine which buildings should be retrofitted first, and how those retrofits should take place to minimize the interruption on building owners and occupants. Taking advantage of existing maintenance schedules for retrofits can reduce the amount of inconvenience retrofits cause to building owners and tenants. Building rating systems should be explored to determine if any existing or new systems could be implemented to prioritize which buildings should be repaired and retrofitted.

\section{A.5.2.3. Developing periodic inspection protocols:}

Buildings designed to immediate occupancy performance objectives should be maintained and inspected periodically to ensure that the buildings continue to meet the IO standard. This is not part of current practice, and therefore would likely require research to determine cost-effective techniques for implementation.

\section{A.6. Monitoring and Assessment}

Monitoring of the building's health after construction is critical to ensure the building meets its intended safety objective and immediate occupancy functionality level. The monitoring 
information can be used to inform the building owner if the building does not satisfy the immediate occupancy requirements at any point during its lifetime due to the environmental degradation effects or minor hazards. Assessing the cumulative impact of hazards on a building over time is a challenge to ensure that building continues to meet the immediate occupancy objective. Moreover, assessing the performance of the building after a natural hazard is essential to determine whether functionality is preserved. Following a natural hazard, expedited assessment of buildings is necessary to determine whether any restrictions are placed on the building re-occupancy. The current method of post-hazard assessment may not be ideal for accomplishing the immediate occupancy goal, as building to an immediate occupancy performance objective when the building cannot be evaluated for several days to weeks following an event would be ineffective. The inspection protocols need to be modified to require rapid assessments to support the immediate occupancy performance objective.

Challenges to the monitoring and assessments include developing cost-efficient remote monitoring techniques for post-hazard surveys. The extent to which data is currently recorded through sensors is limited, and a broader set of data that captures the response parameters of structural and nonstructural components, the connection between the structural and nonstructural systems, as well as the information about the utility services are needed. The broader data will lead to a more accurate decision-making process for maintenance, repair, and retrofit of buildings. The monitoring and assessment requirements for different building types are different and warrant further research.

Another challenge is to identify the extent to which we are willing to rely on the data collected from remote sensing assessment. The assessment data can potentially be used to identify the occupancy (level of safety) of the building or alternatively to inform decision-making on where the first responders should be sent. Relying on the collected data to make decisions on whether the building is occupiable may be a desirable method to expedite the recovery process, however, it brings a liability concern to the decision-making process and involves uncertainty. Further research is needed to address these concerns. The post event evaluations will be necessary in future after development of immediate occupancy performance objective to gather data on the efficiency of the proposed immediate occupancy performance objective, its implementation methods, and the adoption by communities.

\section{A.6.1. Basic and applied research activities}

\section{A.6.1.1. Technology and sensors to assess building performance:}

Research is needed on technologies and methods required for conducting a rapid assessment on buildings. This effort includes developing cost-effective sensors and built-in monitoring systems for collecting data as well as developing performance assessment procedures to analyze the collected data and identify the observed damage. One of the main needs in improving the data collection technologies is developing instrumentation to monitor the response of nonstructural systems. In this process, knowledge and lessons learned from other industries related to rapid inspection and use of sensor data need to be synthesized. Research is also needed to develop sensors that can monitor the degradation of material properties due to environmental impacts. 


\section{A.6.1.2. New data collection methods:}

Research is needed to investigate the use of new data collection methods, such as crowdsourcing, social media, and use of drones for collecting information for monitoring and assessment of buildings after natural hazards.

\section{A.6.1.3. Linking damage measurement to the performance assessment:}

Data collected from sensors or similar technologies need to be processed either by an engineer or through an automated process to quantify the damage in the building after a natural hazard. Research is needed to relate recorded data to observed building damage and post-hazard functionality, and recovery time. This research effort includes benchmarking/validating the linkage between the collected data and observed damage using the available data from instrumented buddings. This research is an important step toward developing a remote assessment system for buildings, where collected data is automatically sent to, and analyzed by, an assessment tool to identify the extent of the observed damage. Moreover, research is needed on developing methods to use recorded data to assist with the decision-making process after a hazard.

\section{A.6.2. Implementation activities \\ A.6.2.1 Improving inspection techniques:}

Currently, post-event evaluation of a building is primarily conducted through visual inspection, which may be adequate to assess collapse likelihood in a general sense but may not be sufficient to identify the safety and functionality of the building. Research is needed to develop new post-hazard evaluation criteria, specifically for immediate occupancy buildings, and to develop an immediate occupancy building tagging process. One of the key issues is to identify who is responsible for tagging of the immediate occupancy buildings and what improvements need to be made to the current tagging process to shorten the inspection period.

\section{A.6.2.2. Developing guidelines/protocols for inspection of the buildings for immediate occupancy:}

Guidelines and protocols on implementation of inspection requirements and methods need to be developed to quantify the preserved level of occupancy and functionality of a building throughout its lifecycle. 


\section{Appendix B: Community Considerations for IO Buildings}

Chapter 4 presented general challenges and research needs, from a community perspective, to achieve IO performance and improve a community's resilience to natural hazards. This section provides a more thorough discussion of community level challenges associated with IO and specific research needs and implementation activities to address these challenges.

\section{B.1. Infrastructure and Building Cluster Interactions}

Buildings do not operate independently from infrastructure in a community. Performance objectives for IO buildings should address the performance of the structural system, building envelope, and interior systems. (Interior systems for distribution of power, water, wastewater, communications, and fuel inside the building are addressed in Chapter 3 on Building Design.)

Buildings require infrastructure services to meet their functions. The minimum level of service from external infrastructure (e.g., electric power, water, wastewater, communications, transportation, and fuels) that is required to maintain the desired IO functionality after a hazard event needs to be determined. The appropriate temporary measures will depend on the IO building's role in the building cluster and community, the desired performance for the building, and the anticipated duration of infrastructure service disruption. This information informs IO building design about the external infrastructure services required for normal operations, as well as supplemental or temporary measures (e.g., service redundancy or backup systems) to sustain the desired functionality after a hazard event for a specified recovery time.

While determining performance goals for external infrastructure systems and services is outside the scope of this report, it is recognized as an important area of research for IO buildings, as well as addressing the cascading consequences that lead to disruption of community social and economic function.

Building clusters support community social and economic functions, such as healthcare, education, business, or governance. A group of buildings that supports a function, also referred to as a building cluster, may be collocated or geospatially distributed across the community. An IO building within a building cluster can have a substantial role in ensuring the continuity or rapid recovery of social and economic functions supported by the building cluster. The role and contributions of IO buildings within a building cluster needs to be characterized, including dependencies and redundancies, both prior to and following a hazard event. Additionally, guidance is needed to help communities identify and prioritize the use of IO buildings for a range of community conditions, preferences, and resilience goals and plans.

\section{B.1.1. Basic and applied research activities \\ B.1.1.1. Characterize dependencies and redundancies for IO buildings, building clusters, and infrastructure:}

To better understand how building clusters and infrastructure systems affect IO building performance and functionality, both prior to and following a hazard event, dependencies and redundancies (geospatial, temporal, physical, and functional) within and between IO buildings, building clusters, and infrastructure systems need to be identified and quantitatively characterized. For example, a geospatial dependency occurs when a building's function has geographic requirements, such as being located next to a body of water or a major transportation route. Dependencies that are temporal change over time, such as when demands for infrastructure services increase or decrease. Physical dependencies are the reliance on other 
physical systems or buildings, and functional dependencies are the reliance on other social or economic systems for a building to serve its intended functions.

\section{B.1.1.2. Characterize the recovery process for buildings and infrastructure:}

The question of "how long can an IO building lose function without adversely affecting the community?" is central to determining the level of services a building will need to achieve IO performance. Given that most buildings and infrastructure systems in a community were designed and built to different codes and standards, a range of performance during and after a hazard event is expected. The performance of the existing built environment depends not only on its original design and construction, but also its current condition. The anticipated damage, loss of functionality, and recovery process of buildings and infrastructure systems after a hazard event need to be characterized to determine available services for IO buildings. This type of information helps determine minimum functional levels that can be achieved by IO buildings relative to their desired performance.

\section{B.1.1.3. Identify temporary solutions for providing infrastructure services to support IO buildings:}

Methods to improve building and community recovery processes need to be identified, such as temporary services (e.g., generators), alternative systems (e.g., microgrids) or redundant services (e.g., two substations for electric power services). To identify temporary solutions for infrastructure services for IO building performance objectives, minimum levels of required infrastructure services need to be determined. Infrastructure services may be met with temporary equipment or supplemental systems to supply power, water, communications, etc. during the recovery process, and should consider appropriate performance variations for residential and commercial buildings. For instance, IO residential construction should account for the range of population needs and vulnerabilities (e.g., healthy population, non-ambulatory population, population requiring electric power for medical equipment, etc.). Additionally, a range of methods to provide temporary and long-term solutions for recovery and upgrading infrastructure need to be identified.

\section{B.1.2. Implementation activities}

\section{B.1.2.1. Develop tools that analyze and visually present data:}

Tools are needed for designers and community planners that analyze and visually present geospatial, temporal, multi-disciplinary data to inform the requirements related to the functionality of IO buildings with regards to building clusters and infrastructure systems. Such tools will help identify areas suitable for locating IO buildings and inform community zoning requirements.

\section{B.1.2.2. Develop guidelines for temporary infrastructure planning:}

Best practice guidance is needed to help estimate the infrastructure services needed to maintain the desired IO functional level, as well as options for the planning and provision of temporary services at the required levels and recovery times. The guidance needs to consider the individual building perspective and the community perspective.

\section{B.2. Community Planning}

IO buildings have the potential to improve the performance and functionality of a community, and the rate of recovery, after a hazard event. However, the relationships and factors that characterize IO building performance and its effect on community functions are not well 
defined. For instance, how long can services by IO buildings be interrupted before community recovery is negatively affected? Objective metrics and assessment methods that include effects on social and economic functions are needed to inform community resilience planning and identify potential IO building impacts.

A community's building stock is renewed over decades, and evaluating the performance of existing buildings can present a substantial challenge. Existing buildings may not meet current codes and standards, or they may not have been adequately maintained. The anticipated performance of existing buildings, which is often difficult to assess, can affect the performance of an IO building within a building cluster. An IO building can provide essential services within a building cluster, but full functionality of the building cluster also depends on other buildings. For example, full community health services may require an urgent care center as well as a pharmacy, dialysis center, and other daily health services. The issue of which existing buildings are suitable for retrofit to achieve IO performance also needs to be addressed.

In addition to tools to help communities characterize their existing building stock and supporting infrastructure capacity, tools to help communities plan for future needs are also needed. If residential, commercial, and critical buildings are to achieve IO performance, what future capacity of infrastructure support is also needed?

Including IO buildings as part of the community building portfolio may require altering local codes and policies, especially with regards to community development and resilience goals. Integrating land use planning, zoning, social and economic vulnerabilities, and community hazard maps will improve the characterization of risks for IO building design. To be useful, this type of information may need to be provided with increased resolution to a block or similar scale.

Community resilience planning should integrate physical, social, and economic system goals. Infrastructure system design approaches (e.g., consensus standards and codes, best practices, regulatory), professional disciplines (e.g., urban planner, economist, engineers, managers), and stakeholders (e.g., residents, business owners, city officials) often have different perspectives and vocabulary, geospatial and temporal scales, design and analysis methods, and performance goals, which makes collaboration challenging. Guidance for IO planning and design needs that addresses multiple disciplines will improve integration of stakeholder perspectives into IO performance objectives.

\section{B.2.1. Basic and applied research activities \\ B.2.1.1. Develop metrics and analysis methods to assess community impacts of IO building performance:}

Metrics and analysis methods, including types and formats of data, are needed to assess IO building performance and its impacts on the community, before and after a hazard event. Impacts include direct and indirect benefits, losses, and cascading consequences of IO building performance on community social and economic functions. Community vulnerabilities (e.g., social, economic, infrastructure, environmental) that may affect the performance of IO buildings should also be included. For instance, there may be levels of building recovery after an event that lead to an indirect loss (e.g., outmigration of businesses or residents). Models and tools are needed that link the social and economic impacts with the performance objectives of 
IO buildings that also consider how a community may change over time (e.g., population growth, development activities) are also needed.

\section{B.2.1.2. Develop methods to assess building inventories and infrastructure to support community planning:}

Methodologies for developing a community building inventory are needed that will support planning, evaluation, and decision-making for IO building performance, including the infrastructure capacity needed to support IO buildings. The methodologies should include metrics for assessing the anticipated performance of existing buildings, the desired performance of new IO buildings, required supporting infrastructure services and capacities, and the current and future performance of IO buildings and associated building clusters.

\section{B.2.1.3. Evaluate land use and zoning policy effects on IO building performance and community development:}

A critical assessment of community zoning codes for residential and commercial construction, including land use, building density, functional redundancy, and community social and economic functions is needed to inform development of IO building performance objectives. The potential risks and outcomes for a community for implementing zoning codes and hazard mitigation, with consideration of scale and effects (building vs. community), also need to be identified and assessed. Criteria should include topics such as the type of locations where achieving immediate occupancy may not be feasible due to local site conditions or which land uses may not be appropriate for IO performance building development, such as flood zones, soil conditions, or seismic fault zones or landslide potentials. Additionally, potential impacts and tradeoffs between IO building performance and its potential to affect community resilience, sustainability, environmental issues, ecological value, and social vulnerabilities need to be identified, as well as methods for evaluation.

\section{B.2.1.4. Develop methods for prioritizing which buildings should be designated as IO in a community:}

A critical assessment of current community resilience planning will inform the development of prioritization criteria for designating IO buildings in a community. An assessment of IO building performance objectives, their actual performance, and effects on building clusters and community functions will provide a basis for determining what works, what local conditions foster success, and what has led to failure of certain efforts. Topics should include land use and zoning codes, codes and standards, additional performance requirements, and community resilience goals.

\section{B.2.2. Implementation activities}

B.2.2.1. Develop multidisciplinary community guidance and tools for IO building planning and design:

Best practice guidance and tools are needed to address IO building performance and issues that support community resilience planning. The guidance and tools should include integrating multidisciplinary perspectives and issues, building inventories, land use and zoning codes, administrative and construction options to supplement the code requirements, and metrics for evaluating IO building influence on community functions and their recovery following a hazard event. 


\section{B.3. Community Decision Support}

Tools and analyses that support community stakeholder assessments and decision-making for IO buildings and performance objectives need to be identified and developed. Such tools can help community stakeholders assess how IO performance objectives will improve continuity of community functions and business operations, reduce risks and losses, meet strategic objectives, and support community resilience goals. To support defining IO performance objectives for residential and commercial buildings, tools are needed to quantitatively link IO building performance to support of community functions, including metrics, dependencies, and decision parameters.

Successful planning, design, construction, maintenance, operations, and enforcement of IO buildings requires technical capabilities and administrative capacity within local governments and by building owners. Technical and administrative requirements for decisions associated with community planning and the design and construction of IO buildings are needed, including variations that need to be considered for a range of community types (e.g., rural, urban, coastal, plains). Tools and best practice guidance are needed for incorporating IO building requirements in community planning and professional practice.

An assessment of existing guidance documents and decisions of residential and commercial building owners and occupants as they prepare for, respond to, and recover from hazard events will provide a foundation for developing IO building performance objectives. Research is needed that defines the role of IO buildings in mitigating hazard risks and recovery of social and economic functions. Depending on their demographic composition, land-use patterns, affluence, and vulnerable populations, community decisions will be based on differing requirements and considerations associated with performance objectives and their community resilience goals.

\section{B.3.1. Basic and applied research activities \\ B.3.1.1. Develop metrics for assessing IO building effect on community functions:}

Research is needed to develop metrics for assessing IO building performance objectives and their effect on community functions, including the planning and recovery process. These metrics should evaluate IO building functionality and its effect on the recovery of supported social and economic functions and the performance of building clusters.

\section{B.3.1.2. Develop technical and administrative requirements for managing IO buildings:}

Technical and administrative requirements to support decision-making are needed by building owners and community officials for the planning, design, construction, maintenance, operations, and code enforcement of IO buildings. Research should include assessment of decision-making needs for various types of communities, such as rural and urban communities, and requirements for different types of hazards.

\section{buildings:}

\section{B.3.1.3. Assess decision-making process for residential and commercial}

A critical assessment of how residential and commercial building owners and communities make decisions for hazard preparedness, mitigation and recovery will provide a basis for developing criteria for IO buildings. This research should include identifying opportunities to 
improve mitigation, response, and recovery planning, as well as key information that would aid stakeholder groups in their decision-making for IO buildings.

\section{B.3.2. Implementation activities \\ B.3.2.1. Develop decision support tools that integrate community data for IO buildings:}

Guidance documents and decision support tools are needed to inform IO building planning, design, and management for individual buildings and communities. These tools need to integrate community information on buildings, infrastructure, land-use, hazards, population, and other important community data at a scale useful for IO buildings. The guidance and tools could also support outreach to community stakeholders involved with the planning and decisions associated with IO buildings and the community.

\section{B.4. Community Stakeholder Communication}

Acceptance and implementation of IO buildings and their performance objectives by community stakeholders will be improved with understanding by stakeholders of the associated benefits and costs at community, institutional, and individual scales.

Research into effective communication approaches and community outreach methods will help communities educate and engage their stakeholders. The type of information that needs to be communicated includes anticipated building performance and hazard risks, individual, organizational, and community impacts, alternative solutions, and associated short-term and long-term benefits and costs. Broad stakeholder input will better inform the design of IO buildings, and increase support for implementation.

Communicating risks associated with current building practices, codes, and performance during hazards is a challenge. Community officials are familiar with ensuring public discourse and input in their administrative programs, however, challenges exist in providing public officials with tools and technical training to effectively communicate and elicit stakeholder input for IO performance objectives. Additional items that contribute to the complexity of communication with a broad range of stakeholders includes uncertainty in future hazard events, dependencies between systems, and consequences of building failure. Adjusting for bias and experience of stakeholders is a substantial, ongoing communication research challenge.

\section{B.4.1. Basic and applied research activities}

B.4.1.1. Identify communication needs of community stakeholders:

Research to identify communication needs and effective methods for engaging community stakeholders is needed. A critical assessment of current methods of communication is needed, and successful case studies should be identified.

\section{B.4.1.2. Develop methods of effective risk communication:}

A variety of methods, models, and approaches are needed that can be used by community officials, facilitators, scientists, engineers, architects, or other stakeholders involved in the IO building performance objective development process to effectively communicate trade-offs and elicit information essential to specifying engineering design criteria. Research conducted under this activity should identify approaches for successful communication of hazard risks and anticipated building performance, alternative solutions, associated short-term and longterm benefits and costs, and eliciting information from community stakeholders. Communication methods could include visual, interactive, or facilitated dialogue approaches. 


\section{B.4.1.3. Develop technical communication capacity:}

Explaining immediate occupancy performance objectives to a range of stakeholders requires education and technical training to ensure the ability to effectively communicate risks, uncertainty, benefits, costs, trade-offs, and other consequences of adopting IO performance objectives. Technical training materials and curricula and communication guides are needed to support engagement with local stakeholders.

\section{B.4.2. Implementation activities}

B.4.2.1. Develop stakeholder communication tools for IO buildings:

Communication tools and vocabulary are needed to convey information about IO building planning, design, and management for individual buildings and communities to and between stakeholders. These tools need to support effective communication of the risks, uncertainty, benefits, costs, trade-offs, and consequences of IO buildings in communities. 


\section{Appendix C: Economic and Social Considerations}

Chapter 5 presented general research topics to study the potential impacts, at the local, regional, and national scales, of implementing IO performance objectives. This section presents more detailed research needs to understand the economic and social impacts of designing new buildings and retrofitting existing buildings to meet IO objectives.

\section{C.1. Economic Feasibility}

The first key challenge is to identify the costs associated with new IO building construction, as well as who bears those costs. Initial costs are a primary driver of IO decisions for developers and building owners. Long-term costs that incorporate maintenance and operating costs over the life of an IO building may be equally important to building owners, occupants, and managers. Existing buildings have different costs associated with retrofit alternatives. Research needs include quantifying costs for both new and existing buildings, data collection, and development of tools to estimate costs.

Another key challenge is to identify benefits to different building stakeholders. Developers are unlikely to benefit from building to IO performance objectives, outside of a potential increase in property values. For business owners, the reduced likelihood of business interruption from loss of building function can be important in making $\mathrm{IO}$ more attractive as an investment and to provide stability for business. Owners who do not occupy their building may benefit from reduced losses following a hazard event, or from higher rents that can be charged even in the absence of a hazard event. This benefit to owners may hurt occupants through higher rents. On the other hand, improved IO building performance with continuous functionality following a hazard event is more likely to benefit occupants. The relationship between costs and benefits will inform policy decisions (such as subsidy recipients and amounts) to support implementing IO performance objectives in the design of buildings.

Finally, research is needed on the role of financing in linking costs and benefits across stakeholders. Lenders, insurers, and investors play a direct role in financing initial costs, but rarely incorporate benefits associated with construction. Whether and how IO buildings can affect mortgage rates, insurance rates, and other forms of return on investment will inform both individual stakeholders' assessment of the net benefit of IO buildings and development of policies and incentives for promoting adoption of IO buildings.

\section{C.1.1. Basic and applied research needs \\ C.1.1.1. Initial and long-term costs:}

Research is needed to identify and quantify the initial costs of IO construction and determine who bears those costs (e.g., developer or owner). Cost estimates, including design, materials, and labor costs, are needed for both new construction and existing buildings. Long-term costs, including life-cycle costs (e.g., operation and maintenance), financing, and insurance, should be evaluated for multiple types of IO buildings. Research is also needed to compare costs for a range of hazard designs, and to find a balance between cost and design. Lastly, research is needed to assess the costs associated with how adoption of IO performance objectives affects the lifespan of a building and the maintenance required to maintain expected functionality. 


\section{C.1.1.2. Direct and indirect benefits:}

Research is needed to identify and quantify benefits directly related to improved performance (e.g., reduced losses from a hazard event and the potential for lower life-cycle costs [LCCs] ${ }^{1}$ of IO buildings. The loan principal is determined by initial costs, but it may be possible to incorporate LCC-related reductions into mortgage rates. As with costs, identifying who benefits is equally important. Research is needed to identify and quantify benefits not directly related to improved performance (e.g., the potential effect of IO buildings on property values, and thus rental rates). Short-term benefits and co-benefits are likely to be attractive to building owners and occupants.

\section{C.1.1.3. Financial mechanisms:}

Research is needed into the potential role of debt instruments in financing IO buildings. For example, a borrower on a mortgage for an IO building may be more likely to repay. Debt instruments include mortgages, bonds, and leases, and vary in length of obligation. Research is also needed into the potential role of insurance in financing IO buildings (e.g., does IO affect insurance rates for IO buildings?) The range of insurance options include homeowner's insurance, commercial property insurance, and hazard-specific insurance policies, as well as reinsurance markets (insuring insurers). Other financial mechanisms that might be relevant include investments in Real Estate Investment Trusts (REITs), federal and local government land acquisition programs, fiscal incentives such as tax breaks, and land-value capture programs such as tax-increment financing.

\section{C.1.2. Implementation activities}

\section{C.1.2.1. Cost estimating tools:}

A range of tools is needed to quantify and predict the cost of an IO building. Examples include estimating differences in construction costs of current new building-code requirements and a new IO building; estimating differences in retrofit costs for current existing building-code requirements and IO; and separately computing costs for different types of IO buildings, including residential and commercial. Research is also needed into infrastructure needs for IO and the relation to initial costs. For example, if IO building design is not appreciably more expensive than the current practice, do infrastructure costs make IO building design prohibitively expensive?

\section{C.1.2.2. Cost-benefit tools:}

Decision makers need tools to evaluate the direct and indirect costs and benefits of IO buildings. More sophisticated tools, such as NIST's Economic Decision Guide Software (EDGe\$) tool, may incorporate uncertainty, externalities, and co-benefits [27].

\section{C.1.2.3. Guidance on financial instruments:}

Guidance documents are needed that identify the broad range of financial instruments, how they could be, or are being used in mitigation planning, and how individuals respond to changes in such financial instruments. Examples include the financial mechanisms discussed under "Basic and applied research needs," as well as catastrophe bonds, social impact bonds, and resilience mortgages.

\footnotetext{
${ }^{1}$ See Ref. [26] for an example definition and breakdown of life-cycle costs.
} 


\section{C.1.2.4. Tracking implementation efforts:}

Data collection efforts are needed to track the range of costs and benefits associated with implementing an IO performance objective for buildings. Data sharing and transparency among stakeholders could support data collection to assist communities, developers, and designers in becoming more knowledgeable about the costs and benefits of IO buildings. Information sharing, perhaps through databases and shared data repositories, has the potential to reduce information costs and facilitate efforts to adopt IO performance objectives.

\section{C.2. Economic Impacts}

A key challenge is to identify economic effects of IO buildings on households. Building failure following a hazard event can result in loss of housing and jobs. An IO performance objective has the potential to mitigate such losses. In the absence of a hazard event, however, IO building performance has the potential to affect households in other ways. For example, higher property values due to IO buildings can lead to higher rents and, consequently, displacement of lowincome populations, or IO buildings may stimulate urban growth, leading to increased job opportunities. Other instances with economic implications such as reducing injury and detrimental mental health outcomes, or behavioral changes such as increased risk taking, are discussed in the following sections.

A second key challenge is to identify effects of IO building performance on businesses. Failures in building functionality from a natural hazard event can result in supply-chain disruptions, decreases in productivity, or business downtime. IO buildings have the potential to affect businesses in other ways in the absence of a hazard event, as well. For instance, higher rents can displace small-business owners or urban growth can attract more businesses, improving local economic productivity.

Finally, research is needed to identify the economic effects of IO building performance on social institutions. For example, following a hazard event school closures can result in missed school days for students and missed workdays for parents and teachers. IO building design could allow schools to serve their intended function, or provide alternative buildings that enable education to continue. Impacts in the absence of a hazard also need to be considered. For example, higher property values due to IO buildings may increase the local tax base, potentially affecting provision of services such as public education. However, migration patterns resulting from higher property values affect who benefits from improvements in public schools.

\section{C.2.1. Basic and applied research needs \\ C.2.1.1. Economic stability and reduced losses:}

Research is needed into the potential for IO to provide economic stability at the local, regional, and national levels, following a hazard event. Economic stability has the potential to stimulate local economic growth, national GDP, and trade. Research into the potential loss reductions to both households and businesses from IO buildings is needed. Impacts are not necessarily exclusive to occupants of IO buildings; e.g., if a household is displaced from their home but can find shelter in an IO building, they may be able to work.

\section{C.2.1.2. Drivers of population change:}

Research is needed on how IO buildings can affect population change. In the preceding subtopic, "Economic Feasibility," we discuss the potential effect of IO on property values. 
Such impacts have consequences for population displacement, migration patterns, and the local tax base. In addition, if IO buildings are too expensive in urban areas, more businesses may relocate to suburban or rural areas. If IO makes coastal cities seem safer, population density may increase.

\section{C.2.1.3. Environmental impacts:}

Research is needed to identify and quantify potential environmental effects of IO, ranging from direct impacts such as changes in demand for construction materials, to indirect impacts such as higher energy consumption to maintain indoor air quality. Environmental costs to society may be evaluated using life-cycle analysis.

\section{C.2.1.4. Synergies between household and business recovery:}

Research is needed into how IO can improve household recovery, business recovery, and the relationship between the two. Such impacts should consider both spatial and temporal dimensions of IO with respect to recovery.

\section{C.2.1.5. Consideration of impacts on willingness-to-pay:}

Research is needed to bring together the full range of costs and benefits indicated in this subtopic and the preceding subtopic, "Economic Feasibility," to determine willingness-to-pay for the new construction or retrofit of buildings for IO for the range of relevant stakeholders, including building owners, occupants, and communities.

\section{C.2.2. Implementation activities}

\section{C.2.2.1. Guidance on business recovery:}

Guidance documents are needed to inform businesses on how IO can protect business inventory and reduce losses from protected inventory; affect both expected and unexpected downtime, and losses to businesses resulting from downtime; and how impacts vary by sector. Benefits are likely to differ for capital-intensive sectors and labor-intensive sectors; e.g., service sectors are generally more labor intensive than manufacturing sectors.

\section{C.2.2.2. Tracking externalities:}

It is important to identify and compile the range of positive and negative externalities from an IO building on the local, regional, and national economy, before and after implementation. Guidance documents on IO should include this information.

\section{C.2.2.3. Tools to quantify externalities:}

Stakeholders such as city planners, managers, and council members who cannot make individual building-level decisions, but are nevertheless interested in IO, should be able to easily quantify externalities associated with enhanced building performance. Tools are needed to provide information on how IO's impacts on the economy cascade through social institutions such as education (e.g., public schools, community colleges, and universities) and social networks (e.g., peer groups, professional networks, and extended family), and how IO's influence on urbanization might change neighborhood and community demographics over time.

\section{C.2.2.4. Guidance on the relationship of IO to other goals:}

Guidance documents are needed that show stakeholders how IO relates to other community goals, including: economic growth, economic inequality, sustainability, adaptation, cybersecurity, and national security. Guidance documents should also articulate how effects 
differ between residential IO buildings (e.g., single-family homes), commercial IO buildings (e.g., office buildings), and industrial facilities (e.g., water treatment plants, power stations, and refineries).

\section{C.2.2.5. Relative costs of implementation mechanisms:}

Databases that bring together the range of costs and benefits are needed to compare various options available for implementing IO; e.g., the cost of land acquisition vs. retrofit programs.

\section{C.3. Social Feasibility}

The feasibility of IO buildings depends, at least in part, upon what building owners, occupants, and communities desire from buildings, and therefore want from IO performance objectives. Needs and desires related to a building's structural performance as well as overall functionality can vary substantially. Goals may vary based on the type of occupants, or an obvious need to maintain the building's typical function (such as a daycare center or a police station). In addition, desires for functionality may change during a hazard scenario (for example, a gas station may not seem very important on a day-to-day basis but would be critical during hurricane evacuation). Assessing the need for IO design should also consider knowledge of current performance of buildings. People may overestimate the ability of a building to withstand a natural hazard event. In addition, older buildings are not typically designed to withstand hazards. Some buildings, such as hospitals, are designed to meet some aspects of IO performance. However, even modern buildings may fail to withstand a natural hazard event with surprising repercussions. For example, in the days following the 2010 Maule earthquake in Chile, a new high-rise apartment building had to be unexpectedly evacuated and eventually demolished because of structural damage barely perceptible to non-experts [28]. After a 2011 earthquake, the central portion of the Christchurch, NZ downtown area was closed for two years due to severe damage of buildings, causing substantial displacement and economic hardship, and certain sections are now deemed ineligible for rebuilding [29]. Understanding of expected building performance (including both new and existing buildings) should be considered alongside needs and desires for new or retrofitted buildings.

A key challenge for individuals or communities interested in investing in immediate occupancy buildings relates to varied perception of risk. People may not have adequate knowledge of how natural hazard events can affect typical buildings and, consequently, their family and community. The risk from natural hazards varies widely by location and by hazard type, rate of occurrence, and magnitude of the event, making assessment and understanding of risks challenging. In addition, lack of experience with natural hazard events, or experience with events of a lesser magnitude may mislead people into a false sense of security relative to their true risk. They may also overestimate the availability and effectiveness of disaster relief and recovery support services (such as after Hurricane Katrina in 2005). Substantial research is needed to quantitatively and qualitatively define risk for a range of stakeholders, and into how to help individuals and communities better understand their risks and their perception of these risks relative to building performance for natural hazards. Information is needed on how long occupants can or will tolerate being without building services (power, water, heat, cooling, internet, plumbing, etc.) before injury or fatalities occur, or without social functions (employment, schools, governance, etc.) before leaving the community. Identifying acceptable limits for building performance also requires understanding performance levels for external infrastructure services after a hazard event [30]. Planning for an individual IO building should 
include consideration of how a lack of performance would disrupt a community's economic and social function and expected time to recovery.

Individuals or groups may decide upon the use and implementation of IO performance objectives. Information from the previous sections, including desires for building performance as well as accurate knowledge relating to risk, is necessary for these parties to evaluate and effectively make decisions regarding IO buildings. However, a few key things can pose obstacles for effective decision-making, including: authority and ability in decision-making, alternative pressing concerns, and conflicts of priority. Individuals may lack or have limited ability to effect change (a worker has no say in what kind of building their employer owns or rents; a parent has limited agency to provide their child a tsunami-safe school). People often have a finite capacity for worry and personal health, financial, or family issues often take precedence. Other priorities may limit the use of IO performance objectives in design or retrofit (such as pre-planned housing developments or big-box chain stores) or create conflicts in priority between multiple parties (for example, reluctance to change the historic character of buildings or tenants desiring IO performance but not wanting to vacate for retrofits). The places where these kinds of conflicts lead to increased vulnerability for certain populations should be explored, and some are identified below. Additional study is needed to identify and develop tools to navigate barriers to effective individual or community decision-making.

\section{C.3.1. Basic and applied research needs \\ C.3.1.1. Benefits of IO buildings:}

Estimate the improved safety and recovery benefits of IO buildings as they relate to human owners and inhabitants in order to better inform knowledge and decision-making related to building performance and risk.

\section{C.3.1.2. Tools for understanding hazard risk:}

Develop simulations and scenarios to provide tailored knowledge of how natural hazard events can affect individuals within local and regional populations. Invest in cross-disciplinary modeling and analysis of social, economic, and ecological risks. For example: impacts to businesses due to loss of workforce or relocation after an event; tools to project risks into the future as communities change with development and population growth; and community level simulation of recovery timeframes and roadblocks.

\section{C.3.1.3. Stakeholder research:}

Qualitative and quantitative stakeholder surveys can support research to identify desired IO performance objectives in terms of performance before and after hazards, the effects of that performance on social systems and the community, and the benefits that support community resilience. For example, studies into how individuals process and interpret information about hazard risk, and how responses change with the type of information (e.g., numerical vs categorical scales of risk). Research is also needed on characterizing the range of desired IO performance objectives when considering the stakeholder perspective relative to the building, social systems, and community scales.

\section{C.3.2. Implementation activities}

\section{C.3.2.1. Localized assessment of risk:}

Use the research needs identified above in conjunction with IO building design and community hazard planning to provide more specific and localized information to inform perception of 
risk. This includes collection of data to inform individuals and communities of the level of protection that current buildings provide. The effectiveness of any tools created also needs to be evaluated.

\section{C.3.2.2. Consequences of IO buildings:}

Track the impact of IO buildings on individuals and communities and share this information with others considering IO adoption. Track how the presence of IO buildings may change perceptions of risk and safety among individuals and communities, for example, through surveys. Owners or occupants may overestimate the safety of their building and increase risktaking behavior, such as under-insuring a building. Alternatively, a community's perception of safety and stability may be improved, leading to strengthened community cohesion and investment. The effectiveness of any tools created also needs to be evaluated.

\section{C.4. Social Impacts}

While the purpose of IO buildings is primarily physical, such as through providing shelter and services such as water and electricity, there are many important non-physical functions that buildings sustain to support our social networks and institutions that buildings sustain. Buildings enable safe and convenient places for enjoyment, productivity, and activities critical for society to function. Natural hazard events can cause disruption that negatively affects social wellbeing and cohesion at multiple scales. Several types of social institutions play important roles in supporting communities in crisis. Obvious ones are government, hospitals, and schools. If schools are not functional, parents cannot work and may have to leave the community to better provide for their families, which can negatively impact the economy. Nonprofit organizations, including churches and community centers, often play a critical role in community support and recovery. Less obvious, but still critical to the health of communities, are pharmacies or urgent-care facilities that are often located in commercial buildings. For example, dialysis centers require water and electricity and even if the building is not damaged, these resources are needed for proper care. Individuals, building owners, or communities could choose to prioritize buildings that house important social institutions or that serve key functions to meet IO performance objectives.

IO buildings can play an important role for vulnerable populations in a post-hazard scenario. Vulnerable populations (those with fewer resources, social capital, mobility, ability to influence change, or access to goods and services) may be able to access key resources if building owners or communities prioritize these kinds of services in IO buildings. For example, mental health care services are critical after a hazard event, especially for low-income residents who may have additional difficulty accessing services. The elderly are also particularly vulnerable and long-term care facilities often do not have adequate resources or plans for remaining in the facility or for evacuation. In 2017, a few days after Hurricane Irma, nursing home residents had to be evacuated and 14 died after the storm disabled the air conditioning (but not power) [31]. Improved understanding of how vulnerable populations could be benefit from IO buildings is needed, but we should recognize these populations may also benefit the least from IO buildings. IO buildings may increase existing inequalities, for example by raising prices for housing and pushing lower-income residents out of neighborhoods. Certain populations may be most at risk for these kinds of impacts, such as minorities, immigrants, the disabled, and the elderly. The increased isolation or clustering of vulnerable populations reduces their capacity to anticipate, cope, respond, and recover from natural hazard events, increasing negative impacts. Decision-making and control of resources without regard for the 
effect on these populations can lead to increased risk for vulnerable people. Research is needed to identify and address the particular needs of vulnerable populations in relation to IO building design and implementation.

Methods are needed to identify and measure disruption to vulnerable populations and social organizations and institutions at multiple scales. In depth research incorporating qualitative methods is necessary as such losses can be difficult to measure quantitatively (such as through monetization). In addition, modeling of dependencies on other institutions and the built environment is needed. For example, multiple failures in normal supply chains are possible after a natural hazard event due to disruptions in transportation, communication, and financial resources. The provision of food, water, and medical supplies through supply chains is critical and should be a part of planning related to support and functioning of IO buildings. The direct and indirect consequences of disruption to social functions from important or critical buildings that are no longer functional need to be evaluated when planning for IO. These impacts should be assessed both in the short- and long-term and should take into consideration the impact on particular populations (due to financial resources, age, ethnicity, etc.). Planners and decision makers should then incorporate this research alongside aspects of social feasibility in prioritizing IO building development to mitigate risk and support recovery.

\section{C.4.1. Basic and applied research needs}

\section{C.4.1.1. Measurement of value of buildings:}

Research is needed to quantitatively and qualitatively assess the value of IO buildings to the community and the local economy in terms of increased ability to provide for residential and economic functions such as reduced business and supply-chain interruptions, reduced housing loss, out-migration and reduced injuries and fatalities.

\section{C.4.1.2. Key institutions:}

Research is needed to understand impacts IO buildings could have on individuals, families, social systems, and communities. Particular attention should be paid to social networks and institutions of the community that can help to provide recovery support and services, and how social institutions are considered in decision-making around IO performance objectives (for example, health facilities and supply chains).

\section{C.4.1.3. Impacts to vulnerable populations:}

Research is needed to anticipate the ways in which vulnerable populations will be affected by IO buildings, and what provisions might be necessary in IO building design or implementation to mitigate negative impacts to those populations. These impacts may be specific to an individual IO building.

\section{C.4.2. Implementation activities}

\section{C.4.2.1. Tools for decision-making:}

Guidance on social impacts to vulnerable populations or social institutions should be developed for planners, designers, and other decision makers to help mitigate any negative impacts from IO building implementation. 


\section{Appendix D: Adoption and Acceptance Considerations}

In Chapter 6, challenges associated with adoption and acceptance of IO performance objectives were introduced, and general research to address these challenges was presented. This section provides a more detailed description of recommended research and implementation activities for each of the research subtopics presented in Chapter 6. Please note that information related to economic and social feasibility is provided in Appendix C.

\section{D.1. Adoption Mechanisms}

A key challenge to adopting IO is the lack of detailed knowledge about current practices. Modern building codes, standards, and construction practices have been developed primarily for life safety with some degree of property protection, but do not ensure functionality or immediate occupancy for most commercial and residential buildings. Building performance likely varies substantially with hazard and location. Understanding the performance anticipated for buildings, as well as understanding regional variability for what IO would look like for different hazards, will be a critical first step.

Another challenge is the potential disconnect between those incurring the costs of creating IO buildings or retrofitting existing ones, and those reaping the benefits. Public policy may be necessary to provide incentives to address this asymmetric cost burden and encourage developers and building owners to prioritize life cycle costs over initial costs. There are a wide range of possible incentives, such as tax benefits, bonds, loans, and other financing mechanisms for new construction and retrofits, and property insurance premium reductions. However, sufficient data are not available to evaluate their effectiveness, quantify costs and benefits, or understand the capability of communities to implement them.

Finally, in addition to top down measures such as financial incentives and municipal requirements, public demand for IO could help drive adoption. There is limited public understanding of the wide range and probabilities of natural hazards that can impact buildings and their potential to remain occupiable. There is also a common misperception of the level of performance that building codes provide. It is often assumed that buildings are more robust than they really are. Additionally, many people rely on post-disaster recovery aid rather than taking proactive mitigation measures.

\section{D.1.1. Basic and applied research needs}

D.1.1.1. Assess the risks of hazards not adequately addressed in current building codes and standards:

Research is needed to obtain a greater understanding and to quantify the full range of natural hazards that affect the ability of a building to remain occupiable following an event. This will enable performance objectives to be developed according to desired risk levels. For example, wind-driven rain during hurricanes is a major contributor to water damage and the oftensubsequent mold growth inside buildings, but little is known about this hazard and how to successfully design to resist it.

\section{D.1.1.2. Develop hazard maps that enable risk-relevant IO performance objectives: \\ Design for immediate occupancy requires explicit consideration of all locally relevant natural hazards, but some hazards are not adequately mapped. For example, the hazard maps currently used for design against flooding were developed for insurance rating purposes, and are}


inadequate for engineering design and risk assessment. Current tornado hazard maps substantially under-predict tornado strike probabilities, and there are no maps quantifying the wind-driven rain hazard.

\section{D.1.1.3. Identify practices and drivers for current IO practice:}

Research is needed to identify current practices and better understand the state-of-the-art in planning, design, and operation of facilities. Research is also needed to understand market forces driving adoption of IO performance objectives within different sectors, such as government, health care, financial services, and others. This information will provide a critical starting point for other adoption and acceptance-related research topics.

\section{D.1.1.4. Identify market mechanisms that support voluntary adoption of IO performance objectives:}

IO buildings possess many characteristics that could encourage others to adopt these performance objectives, such as improved continuity of operations, increased property value, reduced insurance rates and/or deductibles, and reduced maintenance and repair costs. Research is needed to identify and quantify the full range of IO benefits and related market mechanisms that can help build acceptance and demand for IO performance objectives. Research is also needed to determine if an IO rating system would help drive public demand, and how to best structure such a system to positively influence IO-related decisions and actions. The outcomes of this research could be incorporated into guidance for developing a business case to present to private building owners.

\section{D.1.1.5. Investigate public policy measures associated with voluntary adoption of IO performance objectives:}

An analysis of policy options would be needed to identify and assess potential public actions related to voluntary adoption. Examples of such options are tax incentives, financing incentives, adoption of voluntary codes and regulations, and leadership by example through specification of IO performance objectives for government-owned or leased buildings. Leading by example may offer the most effective way of starting the process. Adoption of IO performance objectives by federal and state governments for targeted buildings could provide a strong message about the importance of this concept and a tangible example for implementation.

\section{D.1.1.6. Investigate applications where communities may desire mandatory IO performance objectives:}

Research is needed to identify situations where mandatory IO requirements, such as building code provisions or other regulations, may be appropriate. Possible examples include emergency operations centers, hospitals, and other critical facilities. Research related to evaluating IO compliance and enforcement issues is also needed.

\section{D.1.2. Implementation activities}

D.1.2.1. Develop strategies to support adoption and acceptance of IO performance objectives:

Using results of the research investigating market mechanisms and public policies, strategies should be developed for each key stakeholder group to inform and motivate adoption and acceptance of IO performance objectives. Examples include developing business cases, guidelines, and planning scenarios, as well as performing case studies. Post-disaster recovery 
periods often provide the best window of opportunity for effective communication and changing the status quo; therefore, strategies that can be used during this critical timeframe are needed.

\section{D.1.2.2. Identify effective funding mechanisms to inventory:}

Cities and communities generally lack the resources, capabilities, and tools to track the levels of design and construction of retrofitted buildings. Regular assessments could be made part of the building code. Possible funding sources need to be identified.

\section{D.1.2.3. Identify legal barriers to IO implementation:}

Present laws limit the authority of a city or community to require building improvements to increase safety unless certain triggers are reached in terms of remodeling or repurposing. Cities, communities, and building owners need guidance on the legal questions associated with existing buildings and enforcing IO performance objectives through building codes.

\section{D.2. Education, Training, and Outreach}

Designing buildings to IO performance objectives will be a notable shift from current standards of practice for the engineering and architectural fields. Training programs will be essential to introduce skilled professionals to new concepts and to educate them on new codes, regulations, and inspection protocols. Potential workforce training opportunities include establishing formal apprenticeship and mentoring programs, and developing on the job training. Licensure or accreditation programs could also be established to recognize the unique expertise and skillset that need to be maintained by this professional community.

IO will require substantial investment in additional staffing to support the permitting process at all levels. As the workforce ages, new professionals will need to be trained to maintain the technical pipeline [32]. Studies should be conducted across all relevant fields to better characterize workforce size, skillset, and demographics and to evaluate whether these workforces are adequate to meet the new demands.

Finally, public acceptance and input is an important component of an immediate occupancy design and implementation effort. Effective public outreach requires developing and implementing appropriate educational materials, incorporating risk communication methods, and establishing ongoing engagement mechanisms. Examples of the latter include community workshops, local government forums, public library presentations, training at educational institutions, and discussions at community organization meetings.

\section{D.2.1. Basic and applied research needs \\ D.2.1.1 Develop an accreditation or licensure program to certify technical professionals in IO design expertise:}

Research is needed to identify an effective approach to developing an accreditation program for design professionals to demonstrate expertise in IO. Such a program could be a stand-alone certification or expand upon existing engineering and architectural licensure programs.

\section{D.2.1.2. Identify a set of workforce competencies required to design and sustain IO performance objectives:}

Research is required to identify the workforce competencies necessary to ensure IO performance objectives can be effectively designed, reliably implemented, and consistently enforced. Additionally, research is necessary to identify metrics to track changing workforce 
needs over time, assess programmatic success, and identify additional investment opportunities in workforce training and education.

\section{D.2.2. Implementation activities}

D.2.2.1. Establish professional development programs for continuing education: Professional development opportunities such as apprenticeships, rotations, and other trainee programs are essential to developing a workforce with the interdisciplinary skills to support IO performance objectives. These programs should incorporate best practices from successful international on-the-job training programs and professional development programs across sectors. They should target design professionals (e.g., engineers, architects) and contractors as well as enforcement personnel (e.g., regulators, inspectors).

\section{D.2.2.2. Incorporate performance-based design (PBD) methods in engineering, architectural, and design curricula:}

Programs need to be established to train structural engineers, contractors, architects, inspectors, and regulators on performance-based design as a tool to develop more resilient buildings in a cost-effective manner. Performance-based design may provide more flexibility for building developers over prescriptive methods, but requires a more detailed understanding of hazards, performance objectives, and structural and non-structural design techniques.

\section{D.2.2.3. Recommend expanded undergraduate and graduate curricula to include interdisciplinary concepts:}

Research is needed to determine how to most effectively incorporate IO performance objectives concepts and design principles into curricula at the graduate and undergraduate level across disciplines, including engineering, architecture, and the social and behavioral sciences. Such programs should augment traditional technical training with critical knowledge in stakeholder communication, economics, and social and behavioral concepts in order to reflect the interdisciplinary nature of the field.

\section{D.2.2.4. Establish common terms to discuss IO performance objective related concepts across stakeholder groups:}

In order to facilitate effective information sharing, consistent and comparable data collection, and cross-stakeholder interaction, a common set of terminology and definitions needs to be established. This will ensure consistency in training across disciplines. It will also help ensure that all stakeholder interests are represented in the planning, design, and implementation processes.

\section{D.2.2.5. Assess existing mechanisms to facilitate ongoing cross-stakeholder engagement:}

Once a standard terminology has been developed, ongoing dialogue among stakeholders is essential. Code councils, conferences, city boards, and seminars should be assessed for their applicability to facilitating dialogue among IO stakeholders.

\section{D.3. Monitoring and Assessing IO Performance Objectives Adoption, Practice, and Performance}

There are three areas of challenge in terms of monitoring. First, communities need to know which buildings are built utilizing IO performance objectives and which are used during and after natural hazard events. Therefore, tracking implementation and building use is necessary. Platforms for compiling and maintaining this building level data need to be developed. Second, 
inspection protocols need to be developed. Implementing IO performance objectives will substantially affect the nonstructural elements of buildings, including architectural components, mechanical/electrical components, and equipment. This will add to the complexity of the permitting process, and may require instituting a more comprehensive permitting process like that found in California's Office of Statewide Health Planning and Development (OSHPD). Their process involves all of these aspects of building and system performance [33]. Finally, evaluation protocols to assess the performance of IO buildings immediately following a hazard event are necessary.

\section{D.3.1. Basic and applied research needs \\ D.3.1.1. Quantify and categorize the IO performance of existing buildings, and new buildings designed to current codes:}

Research is needed to provide a detailed understanding of the actual and anticipated performance of:

- Current building stock under the full range of hazards, and

- New facilities designed using the latest building codes, standards, and practices.

This effort will aid in identification of areas for further research and implementation.

\section{D.3.1.2. Distinguish between monitoring and assessment for different building types and different hazards:}

Different building types require specific protocols for both routine monitoring and assessment following a hazard event. A first step is to establish a baseline understanding of the performance targeted for buildings and their systems prior and following a hazard event. Monitoring and assessment protocols can then be developed for different building types and various hazard scenarios. The scale of this effort requires care in developing a sound approach that can be as efficient as possible.

\section{D.3.1.3. Develop an evaluation framework for simplified communication of IO building performance:}

A system for evaluating and communicating the anticipated performance of IO buildings to the public could be developed. The anticipated performance of IO buildings could be expressed in terms of a limited number of understandable performance metrics. Some systems have been developed to predict and classify building performance for earthquake. The available systems may help inform development of more robust consensus-based evaluation and assessment tools suitable for a full range of natural hazards. The evaluation framework would have to consider how each building performs over time, as well as how they perform across regions and across hazards. The system would need to include both structural and nonstructural components, and could also help identify buildings that need to be replaced or retrofitted as their performance declines.

\section{D.3.2. Implementation activities}

D.3.2.1. Recommend code enforcement and inspection guidelines:

The existing system is tied to life safety considerations and is not well suited to supporting the IO environment. Present building department functions are to review building plans, issue building permits, and inspect and monitor buildings for code compliance and conformance to approved plans. Adoption of IO performance objectives would require a systemic expansion of the building department role in determining the state of buildings in a jurisdiction. Research 
is needed to evaluate the effectiveness of code enforcement and inspection guidelines for buildings designed for life safety objectives, which will inform the enforcement and inspection processes for buildings designed for IO performance.

\section{D.3.2.2. Develop tools, platforms, methods for data collection:}

Monitoring and assessment data is needed at scales ranging from individual buildings to communities. As part of this collection effort, there is a need to collect data to study the frequency of IO adoption and implementation, including regional-specific data to understand IO adoption and its efficacy across disasters. It is important to know whether people are implementing IO concepts, what they are implementing, and why. 


\section{Appendix E: Research Needs Summary Tables}

Table 3. Research Needs from Chapter 3, Building Design Considerations

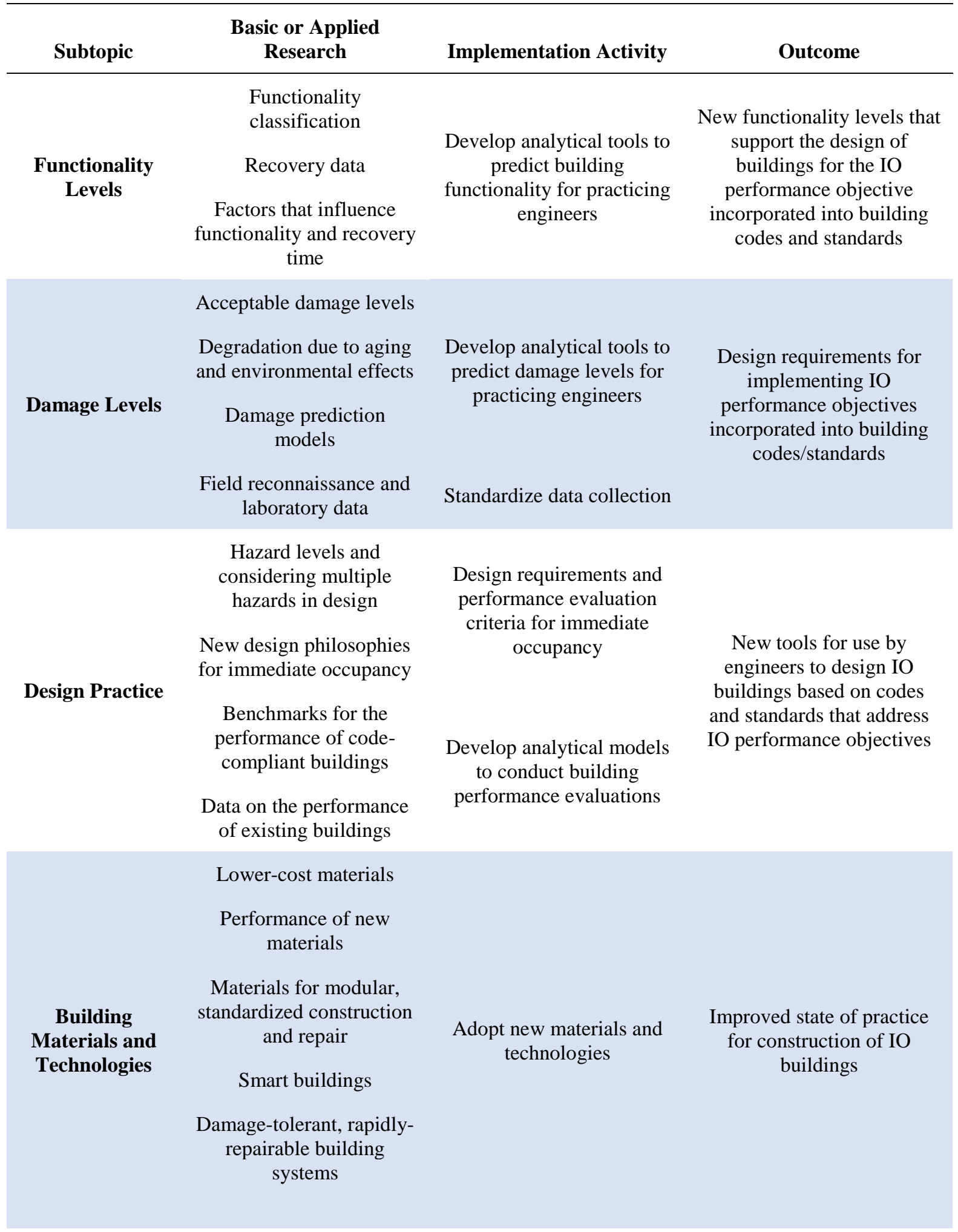




\begin{tabular}{|c|c|c|c|}
\hline Subtopic & $\begin{array}{l}\text { Basic or Applied } \\
\text { Research }\end{array}$ & Implementation Activity & Outcome \\
\hline \multirow{6}{*}{$\begin{array}{l}\text { Maintenance, } \\
\text { Repair, and } \\
\text { Retrofit }\end{array}$} & $\begin{array}{l}\text { Inventory of existing } \\
\text { building stock }\end{array}$ & & \multirow{6}{*}{$\begin{array}{l}\text { Improved maintenance and } \\
\text { repair strategies for } \\
\text { enhancing the performance } \\
\text { of existing buildings to } \\
\text { satisfy IO performance } \\
\text { objective }\end{array}$} \\
\hline & $\begin{array}{l}\text { Decreasing cost and } \\
\text { improving methods to } \\
\text { repair and retrofit } \\
\text { buildings }\end{array}$ & $\begin{array}{l}\text { Improve availability of } \\
\text { tools, parts, and labor }\end{array}$ & \\
\hline & Behavioral research & $\begin{array}{l}\text { Develop methods to } \\
\text { strategically implement }\end{array}$ & \\
\hline & \multirow{2}{*}{$\begin{array}{l}\text { Understanding and } \\
\text { enhancing repair } \\
\text { effectiveness }\end{array}$} & retrofits & \\
\hline & & $\begin{array}{l}\text { Develop periodic } \\
\text { inspection protocols }\end{array}$ & \\
\hline & $\begin{array}{l}\text { Understanding resources } \\
\text { needed for repairs and } \\
\text { retrofits }\end{array}$ & & \\
\hline \multirow{3}{*}{$\begin{array}{l}\text { Monitoring and } \\
\text { Assessment }\end{array}$} & $\begin{array}{l}\text { Technology and sensors to } \\
\text { assess building } \\
\text { performance }\end{array}$ & $\begin{array}{l}\text { Improve inspection } \\
\text { techniques }\end{array}$ & \multirow{3}{*}{$\begin{array}{l}\text { Improved and expedited } \\
\text { monitoring and assessment } \\
\text { process of IO buildings } \\
\text { before and after hazard } \\
\text { events }\end{array}$} \\
\hline & $\begin{array}{l}\text { New data collection } \\
\text { methods }\end{array}$ & $\begin{array}{l}\text { Develop } \\
\text { guidelines/protocols for } \\
\text { inspection of the buildings } \\
\text { for IO performance criteria }\end{array}$ & \\
\hline & $\begin{array}{l}\text { Linking damage } \\
\text { measurement to the } \\
\text { performance assessment }\end{array}$ & & \\
\hline
\end{tabular}


Table 4. Research Needs from Chapter 4, Community Considerations

\begin{tabular}{|c|c|c|c|}
\hline Subtopic & $\begin{array}{l}\text { Basic or Applied } \\
\text { Research } \\
\end{array}$ & Implementation Activity & Outcome \\
\hline \multirow[t]{2}{*}{$\begin{array}{l}\text { Infrastructure } \\
\text { and Building } \\
\text { Cluster } \\
\text { Interactions }\end{array}$} & $\begin{array}{c}\text { Characterized } \\
\text { dependencies and } \\
\text { redundancies for IO } \\
\text { buildings, building } \\
\text { clusters, and infrastructure } \\
\text { Characterized recovery } \\
\text { process for buildings and } \\
\text { infrastructure }\end{array}$ & $\begin{array}{l}\text { Develop tools that analyze } \\
\text { and visually present data }\end{array}$ & \multirow[t]{2}{*}{$\begin{array}{c}\text { Improved infrastructure } \\
\text { services during and after a } \\
\text { hazard event as communities } \\
\text { use accessible data related to } \\
\text { capacity and temporary } \\
\text { service needs }\end{array}$} \\
\hline & $\begin{array}{l}\text { Identification of temporary } \\
\text { solutions for providing } \\
\text { infrastructure services to } \\
\text { support IO buildings }\end{array}$ & $\begin{array}{l}\text { Develop guidelines for } \\
\text { temporary infrastructure } \\
\text { planning }\end{array}$ & \\
\hline
\end{tabular}

\section{Community \\ Planning}
Development of metrics
and analysis methods to assess required

infrastructure support and the role of IO buildings in building cluster performance

Development of methods that assess building inventories and infrastructure to support community planning

Evaluation of land use and zoning policy impacts on IO building performance and community development

Development of methods for prioritizing which buildings should be designated as IO in a community

Develop multidisciplinary community guidance and tools for IO building planning and design
Community planning design policies, guidelines and tools that define impacts and roles of IO buildings in the community, particularly with regards to social and economic functions, infrastructure support, and community resilience
Development of metrics for assessing $\mathrm{IO}$ building impact on community functions

\section{Community \\ Decision \\ Support}

Development of technical and administrative requirements for managing IO buildings

Assessment of decisionmaking process for residential and commercial buildings
Develop decision support tools that integrate community data for IO buildings
Community decision support tools based on integrated community data and metrics for IO buildings and their impact to communities 


\begin{tabular}{cccc}
\hline Subtopic & $\begin{array}{c}\text { Basic or Applied } \\
\text { Research }\end{array}$ & Implementation Activity & Outcome \\
\hline $\begin{array}{c}\text { Community } \\
\text { Stakeholder } \\
\text { Communication }\end{array}$ & $\begin{array}{c}\text { Identification of } \\
\text { communication needs of } \\
\text { community stakeholders } \\
\text { Development of methods } \\
\text { of effective risk } \\
\text { communication }\end{array}$ & $\begin{array}{c}\text { Develop stakeholder } \\
\text { communication tools for } \\
\text { IO buildings } \\
\text { Development of technical } \\
\text { communication capacity }\end{array}$ & $\begin{array}{c}\text { A broad range of data and } \\
\text { resources that effectively } \\
\text { translate technical } \\
\text { information, such as } \\
\text { performance levels, costs } \\
\text { and benefits, and community } \\
\text { impacts }\end{array}$ \\
\hline
\end{tabular}


Table 5: Research Needs from Chapter 5, Economic and Social Considerations

\begin{tabular}{|c|c|c|c|}
\hline Subtopic & Basic or Applied Research & $\begin{array}{l}\text { Implementation } \\
\text { Activity }\end{array}$ & Outcome \\
\hline \multirow{4}{*}{$\begin{array}{l}\text { Economic } \\
\text { Feasibility }\end{array}$} & Initial and long-term costs & $\begin{array}{c}\text { Develop cost estimating } \\
\text { tools }\end{array}$ & \multirow{4}{*}{$\begin{array}{l}\text { Guidance, tools, and tracking } \\
\text { mechanisms that support } \\
\text { evaluating the economic } \\
\text { feasibility of IO buildings }\end{array}$} \\
\hline & Direct and indirect benefits & $\begin{array}{l}\text { Develop cost benefit } \\
\text { tools }\end{array}$ & \\
\hline & Financial mechanisms & $\begin{array}{l}\text { Develop guidance on } \\
\text { financial instruments }\end{array}$ & \\
\hline & & $\begin{array}{l}\text { Track implementation } \\
\text { efforts }\end{array}$ & \\
\hline \multirow{4}{*}{$\begin{array}{l}\text { Economic } \\
\text { Effects }\end{array}$} & $\begin{array}{l}\text { Economic stability and } \\
\text { reduced losses }\end{array}$ & $\begin{array}{l}\text { Provide guidance on } \\
\text { business recovery }\end{array}$ & \multirow{4}{*}{$\begin{array}{l}\text { Improved understanding of } \\
\text { economic issues; guidance } \\
\text { and tools to evaluate the } \\
\text { positive and negative } \\
\text { economic effects of IO } \\
\text { buildings }\end{array}$} \\
\hline & $\begin{array}{l}\text { Drivers of population } \\
\text { change }\end{array}$ & $\begin{array}{l}\text { Measure and track } \\
\text { externalities }\end{array}$ & \\
\hline & $\begin{array}{l}\text { Environmental impacts } \\
\text { Synergies between } \\
\text { household and business } \\
\text { recovery }\end{array}$ & $\begin{array}{l}\text { Provide guidance on the } \\
\text { relationship of IO to } \\
\text { other goals }\end{array}$ & \\
\hline & $\begin{array}{l}\text { Considerations of impacts } \\
\text { on willingness-to-pay }\end{array}$ & $\begin{array}{c}\text { Provide relative costs of } \\
\text { implementation } \\
\text { mechanisms }\end{array}$ & \\
\hline \multirow{4}{*}{$\begin{array}{c}\text { Social } \\
\text { Feasibility }\end{array}$} & Benefits of IO buildings & & \multirow{4}{*}{$\begin{array}{l}\text { Guidance, tools, and tracking } \\
\text { mechanisms that support } \\
\text { decision-making related to } \\
\text { the social feasibility of IO } \\
\text { buildings }\end{array}$} \\
\hline & $\begin{array}{l}\text { Tools for understanding } \\
\text { hazard risk }\end{array}$ & $\begin{array}{l}\text { Develop localized } \\
\text { assessment of risk }\end{array}$ & \\
\hline & $\begin{array}{l}\text { Stakeholder research for } \\
\text { decision-making }\end{array}$ & & \\
\hline & & $\begin{array}{l}\text { Track consequences of } \\
\text { IO buildings }\end{array}$ & \\
\hline Social Effects & $\begin{array}{l}\text { Measurement of value of } \\
\text { buildings } \\
\text { Key social institutions } \\
\text { Impacts to vulnerable } \\
\text { populations }\end{array}$ & $\begin{array}{l}\text { Provide guidance and } \\
\text { tools to support } \\
\text { decision-making }\end{array}$ & $\begin{array}{l}\text { Improved understanding of } \\
\text { social issues; guidance and } \\
\text { tools to evaluate positive and } \\
\text { negative social impacts of IO } \\
\text { buildings that support } \\
\text { decision-making }\end{array}$ \\
\hline
\end{tabular}




\begin{tabular}{|c|c|c|c|}
\hline Subtopic & $\begin{array}{l}\text { Basic or Applied } \\
\text { Research Item }\end{array}$ & Implementation Activity & Outcome \\
\hline \multirow{4}{*}{$\begin{array}{c}\text { Adoption } \\
\text { Mechanisms }\end{array}$} & $\begin{array}{l}\text { Assessment of the risks of } \\
\text { hazards not adequately } \\
\text { addressed in building } \\
\text { codes and standards } \\
\text { Development of hazard } \\
\text { maps that enable risk- } \\
\text { relevant IO performance } \\
\text { objectives }\end{array}$ & $\begin{array}{l}\text { Develop strategies to } \\
\text { support adoption and } \\
\text { acceptance of IO } \\
\text { performance objectives }\end{array}$ & \multirow{4}{*}{$\begin{array}{l}\text { Improved resilience of } \\
\text { buildings across the nation } \\
\text { due to multiple processes } \\
\text { and approaches that help } \\
\text { communities and } \\
\text { stakeholders tailor adoption } \\
\text { of IO performance objectives } \\
\text { to their unique hazard risks, } \\
\text { constraints, and needs. }\end{array}$} \\
\hline & $\begin{array}{c}\text { Identification and } \\
\text { assessment of current IO } \\
\text { practice } \\
\text { Investigation of } \\
\text { applications where } \\
\text { communities desire } \\
\text { mandatory IO performance } \\
\text { objectives }\end{array}$ & & \\
\hline & $\begin{array}{l}\text { Identification of market } \\
\text { mechanisms that support } \\
\text { voluntary adoption of IO } \\
\text { performance objectives }\end{array}$ & $\begin{array}{l}\text { Identify effective funding } \\
\text { mechanisms to inventory }\end{array}$ & \\
\hline & $\begin{array}{c}\text { Investigation of public } \\
\text { policy measures associated } \\
\text { with voluntary adoption of } \\
\text { IO performance objectives }\end{array}$ & $\begin{array}{l}\text { Identify legal barriers to } \\
\text { IO implementation }\end{array}$ & \\
\hline & $\begin{array}{l}\text { Development of an } \\
\text { accreditation or licensure } \\
\text { program to certify } \\
\text { technical professionals in } \\
\text { IO design expertise }\end{array}$ & $\begin{array}{l}\text { Establish professional } \\
\text { development programs for } \\
\text { continuing education }\end{array}$ & \multirow[b]{2}{*}{$\begin{array}{l}\text { Adequate knowledge, skills, } \\
\text { and ability to design, build, } \\
\text { maintain, and evaluate IO } \\
\text { buildings will be widely } \\
\text { available amongst the } \\
\text { appropriate professionals, } \\
\text { technicians, and trade } \\
\text { workers. }\end{array}$} \\
\hline $\begin{array}{l}\text { Education, } \\
\text { Training, and } \\
\text { Outreach }\end{array}$ & $\begin{array}{l}\text { Identification of a set of } \\
\text { workforce competencies } \\
\text { required to design and } \\
\text { sustain IO performance } \\
\text { objectives }\end{array}$ & $\begin{array}{l}\text { Incorporate Performance } \\
\text { Based Design (PBD) } \\
\text { methods in engineering } \\
\text { and architectural curricula } \\
\text { Recommend expanded } \\
\text { undergraduate and } \\
\text { graduate curricula to } \\
\text { include inter-disciplinary } \\
\text { concepts }\end{array}$ & \\
\hline
\end{tabular}




\begin{tabular}{|c|c|c|c|}
\hline Subtopic & $\begin{array}{l}\text { Basic or Applied } \\
\text { Research Item }\end{array}$ & Implementation Activity & Outcome \\
\hline & & $\begin{array}{l}\text { Establish common terms } \\
\text { to discuss IO performance } \\
\text { objective related concepts } \\
\text { across stakeholder groups }\end{array}$ & \\
\hline & & $\begin{array}{c}\text { Access existing } \\
\text { mechanisms to facilitate } \\
\text { ongoing cross-stakeholder } \\
\text { engagement }\end{array}$ & \\
\hline \multirow{3}{*}{$\begin{array}{l}\text { Monitoring and } \\
\text { Assessing IO } \\
\text { Performance } \\
\text { Objective } \\
\text { Adoption, } \\
\text { Practice, and } \\
\text { Performance }\end{array}$} & $\begin{array}{l}\text { Quantification and } \\
\text { categorization of the IO } \\
\text { performance of existing } \\
\text { buildings, and new } \\
\text { buildings designed to } \\
\text { current codes }\end{array}$ & \multirow[b]{2}{*}{$\begin{array}{l}\text { Recommend code } \\
\text { enforcement and } \\
\text { inspection guidelines }\end{array}$} & \multirow{3}{*}{$\begin{array}{c}\text { Improved IO building } \\
\text { performance supported by } \\
\text { feedback loops of knowledge } \\
\text { sharing and improved } \\
\text { decision-making, including } \\
\text { retrofits and code } \\
\text { enforcement }\end{array}$} \\
\hline & $\begin{array}{l}\text { Development of an } \\
\text { evaluation framework for } \\
\text { simplified communication } \\
\text { of IO building } \\
\text { performance } \\
\text { Distinguish between } \\
\text { monitoring and assessment } \\
\text { for different building types } \\
\text { and different hazards }\end{array}$ & & \\
\hline & & $\begin{array}{l}\text { Develop tools, platforms, } \\
\text { methods for data } \\
\text { collection }\end{array}$ & \\
\hline
\end{tabular}




\section{Appendix F: Steering Committee Member Affiliations}

\begin{tabular}{|c|c|}
\hline Name & Organization/Affiliation \\
\hline Mary Comerio & University of California, Berkeley \\
\hline Gregory Deierlein & Stanford University \\
\hline Susan Dowty & International Code Council \\
\hline John Gillengerten & $\begin{array}{c}\text { CA Office of Statewide Health Planning and } \\
\text { Development (retired) }\end{array}$ \\
\hline James Harris & JR Harris \& Co. \\
\hline William Hirano & General Services Administration (retired) \\
\hline Laurie Johnson & Laurie Johnson Consulting \\
\hline Timothy Reinhold & $\begin{array}{l}\text { Insurance Institute for Business \& Home Safety } \\
\text { (retired) }\end{array}$ \\
\hline James Rossberg & American Society of Civil Engineers \\
\hline
\end{tabular}




\section{Appendix G: January 2018 Workshop Agenda}

NIST Workshop on Research Needed to Develop al New Innmediate Occupancy Performance Objective January 16-17, 2018 Institute for Defense Analyses

\section{Agenda}

DAY 1 - TUESDAY, JANUARY 16, 2018

\begin{tabular}{llll} 
Time & Title & Speaker(s) & Location \\
\hline \hline $8: 00-8: 30$ & REGISTRATION \& REFRESHMENTS & & Lobby \\
\hline $8: 30-8: 35$ & Welcoming Remarks & Chris Clavin & 1301 \\
\hline $8: 35-8: 45$ & Workshop Opening & Jason Averill & 1301 \\
\hline $8: 45-9: 30$ & Project and Workshop Framing & $\begin{array}{l}\text { Steve McCabe } \\
\text { Chris Clavin }\end{array}$ & 1301 \\
\hline \hline $9: 30-10: 00$ & Envisioning Immediate Occupancy & Mat Heyman & 1301 \\
\hline \hline & Session 1: Building Design & $\begin{array}{l}\text { Greg Deierlein } \\
\text { Tim Reinhold }\end{array}$ & 1301 \\
\hline & Considerations & $\begin{array}{l}\text { John Gillengerten } \\
\text { Jim Harris }\end{array}$ & \\
\hline
\end{tabular}

10:45 - 11:00 BREAK

\begin{tabular}{lll} 
11:00 - 12:30 & Breakout Session: Building Design Subtopics & $\begin{array}{l}\text { Breakout } \\
\text { Rooms }\end{array}$ \\
\hline $12: 30-1: 15$ & LUNCH & Cafeteria
\end{tabular}

1:15 - 1:45 Report-Out on Building Design Considerations 1301

1:45-2:15 Large Group Discussion $\quad$ Sharon Williams $\quad 1301$

$\begin{array}{llll}\text { 2:15-2:45 Session 2: Adoption Considerations } & \begin{array}{l}\text { Susan Dowty } \\ \text { Jim Rossberg }\end{array} & 1301\end{array}$

2:45 - 3:00 BREAK

3:00 - 4:30 Breakout Session: Adoption Considerations 


\begin{tabular}{|c|c|c|c|}
\hline $4: 30-5: 00$ & Report-Out on Adoption Considerations & & 1301 \\
\hline $5: 00-5: 30$ & Large Group Discussion & Sharon Williams & 1301 \\
\hline $5: 30-5: 35$ & \multicolumn{2}{|l|}{ Workshop Day 1 Wrap-Up } & 1301 \\
\hline $5: 35-7: 00$ & \multicolumn{3}{|l|}{ HAPPY HOUR - Hilton Alexandria Mark Center } \\
\hline \multicolumn{4}{|c|}{ WEDNESDAY, JANUARY 17, 2018} \\
\hline Time & Title & Speaker(s) & Location \\
\hline $8: 00-8: 15$ & MORNING REFRESHMENTS & & Lobby \\
\hline $8: 15-8: 30$ & Opening and Framing Remarks & $\begin{array}{l}\text { Therese } \\
\text { McAllister }\end{array}$ & 1301 \\
\hline $8: 30-8: 45$ & Session 3: Community Considerations & Mary Comerio & 1301 \\
\hline $8: 45-9: 00$ & Session 4: Social and Economic Impacts & $\begin{array}{l}\text { Walt Peacock } \\
\text { Shannon Van } \\
\text { Zandt }\end{array}$ & 1301 \\
\hline $9: 00-10: 30$ & Breakout Session: Community Considerations & & $\begin{array}{l}\text { Breakout } \\
\text { Rooms }\end{array}$ \\
\hline $10: 30-10: 45$ & BREAK & & \\
\hline $10: 45-12: 15$ & Breakout Session: Social and Economic Impacts & & $\begin{array}{l}\text { Breakout } \\
\text { Rooms }\end{array}$ \\
\hline $12: 15-1: 00$ & LUNCH & & Cafeteria \\
\hline $1: 00-1: 45$ & $\begin{array}{l}\text { Report-Out on Community Considerations } \\
\& \text { Social and Economic Impacts }\end{array}$ & & 1301 \\
\hline $1: 45-2: 45$ & Large Group Discussion & Sharon Williams & 1301 \\
\hline $2: 45-3: 00$ & $\begin{array}{l}\text { Workshop Day } 2 \text { Wrap-Up and Closing } \\
\text { Remarks }\end{array}$ & Steve McCabe & 1301 \\
\hline
\end{tabular}




\section{Appendix H: Abbreviations}

ASCE

ATC

DHS

EDGe\$

FEMA

FY

ICC

IDA

IO

LCCs

NAHB

NCEI

NEHRP

NIBS

NIST

NOAA

NSF

OSTP

PBD

REITs

S\&T

SDOs

STPI

USGS

VA
American Society of Civil Engineers

Applied Technology Council

Department of Homeland Security

Economic Decision Guide Software

Federal Emergency Management Agency

Fiscal Year

International Code Council

Institute for Defense Analyses

immediate occupancy

life-cycle costs

National Association of Home Builders

National Centers for Environmental Information

National Earthquake Hazards Reduction Program

National Institute of Building Sciences

National Institute of Standards and Technology

National Oceanic and Atmospheric Administration

National Science Foundation

Office of Science and Technology Policy

Performance-based design

Real Estate Investment Trusts

science and technology

standards developing organizations

Science and Technology Policy Institute

United States Geological Survey

Department of Veterans Affairs 